\title{
Oxygen Transport Kinetics of Surface Modified Mixed Conductor (La0.60Sr0.40)0.95Co0.20Fe0.8003-x as Solid Oxide Fuel Cell Cathode
}

Manuel Serrano Laguna

West Virginia University, maserranolaguna@mix.wvu.edu

Follow this and additional works at: https://researchrepository.wvu.edu/etd

Part of the Ceramic Materials Commons

\section{Recommended Citation}

Serrano Laguna, Manuel, "Oxygen Transport Kinetics of Surface Modified Mixed Conductor (La0.60Sr0.40)0.95Co0.20Fe0.8003-x as Solid Oxide Fuel Cell Cathode" (2020). Graduate Theses, Dissertations, and Problem Reports. 7535.

https://researchrepository.wvu.edu/etd/7535

This Thesis is protected by copyright and/or related rights. It has been brought to you by the The Research Repository @ WVU with permission from the rights-holder(s). You are free to use this Thesis in any way that is permitted by the copyright and related rights legislation that applies to your use. For other uses you must obtain permission from the rights-holder(s) directly, unless additional rights are indicated by a Creative Commons license in the record and/ or on the work itself. This Thesis has been accepted for inclusion in WVU Graduate Theses, Dissertations, and Problem Reports collection by an authorized administrator of The Research Repository @ WVU. For more information, please contact researchrepository@mail.wvu.edu. 


\title{
Oxygen Transport Kinetics of Surface Modified Mixed Conductor $\left(\mathrm{La}_{0.60} \mathrm{Sr}_{0.40}\right)_{0.95} \mathrm{Co}_{0.20} \mathrm{Fe}_{0.80} \mathrm{O}_{3-\mathrm{x}}$ as Solid Oxide Fuel Cell Cathode
}

\author{
Manuel Serrano Laguna \\ Thesis submitted \\ to the College of Engineering and Mineral Resources \\ at West Virginia University \\ in partial fulfillment of the requirements for the degree of \\ Master of Science in \\ Mechanical Engineering \\ Yun Chen, Ph.D. \\ Xueyan Song, Ph.D. \\ Hailin Li, Ph.D. \\ Department of Mechanical and Aerospace Engineering \\ Morgantown, West Virginia \\ December 2019
}

Keywords: LSCF, ECR, ORR, MIEC, SOFC

Copyright 2020 Manuel Serrano Laguna 


\begin{abstract}
Oxygen Transport Kinetics of Surface Modified Mixed Conductor $\left(\mathrm{La}_{0.60} \mathrm{Sr}_{0.40}\right)_{0.95} \mathrm{Co}_{0.20} \mathrm{Fe}_{0.80} \mathrm{O}_{3-\mathrm{x}}$ as Solid Oxide Fuel Cell Cathode

Manuel Serrano Laguna
\end{abstract}

The oxygen transport kinetics of the electrodes of Solid Oxide Fuel Cells (SOFC) are critical properties to achieve higher efficiencies in the cell. ( $\left.\mathrm{La}_{0.60} \mathrm{Sr}_{0.40}\right)_{0.95} \mathrm{Co}_{0.20} \mathrm{Fe}_{0.80} \mathrm{O}_{3-\mathrm{x}}$ (LSCF) is a mixed ion-electron conductor material that is expected to be optimized and utilized as the cathode of the SOFC's. The reason for LSCF to be considered as the next cathode material for SOFC is due to its high ionic and electronic conductivities, and high oxygen transport kinetics. Additionally, to the excellent properties that this material offers, it has been seen that the kinetic properties of the material can be further optimized by adding a metal oxide coating on top of the LSCF surface. In this research study, baseline LSCF pellets were fabricated using commercial powders, and their conductance was measured using the Electrical Conductivity Relaxation (ECR) technique. The surface exchange coefficient ( $k$ ) and bulk diffusion coefficient (D) were determined by fitting the normalized conductance data into Fick's second law. To further enhance the oxygen transport kinetics of the LSCF, surface modification was added on top of the baseline LSCF pellets using two methods: Atomic Layer Deposition (ALD) and ink coating. The materials that were used as surface modifiers were: $\mathrm{CoO}_{\mathrm{x}}$, a mixture consisting $\mathrm{CoO}_{\mathrm{x}}$ and $\mathrm{Pt}, \mathrm{MnO}_{\mathrm{x}}$, and $\mathrm{Pr}_{2} \mathrm{O}_{\mathrm{x}}$. The oxygen transport kinetics of the surface-modified pellets were determined using the same method that was used for the baseline LSCF pellets. A comparison between the baseline and the surface-modified LSCF was presented along with the experimental errors. It was observed that surface modifiers can either enhance or reduce the oxygen transport kinetics of the perovskite oxide, depending on the type of coating that is added. All the coatings that were used in this project are metal oxides that have high electrical conductivity and ionic conductivity to transport the oxygen ions. Among the used coatings, the most remarkable one was $\mathrm{CoO}_{x}$ that showed an enhancement of the surface exchange of LSCF while producing a minimal reduction of the diffusion coefficient. The addition of Pt on top of $\mathrm{CoO}_{x}$ coating showed a surface exchange enhancement while maintaining the same diffusion coefficient as the perovskite oxide. Lastly, $\mathrm{MnO}_{\mathrm{x}}$ and $\mathrm{Pr}_{2} \mathrm{O}_{\mathrm{x}}$ showed a reduction in the surface exchange and diffusion coefficient of the LSCF due to their lower electrical conductivities. 


\section{Acknowledgment}

The completion of this project would have not been possible without the help from my research advisors, research group, friends and family.

I would like to thank Dr. Yun Chen for all the inputs that he made on my work. Dr. Chen helped me during this whole project to find solutions to different issues that came along the way. Working with Dr. Chen and counting on his extended knowledge on cathode materials for solid oxide fuel cells helped me to complete my research project. I appreciate having Dr. Chen as a research advisor for guiding me during this project.

I would like to thank Dr. Xueyan Song that helped me very patiently throughout my whole project. Dr. Song pushed me to improve myself not only as an engineer, but also as a person. Dr. Song helped me mature and taught me many lessons during this project. I am very grateful for all the quality guidance that Dr. Song provided for me during this project.

I would like to thank Dr. Hailin Li for his inputs, and suggestions for this project.

I would like to thank Sergio Andres Paredes Navia for training me on how to use all the necessary engineering equipment for the completion of my project.

I would like to thank Bryan Jackson for assisting me to synthetize the ink coating materials.

I would like to thank Liang Liang for helping me obtain TEM images of my samples.

I would like to thank Geoffroy Gauneau and Andre Fernandes for their support in and out of the lab.

Finally, I would like to thank my family and friends in Spain for their continuous support out of the lab. 


\section{Table of Contents}

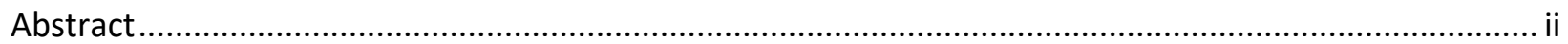

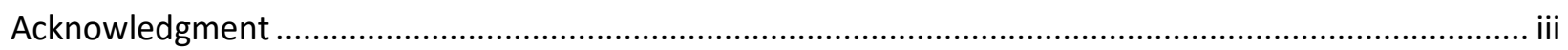

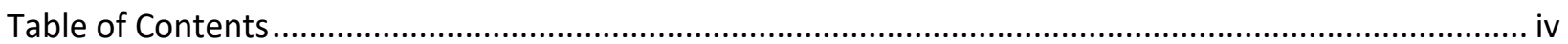

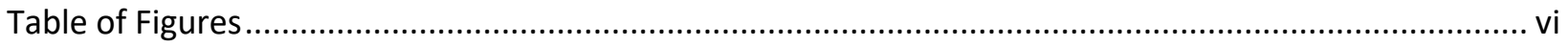

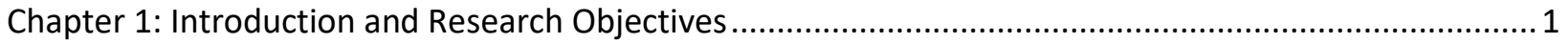

1.1 Introduction to Electrical Conductivity Relaxation ............................................................

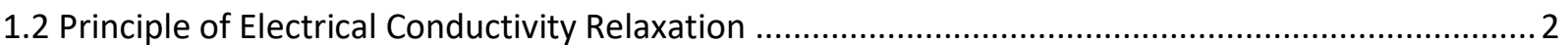

1.3 Electrical Conductivity Relaxation in Mixed Ionic-Electronic Conductors .................................... 3

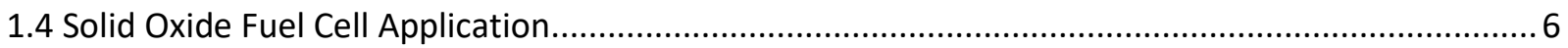

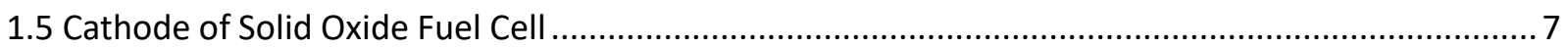

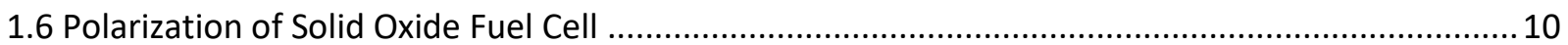

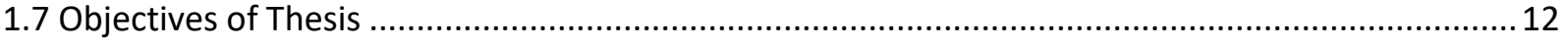

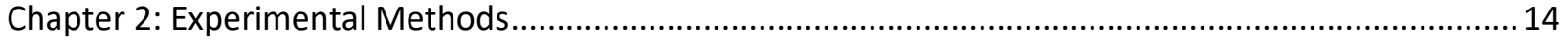

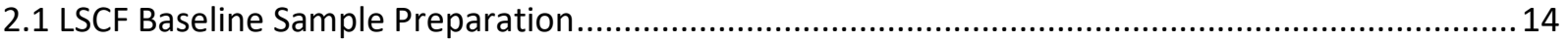

2.2 LSCF Surface Modified Sample Preparation ................................................................... 17

2.3 Measurement Procedure .......................................................................................... 20

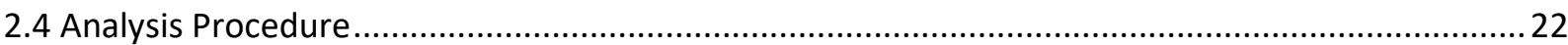

2.5 Microstructure Characterization using Scanning Electron Microscopy......................................24

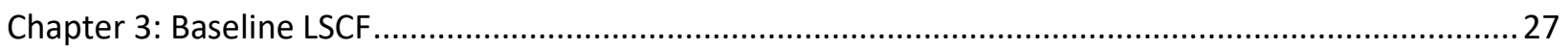

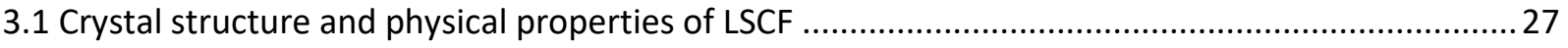

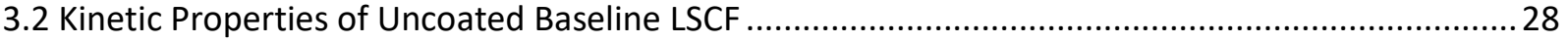

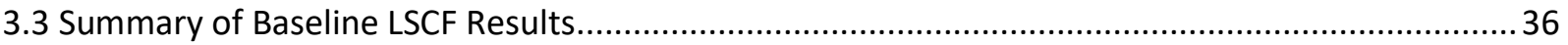

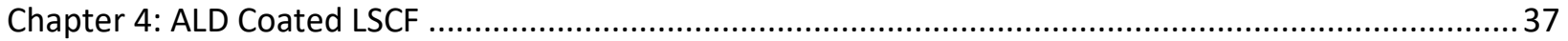

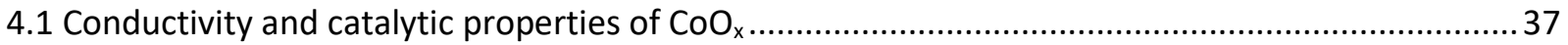

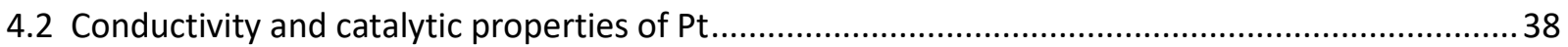

4.3 Effect of ALD $\mathrm{CoO}_{x}$ Coating on the Kinetic Properties of LSCF ...............................................39

4.4 Effect of ALD CoO $\mathrm{CoO}_{\mathrm{x}}+$ Pt Coating on the Kinetic Properties of LSCF........................................47

4.5 Summary of $\mathrm{CoO}_{x}-\mathrm{ALD}$ and $\mathrm{CoO}_{\mathrm{x}}+$ Pt-ALD Coated LSCF Results ............................................56

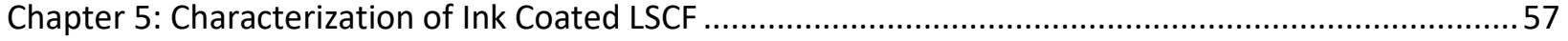

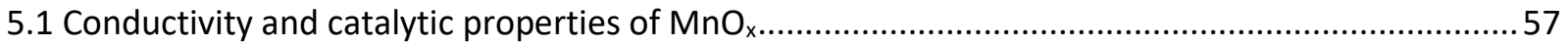




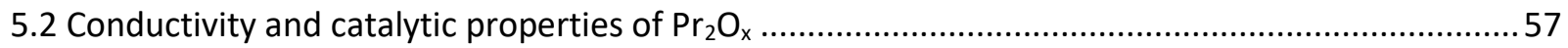

5.3 Effect of Ink $\mathrm{CoO}_{x}$ Coating on the Kinetic Properties of LSCF ...................................................58

5.4 Effect of Ink $\mathrm{MnO}_{\mathrm{x}}$ Coating on the Kinetic Properties of LSCF ..................................................65

5.5 Effect of Ink $\mathrm{Pr}_{2} \mathrm{O}_{x}$ Coating on the Kinetic Properties of LSCF ..................................................... 73

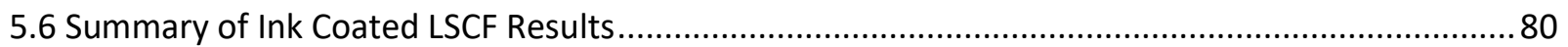

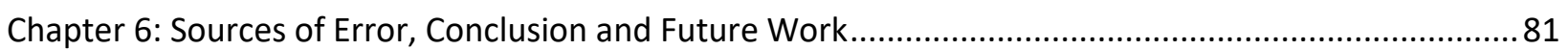

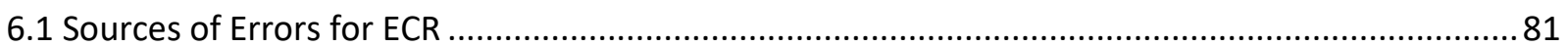

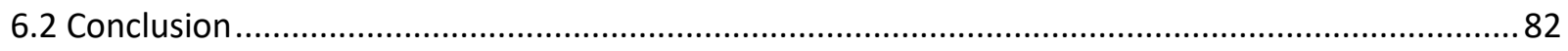

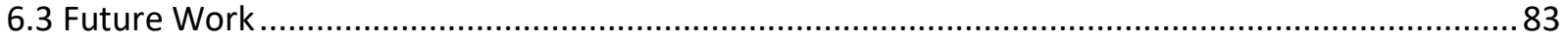

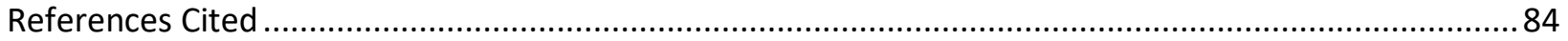




\section{Table of Figures}

Figure 1 ECR Response to O2 Step Pressure Change

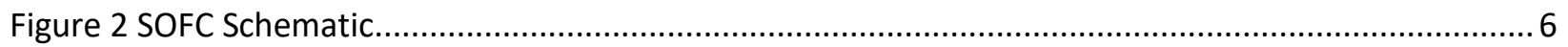

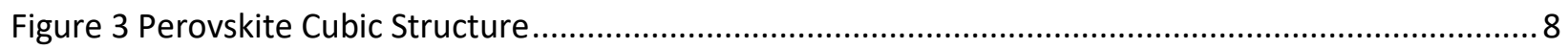

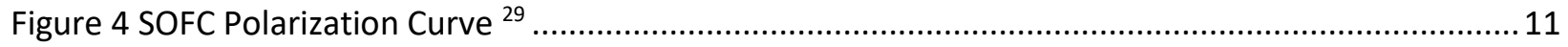

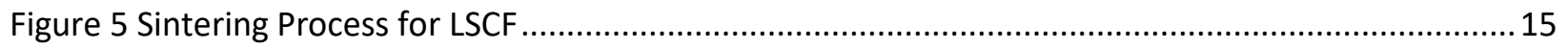

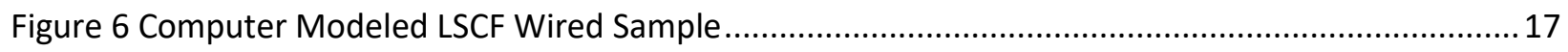

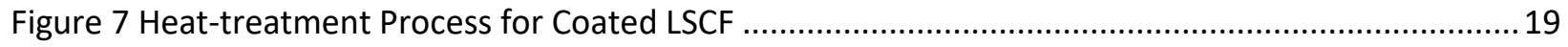

Figure 8 Experimental Setup of Electrical Conductivity Relaxation ...........................................................20

Figure 9 Computer Modeled LSCF Current and Voltage Connections................................................... 21

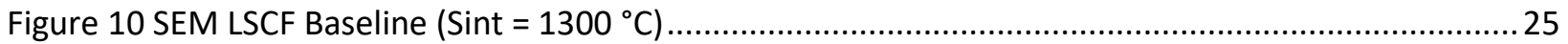

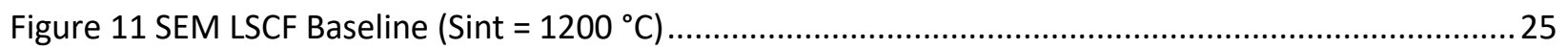

Figure 12 Computer Modeled LSCF Cubic Structure .......................................................................2

Figure 13 Surface Exchange vs Temperature - Baseline LSCF............................................................ 30

Figure 14 Surface Exchange Comparison with Literature - Baseline LSCF ............................................ 32

Figure 15 Bulk Diffusion Coefficient vs Temperature - Baseline LSCF ................................................... 33

Figure 16 Bulk Diffusion Comparison with Literature - Baseline LSCF.................................................. 35

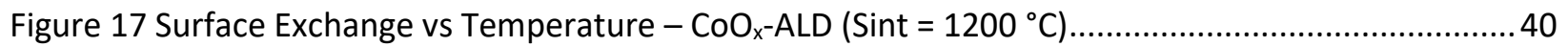

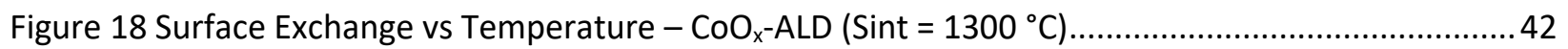

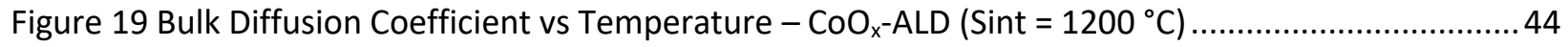

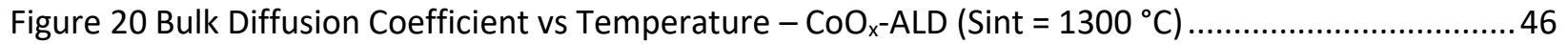

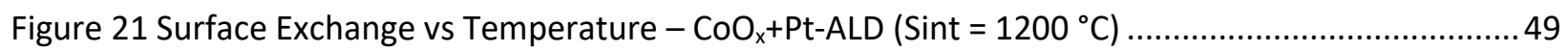

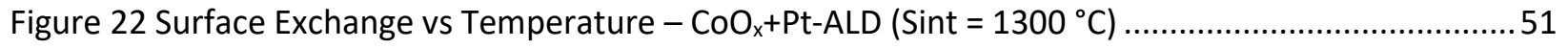

Figure 23 Bulk Diffusion Coefficient vs Temperature $-\mathrm{CoO}_{x}+\operatorname{Pt}-\mathrm{ALD}\left(\operatorname{Sint}=1200^{\circ} \mathrm{C}\right) \ldots \ldots \ldots \ldots \ldots \ldots \ldots \ldots \ldots . . . . . . . . . . . . .53$

Figure 24 Bulk Diffusion Coefficient vs Temperature $-\mathrm{CoO}_{x}+\mathrm{Pt}-\mathrm{ALD}\left(\mathrm{Sint}=1300{ }^{\circ} \mathrm{C}\right)$...........................55

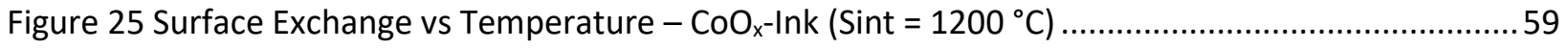

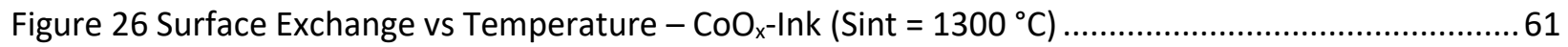

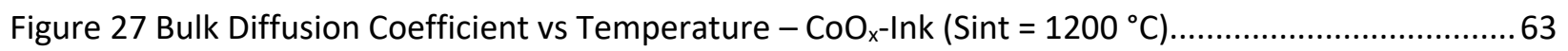

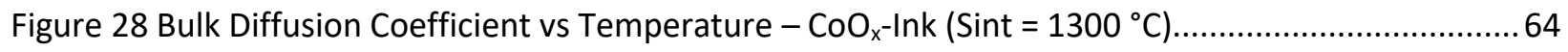

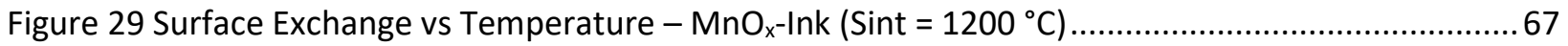

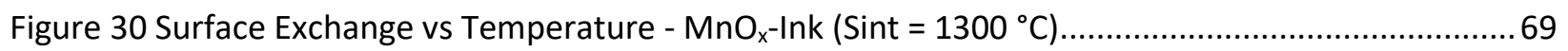

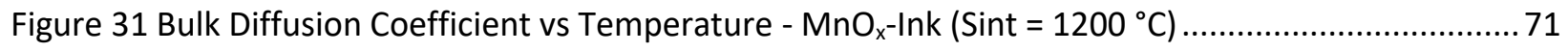

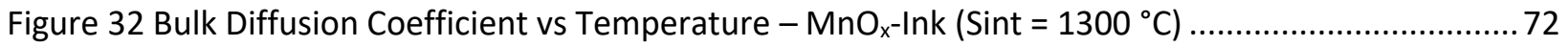

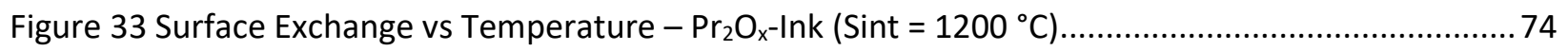

Figure 34 Surface Exchange vs Temperature $-\mathrm{Pr}_{2} \mathrm{O}_{\mathrm{x}}-\operatorname{Ink}\left(\mathrm{Sint}=1300^{\circ} \mathrm{C}\right)$............................................76

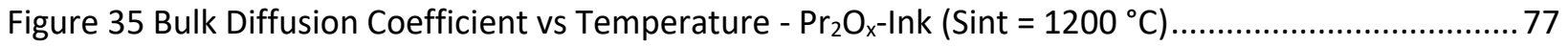

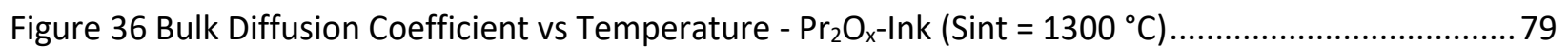




\section{Chapter 1: Introduction and Research Objectives}

\subsection{Introduction to Electrical Conductivity Relaxation}

The need for determining the kinetic properties of conductors is crucial for Solid Oxide Fuel Cells (SOFC) that employs various conductors ${ }^{1,2,3,4,5}$. Several techniques have been utilized to determine kinetic properties on materials. Electrical Conductivity Relaxation (ECR) ${ }^{6}$, Isotope Exchange (IE) and Impedance Spectroscopy (IS) are the most remarkable techniques to determine the kinetic properties of conductors $7,8,9$.

This thesis focuses on the ECR technique. Such a technique requires a wired sample that is placed inside of a tube furnace where it will be subjected to a sudden change in oxygen partial pressure from a gas mixture of nitrogen and oxygen. In comparison with the methods mentioned above, the ECR is one of the most used methods to determine kinetics properties due to its simplicity and easier accessibility for researchers. Methods such as IE and IS require more complex equipment that is not only more expensive than the ECR's equipment, it also requires a more complex operation ${ }^{10}$. Therefore, the ECR approach is one of the methods that is most widely used by researchers to determine the kinetic properties of materials due to its simplicity and ease of use.

As mentioned before, one of the main applications for the materials characterized with ECR is the SOFC. These electrochemical devices were invented and developed about a century ago and had several applications ${ }^{11}$. The main application for the SOFC is generating energy that can have commercial applications such as vehicles, houses, satellites ${ }^{12}$. Additionally, SOFC are known as electrochemical devices due to the process they undergo. These devices convert chemical energy into electrical energy. SOFC are not the only fuel cells that can transform chemical energy into electrical energy. This thesis focuses on the SOFC, although there are more types of fuel cells that have energy conversion applications. Among the most remarkable fuel cells, there are Polymer Electrolyte Membrane Fuel Cell (PEMFC) ${ }^{13}$, Direct Methanol Fuel Cells (DMFC) ${ }^{14}$, Alkaline Fuel Cells (AFC) ${ }^{15}$, Phosphoric Acid Fuel Cells (PAFC) ${ }^{16}$, and Molten Carbonate Fuel Cells (MCFC) ${ }^{17,18}$. Those fuel cells utilize different fuels than SOFC and different electrolytes. However, SOFC is expected to be one of the most promising ones due to the high 
electrical efficiencies and the low cost to operate the cell. Therefore, SOFC are expected to be one of the most efficient types of fuel cells.

Over the next decade SOFC are expected to be optimized and begin commercialization. The SOFC market is expected to grow and develop until it exceeds US\$1 billion by $2024{ }^{19}$. Currently, the main research focus for the SOFC is focused on the components of the cell (anode, cathode, and electrolyte). Different materials are being investigated to optimize and improve the performance of the cells. Also, there is an interest in driving down the manufacturing cost of the SOFC. Even though these cells are inexpensive when it comes to operating them, the manufacturing cost of the cells is high due to the materials used on it. Moreover, there is an interest in reducing the long-term degradation of the cells and improving the cell structure to make them more durable ${ }^{20}$. These devices operate at high temperatures, and the materials that form the cell degrade over time.

\subsection{Principle of Electrical Conductivity Relaxation}

The Electrical Conductivity Relaxation is a method used to characterize the kinetic properties of Mixed Ionic and Electronic Conductors (MIEC). MIEC are materials that have a significant conduction ionically and electronically ${ }^{21}$. The properties of interest measured on these materials are the surface exchange coefficient $(K)$ and the bulk diffusion coefficient (D) ${ }^{22}$. This method is characterized by a change in the gas pressure $\left(\mathrm{O}_{2}\right)$ that produces a change in the $\mathrm{O}_{2}$ stoichiometry of the sample and consequently alters the resistance of the sample. Before producing a change in the pressure of the gas that constitute the atmosphere inside the furnace, the sample must have achieved a stabilization phase. During the stabilization the temperature must be constant, and the resistance/conductivity of the sample must be constant over time. Once stability has been achieved, the gas pressure is changed, and the resistance of the sample will change until reaching a new stabilization point. The step change in pressure can be produced by increasing the pressure or by decreasing it. When the pressure is increased, the process is known as oxidation. However, when it is reduced the process is known as oxygen reduction. Both processes will determine the kinetic properties of the MIEC sample. 
Additionally, the sample response to the step change in pressure can be described by the following figure ${ }^{23}$ :

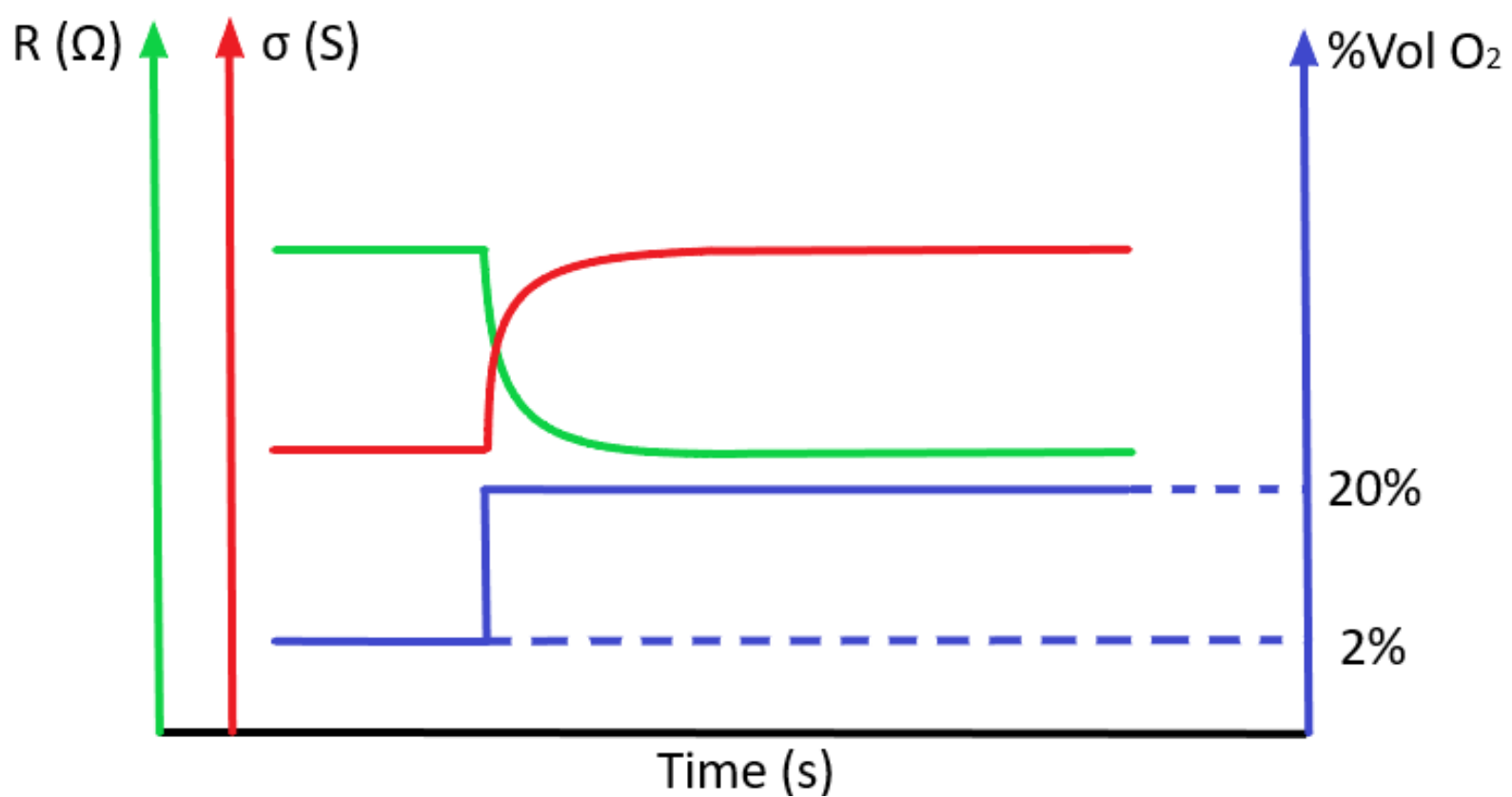

Figure 1 ECR Response to 02 Step Pressure Change

On figure 1 it can be seen the ECR response from a LSCF sample to a step pressure change. When the \%volume of $\mathrm{O}_{2}$ increases drastically, the resistance of the sample drops until it reaches the next stabilization point. On the other hand, the conductance of the sample increases since it is inversely proportional to the resistance. Once the step-change in pressure has been performed and the resistance of the sample has been measured, the data can be fitted to obtain the kinetic properties of the material. To characterize the properties properly, the key parameters mentioned above (surface exchange coefficient $(k)$ and diffusion coefficient (D) are fit into Fick's second law equation. Then, an assumption for the kinetic properties is used in the equation to begin the iterations. The iterations need to be calculated until there is no change in the values of the kinetic properties.

\subsection{Electrical Conductivity Relaxation in Mixed Ionic-Electronic Conductors}

As it was mentioned before the materials that are characterized using the ECR technique are known as Mixed Ionic-Electron Conductors (MIEC). Over the last 30 years attention have been brought to MIEC membranes due to the potential applications of these materials ${ }^{24}$. MIEC membranes are known as dense ceramic membranes where oxygen ions 
diffuse through them. The diffusion process is performed thanks to the chemical potential gradient between the membranes. During the diffusion process, the oxygen ions transfer from one side of the membrane to the other side through lattice vacancies and interstitials. Oxygen cannot be transported through the pores of the membrane as the MIEC membranes are dense 25. MIEC operates at high temperatures in the range of $600-1000^{\circ} \mathrm{C}$, while high-pressure air is supplied to the membrane in one of the sides.

There are two main parts of interest in every MIEC membrane, the retention side and the permeation side. The retention side is the side that is fed with air during the diffusion process. At the retention side, the membrane will separate the oxygen ions from the air and incorporate them into the membrane through vacancies and interstitials. On the other hand, at the permeation side, the membrane will transfer the oxygen ions that were exchanged in the retention side. During the diffusion process, the oxygen permeates the MIEC membranes through three main steps: oxygen exchange at the gas-solid interface of the retention side, oxygen-electron through the bulk, and oxygen exchange at the gas-solid interface of permeation side ${ }^{24}$. The reactions that are performed at the gas-solid interface are known as surface exchange reactions. The reaction that is performed through the bulk is known as diffusion reaction.

The surface exchange reactions can be addressed through the following equations if oxygen ions and electrons are assumed to be the charge carriers:

$$
\begin{array}{cc}
\text { Retention Side: } & \mathrm{O}_{2}+4 e^{-} \rightarrow 2 \mathrm{O}^{2-} \\
\text { Permeation Side: } & 2 \mathrm{O}^{2-} \rightarrow \mathrm{O}_{2}+4 e^{-}
\end{array}
$$

However, if the charger carriers are assumed to be holes and oxygen vacancies, the surface exchange reactions will be written using the Kröger-Vink notations as shown in the following equation:

$$
\begin{array}{cc}
\text { Retention Side: } & O_{2}+2 V_{o}^{\prime \prime} \rightarrow 2 O_{o}^{x}+4 h^{\prime} \\
\text { Permeation Side: } & 2 O_{o}^{x}+4 h^{\prime} \rightarrow O_{2}+2 V_{o}^{\prime \prime}
\end{array}
$$


The Kröger-Vink notations are used to describe electric charges and lattice positions in crystals. In the above equations, the notations shown in $O_{o}^{x}, V_{o}^{\prime \prime}$, and $h^{\prime}$ represent the oxygen lattice site, oxygen vacancy, and the holes, respectively ${ }^{24}$. The above equations represent a simplification of the whole diffusion process. The diffusion process contains more steps that can be shown using chemical reactions. However, there are general equations that help describe the process step by step, but these general equations could change depending on the material that is used. The following equations describe the oxygen permeation process step by step for a general MIEC membrane:

$$
\begin{gathered}
\text { Adsorption: } \mathrm{O}_{2(\mathrm{~g})} \rightarrow \mathrm{O}_{2(\mathrm{ad})} \\
\text { Combining with electron: } \mathrm{O}_{2(\mathrm{ad})}+e^{-} \rightarrow \mathrm{O}_{2(\mathrm{ad})}^{-} \\
\text {Changing the adsorption state: } \mathrm{O}_{2(a d)}^{-} \rightarrow \mathrm{O}_{2(a d, b i)}^{-} \\
\text {Combining with electron: } \mathrm{O}_{2(a d, b i)}^{-}+e^{-} \rightarrow O_{2(a d, b i)}^{2-} \\
\text { Dissociation: } O_{2(a d, b i)}^{-} \rightarrow 2 O_{(a d)}^{-} \\
\text {Combining with electron: } O_{(a d)}^{-}+e^{-} \rightarrow O_{(a d)}^{2-} \\
\text { Incorporating into lattice: } O_{(a d)}^{2-}+V_{o}^{\prime \prime} \rightarrow O_{o}^{x}
\end{gathered}
$$

The equations above describe how the $\mathrm{O}_{2}$ ions are separated from the air that is fed into the MIEC membrane, how they combine with electrons and gain and electrical charge, the change in adsorption state, the dissociation process and the incorporation of the $\mathrm{O}_{2}$ ion into the lattice. Even though these equations generally describe the diffusion process for MIEC membranes, it is not complete for the main application of these membranes. As it was mentioned above, the SOFC are devices that transform the chemical energy into electrical energy. In order to achieve the function properly, SOFC count with an electrolyte where the cathode (MIEC membrane) will transfer the $\mathrm{O}_{2}$ to. During the diffusion process through the MIEC cathode, the oxygen ions will move into the electrolyte and the electrolyte will transport such oxygen ions in bulk to its interface with the anode where the reaction will occur. The electrolyte can continuously produce electrical energy if it keeps receiving $\mathrm{O}_{2}$ from the cathode 
and hydrogen $(\mathrm{H})$ from the anode. The oxygen ions can take the vacancy path to transport from vacancy to vacancy in the sample, or the interstitial path to transport from interstitial to interstitial within the sample. However, most of the $\mathrm{ABO}_{3}$ perovskite oxides adopt the vacancy diffusion mechanism which is the method of interest in this paper since the research was performed using LSCF, a perovskite oxide. On the other hand, the interstitial diffusion mechanism is seen in $\mathrm{K}_{2} \mathrm{NiF}_{4}$ type oxides, or a mixed vacancy-interstitial diffusion mechanism ${ }^{24}$.

\subsection{Solid Oxide Fuel Cell Application}

The need for energy has always been a worldwide challenge. Every person uses energy in the daily basis, which makes this need for energy even greater. There are many energy sources available, however, renewable sources are showing very promising research results. SOFC are devices that transform chemical energy into electrical energy. The cells can produce energy while generating no pollution. They only need to be loaded with a fuel such as hydrogen, biofuel or hydrocarbons. Additionally, SOFC can attain efficiencies of up to $60 \%{ }^{26}$. Fuels cells work by separating hydrogen atoms from their electrons, shown in the following figure ${ }^{27}$ :

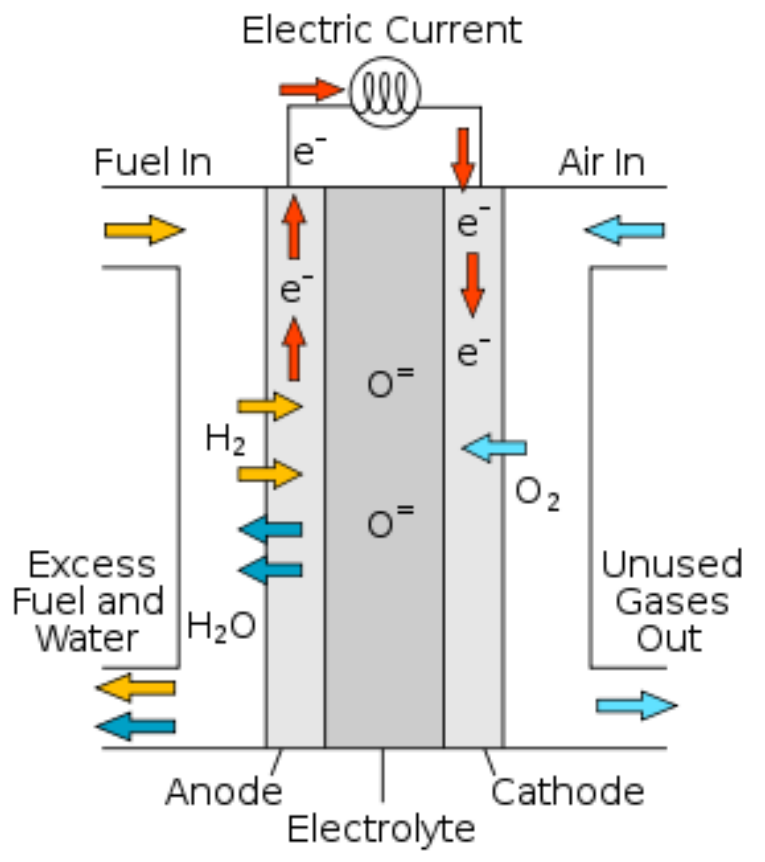

Figure 2 SOFC Schematic 
The separation is completed by producing an oxygen reduction. This is done when hydrogen fuel comes inside the fuel cell through the anode. The hydrogen atoms are now carrying a positive electrical charge. On the other side, oxygen comes into the fuel cell through the cathode. The oxygen is mixed with hydrogen going through the electrolyte, along with electrons coming from the electrical circuit. Once oxygen and hydrogen are mixed inside the electrolyte, the chemical reaction between these two components is used to transform it into electrical energy. Consequently, energy is generated and will keep generating as long as the fuel cell is fed with hydrogen and oxygen. The fuel cell technology is still in the developing stages of research and development. Even though the illustration of a fuel cell is quite simple, shown in figure 2, the manufacturing of an efficient and inexpensive fuel cell remains a challenge. Many of the cells that are produced do not have a durable surface. Since the electrolyte is one of the most important parts of the cell since the electrochemical reactions happen there, it is important to make it durable. As the electrons flow through the electrolyte, it gets deteriorated and shortens the working lifetime of the fuel cell. Therefore, the main challenge is to find a material that can withstand for a long period of use, withstand intermediate temperatures, be inexpensive and have great electrical properties.

Even though the electrolyte is quite important, and it is necessary to keep it functional, the anode and cathode will contribute to make the cell functional. The anode and cathode are not only functional parts that separate electrons from atoms, they also contribute as the main structural supports of the cell. Therefore, it is important that the anode and cathode are formed by a conductive material and contribute to the oxygen reduction and absorption.

\subsection{Cathode of Solid Oxide Fuel Cell}

The cathode of a SOFC is a part of the cell that takes care of the oxygen dissociation and reduction processes. The cathode is directly linked to the electrolyte of the cell since it feeds oxygen to it and forms a part of the structure of the cell. As it was mentioned in the ECR materials section, the cathode is made of MIEC materials that are materials with a significant ionic and electric conductivity ${ }^{28}$. It was also mentioned that the process for oxygen dissociation and reduction are very complex and count have many steps from beginning to end. Those steps were broken down in the previous section and this section will be structure of the materials use 
for cathodes and how the SOFC cathodes can be improved. The complexity and quantity of steps during the diffusion processes performed by the cathode of the SOFC were stated in previous sections. The cathode produces voltage losses due to the complexity of this process. However, the main factor when determining the cause of the voltage losses is the microstructure and conditions of the testing material ${ }^{29}$.

Most of the materials that are used in the ECR application belong to the family of MIEC. Among the MIEC materials that are analyzed the most common type of microstructure that is found is the perovskite. Such structure receives its name from the mineral $\mathrm{CaTiO}_{3}{ }^{30}$. This complex structure can order several lattice mismatches due to the A-O and B-O bond lengths. The following image shows a general computer modeled perovskite structure ${ }^{29}$ :

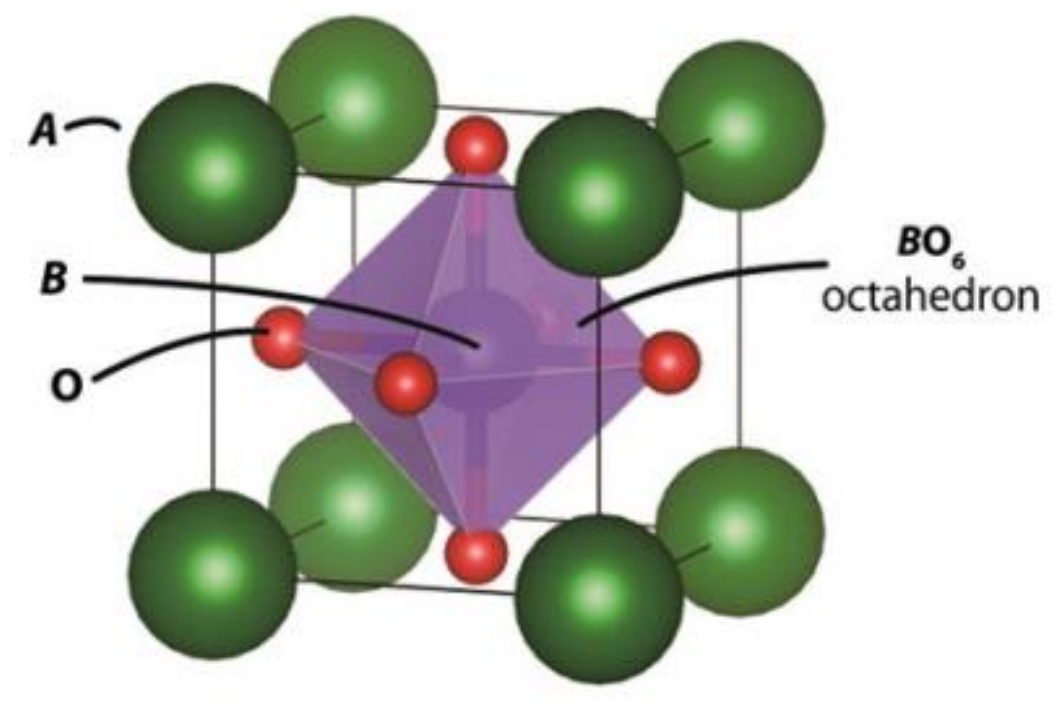

Figure 3 Perovskite Cubic Structure

In figure 3 a general microstructure for perovskite compounds have been modeled. In the image the perovskite structure consists of a general formula $\mathrm{ABO}_{3}$ which includes an octahedron in the middle of the unit cell with formulation $\mathrm{BO}_{6}$ and eight $\mathrm{A}$ cations in every corner of the unit cell. Depending on the exact composition that the perovskite material will adopt, the material will have different properties. The B dopants will vary the electronic conductivity and catalytic properties of the material. On the other hand, the A dopants will modify the concentration of vacancies and alter both conductivities (ionic and electronic) ${ }^{29}$. 
Lanthanum Strontium Manganese (LSM) is one of the most used materials for SOFC cathodes. This is due to its high electronic conductivity at high temperatures. However, recent research studies have focused their attention in Lanthanum Strontium Cobalt Ferrite (LSCF). The main difference between LSM and LSCF is the ionic conductivity. The LSCF compound have higher ionic conductivity than LSM. Additionally, the oxygen reduction rate is higher in LSCF than it is in LSM. In this thesis the focus is given to LSCF and surface modified LSCF. The surface modification process can result in a conductivity enhancement and a notable improvement of the mechanical properties of LSCF.

LSCF is becoming more and more popular since many research studies are performed to optimize the material and make it suitable for intermediate temperatures SOFC. In the following recent study performed by Jiang ${ }^{31}$, LSCF is characterized as an electrode for SOFC. The paper focuses on providing a comprehensive review of the material. The main points that were studied were the structure, defect chemistry, electrical and ionic conductivity. The material was characterized for every function that the cathode performs as part of a SOFC. Jiang concluded that LSCF is the most popular material for cathodes of SOFC's. It is explained in the literature that LSCF has all the properties that the cathode needs to have a good performance of the cell. The main reason for the LSCF to become very popular among the MIEC's that are used for SOFC is because the high electrical and ionic conductivities that it offers. Compared to other materials, LSCF offers high electronic and ionic conductivities at intermediate temperatures. Additionally, it allows to make modifications to its composition. The $A$ and $B$ sites offer many options when it comes to modifying the composition of LSCF. The composition modification allows to alter properties such as the conductivities of the material. Finally, LSCF offers a microstructure stability, high oxygen reduction and proven stability while working as a cathode of a SOFC.

As mentioned in the last paragraph, the composition modification can alter the electrochemical properties and microstructure of the LSCF material. However, there are more ways to alter the properties of this material and make it more suitable to work as a cathode. Jiang ${ }^{31}$ mentions in the literature that the LSCF electrochemical properties and microstructure can be enhanced through several processes. Composition modification will make the LSCF gain 
microstructure stability and must be optimized depending on the application. Surface modification, interface manipulation, reduce the activation energy, and inhibit surface segregation and chemical reactivity are the most used techniques to optimize an LSCF cathode for SOFC. In this thesis the focus is the surface modification techniques. Two surface modification techniques are proposed for MIEC that will be employed as cathodes of SOFC. The surface modification techniques that are proposed in this thesis paper are ink coated and atomic layer deposition coated. In the following sections the main differences between them will be explained and compared to determine which one will result in a better cathode enhancement.

\subsection{Polarization of Solid Oxide Fuel Cell}

Modeling SOFC's is a complex process that requires to take into consideration several aspects of the cell. Due to the complexity of the SOFC systems the modeling of the cell considers mass, momentum, energy, and charge transfer along with the chemical and catalytic reactions that take place in the cell ${ }^{29}$. It is important each aspect of the cell when modeling it, notwithstanding the focus of the modeling should be paid depending on the application of the cell. The application will determine which characteristic of the cell is the most important one, and a different approach or method must be used depending on it. On this section, polarization of SOFC is introduced and explained how it can affect the cell. The polarization would belong to the charge transfer aspect of the cell that is consider while modeling it.

The polarization term refers to the voltage loss or overpotential that is seen between the two electrodes of the SOFC. This voltage loss is a function of current density and can be broken down into three main polarization types: ohmic polarization, concentration polarization and activation polarization. Those are the three main types of polarization that are found in SOFC. The polarization will decrease the performance of the cell hence, accounting for the polarization is quite important when modeling a SOFC. The electrochemical model needs to characterize three main points of the SOFC. This type of modeling will account for the potential difference between electrodes, electrochemical reactions within the cell and charge transport 32. In the following diagram it can be seen a general polarization curve for a SOFC: 


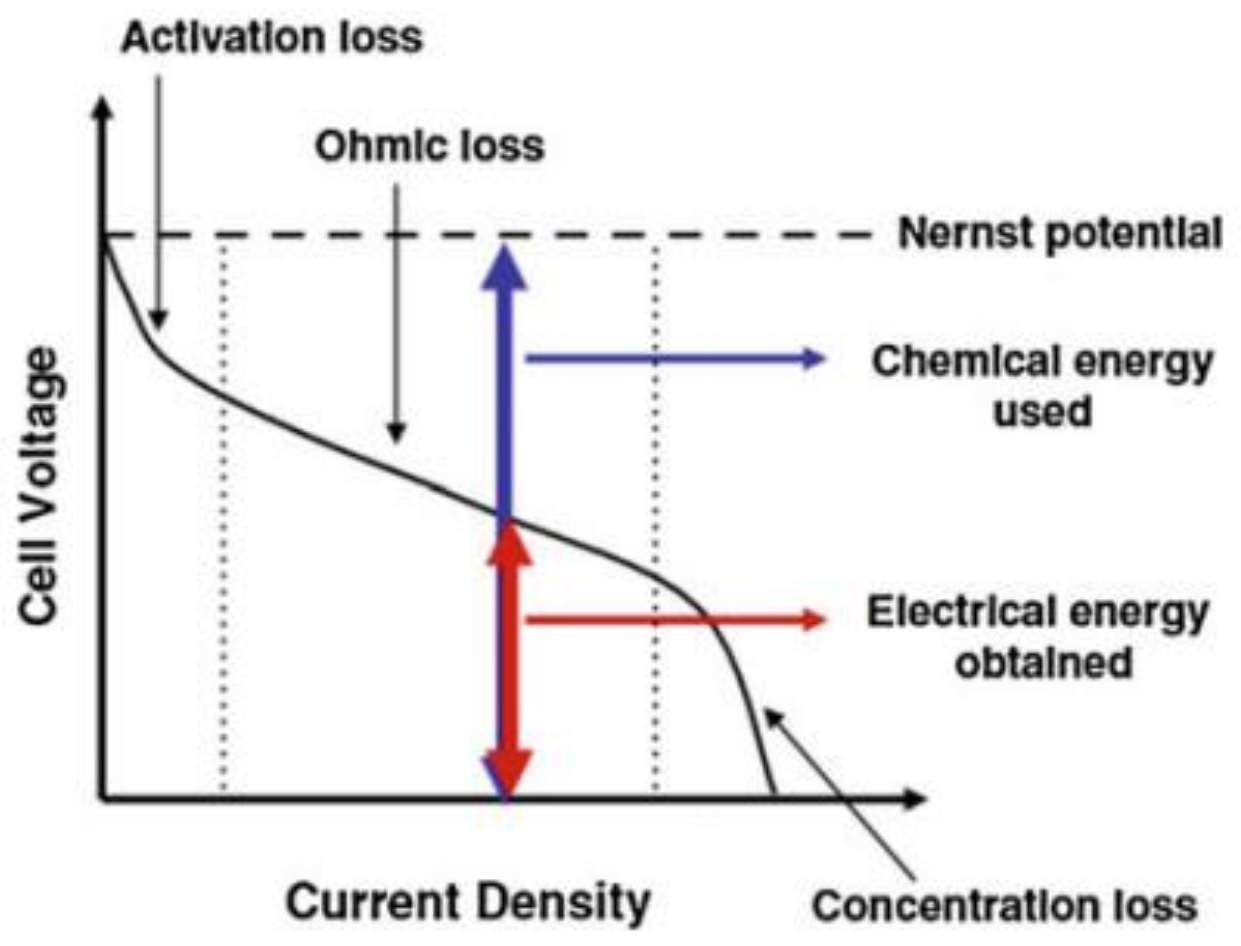

Figure 4 SOFC Polarization Curve 29

In figure 4 a general polarization curve for SOFC is shown. It can also be seen the losses caused by the different types of polarization. The activation loss, ohmic loss and concentration loss are shown and occur depend on the current density of the cell. On the other hand, the Nernst potential is shown, which is the maximum potential difference that a cell can produce between the electrodes. Also, the two main energies of the cell are shown. The chemical energy is the energy that is required by the electrodes to feed the electrolyte with the needed gases. The electrical energy is the energy that the electrolyte produces after being fed by the electrodes. As it was mentioned previously on this section, there are three main types of polarization losses. The ohmic loss is caused due to electrical resistances that are seen among the cell elements. Even though all the components have electrical and ionic resistances, the ohmic polarization is greatly influenced by the ionic resistance that is seen in the electrolyte. However, the ionic resistance of the electrolyte is not the only resistance that will cause the cell to have ohmic polarization. The ionic and electrical resistances of the catalyst layer, electrodebacking layer, and interface contact also increase the ohmic polarization within the cell. 
Although the resistances of the components of the cell cause drops in the performance of it, they are not the only reason that causes polarization. The activation polarization is based on the chemical reaction that is necessary to occur in the electrolyte to produce electrical energy. The reaction that occurs at the electrolyte spontaneously needs to overcome an activation barrier for the reactants to become the desired produces. The activation barrier that needs to be overcome is the impedance and for the cell to overcome the barrier there needs to be an increment of voltage within the cell. Therefore, the activation polarization is the extra voltage that the cell requires to overcome the barrier of the electrochemical reaction ${ }^{33}$.

Finally, the last polarization loss that was mentioned was the concentration polarization. This last type of polarization is caused by the reactants that take place in the electrochemical reaction within the electrolyte. The reactants depend on the current density and will cause a voltage drop depending on the concentration the reactants have at the reaction site of the cell. The concentration polarization is caused by a lower concentration of the reactants which causes a voltage drop at the reaction site ${ }^{33}$. This voltage drop is produced because a lower concentration of the reactant does not need as much voltage as higher concentrations do to perform the electrochemical reaction.

\subsection{Objectives of Thesis}

Recent research studies are focusing on characterizing materials to improve the performance, structure, and durability of SOFC. Those studies try to find the most suitable materials for each part of the cell (cathode, anode, and electrolyte). The current SOFC require high operating temperatures $\left(800-1000^{\circ} \mathrm{C}\right)$, and do not have a high long-term durability. The research studies focus on dropping the operating temperatures from high to intermediate operating temperatures $\left(500-800^{\circ} \mathrm{C}\right)$. Additionally, the focus of the research studies is seen in the materials of the cell. The materials can drop the operating temperatures of the cell and greatly improve the efficiency of the cell. Even though the efficiency and durability of the SOFC's are quite important, they are not the only reasons to drive so much research attention to the cells. SOFC's are devices that have a great commercial potential. Those devices are not only capable of converting chemical energy into electrical energy, but also the emissions that they release are much lower than previous power generation systems. The emissions of 
nitrogen oxides are lower than 0.5 parts per million (PPM), which makes these cells very attractive for the power generation market ${ }^{34}$. The fact that SOFC's can produce energy without producing emissions could make them the next most popular power generation system. SOFC can serve for different applications as power generation solutions and reduce emissions globally.

The work covered in this thesis shows the characterization of the kinetic properties of LSCF baseline at different sintering temperatures. This LSCF material was widely used as cathode of a SOFC. Therefore, the experimental parameters are set according to the SOFC operating parameters. After determining the kinetic properties of baseline LSCF, surface modification was applied to the LSCF baseline. Two types of surface modification techniques were used: Atomic Layer Deposition (ALD) and ink coating applied through screen printing. The two methods are compared in this thesis to determine which one provides the best surface modification to the LSCF baseline, and the highest improvement of the kinetic properties of the LSCF. The ALD method was performed using Cobalt Oxide ( $\left.\mathrm{CoO}_{x}\right)$ and Platinum (Pt) coatings. On the other hand, the ink coatings that were screen printed were $\mathrm{CoO}_{x}$, Manganese Dioxide $\left(\mathrm{MnO}_{\mathrm{x}}\right)$ and Praseodymium III $\left(\mathrm{Pr}_{2} \mathrm{O}_{\mathrm{x}}\right)$. The impact of different surface modification on the kinetic properties of LSCF cathode materials are systematically characterized. 


\section{Chapter 2: Experimental Methods}

\subsection{LSCF Baseline Sample Preparation}

The electrical conductivity relaxation method requires a sample to be placed in the tube, as it was mentioned in the previous chapter. The samples used need to follow a procedure before they can be measured and place in the tube furnace for the experiment. All the LSCF samples that were used in the experiments were prepared using a mix of commercial powder and binding material (PVB - Polyvinyl Butyral), Zhu reported in his literature the use of commercial powders ${ }^{23}$. The commercial powder was LSCF, and it had the following formulation $\left(\mathrm{La}_{0.60} \mathrm{Sr}_{0.40}\right)_{0.95} \mathrm{Co}_{0.20} \mathrm{Fe}_{0.80} \mathrm{O}_{3-x}$. Every batch that was prepared was mixed in a ratio where there are 5\% PVB and 95\% LSCF material. To mix the powders properly, they were manually ground to ensure that the mix was well blended. After grinding the powders, they were stirred using a Fisher Scientific Isotemp stirring hotplate, in contrast with the ball-milled employed by Zhu ${ }^{23}$. In order to stir them, the powders were mixed with ethanol to achieve a uniform particle size. The hotplate was set at a fixed temperature of $80^{\circ} \mathrm{C}$ while the stirring device was spinning at $120 \mathrm{rpm}$. The powder was stirred in the stirring hotplate for about an hour. Once the stirring was completed, the powders were manually ground again until the particle size was uniform for all the powder.

After the powder was well blended, the next step is to press it into a pellet. A one-inch diameter die was used to shape the pellets into a solid circle, in contrast with Zhu that pressed them in a rectangular shape ${ }^{23}$. The die was cleaned using ethanol before using it to ensure that no contamination from other materials is mixed with the LSCF powder. Also, the die sides that were in contact with the powder were sprayed with graphite to ensure that the powder did not stick to the die. Once these two steps were completed, the powder was fit into the die and moved to a hydraulic press. The bench press that was used to press the samples was a carver bench model 4389 . The samples were pressed at room temperature $\left(25^{\circ} \mathrm{C}\right)$ for 10 minutes. The pressure exerted on the die was $0.4 \mathrm{GPa}$, in contrast with Zhu that pressed the powders at 100 $\mathrm{kPa}{ }^{23}$. After the pressing is completed, the diameter, thickness, and weight of the sample were measured. The dimensions of the sample were taken to determine the density of the sample and the imperfections. 
Once the samples have been pressed, and the density has been examined, the next step is to perform a sintering process on the samples. The sintering process ensures that the samples become fully dense, and there are no cracks inside the pellet. Ensuring that the pellets are fully packed is very important for the ECR analysis since the oxygen ions need to be transported throughout the sample. If the pellets are not fully dense, the oxygen will go through the cracks of the sample during the experiment. This will cause the measured resistance from the sample is not correct because the oxygen will not be permeating through the sample. Therefore, it is critical to ensure that the pellets have a relative density of at least $90 \%$, Zhu's reference density is $95 \%{ }^{23}$. The relative density was calculated by measuring the density of the sample and dividing it by the theoretical density of the sample material. The sintering process will cause the pellets to shrink due to the mass loss produced by the high temperatures inside the furnace. The process followed to sinter the LSCF pellets was:

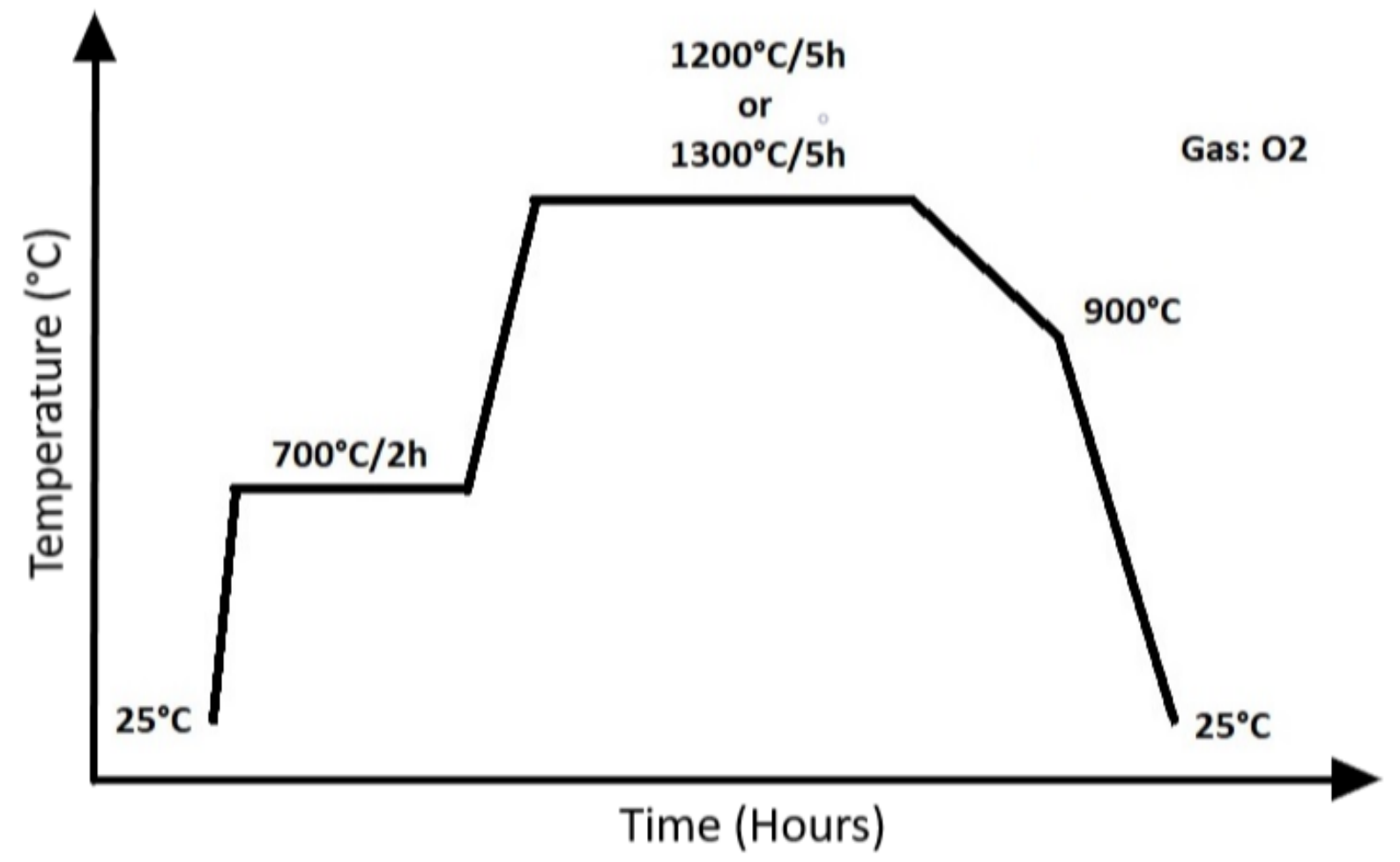

Figure 5 Sintering Process for LSCF

The sintering atmosphere was oxygen and was kept at a constant flow rate of $150 \mathrm{ccm}$. The maximum temperature of the process was varied depending on the samples. Certain 
samples were sintered at $1200^{\circ} \mathrm{C}$, meanwhile, other certain samples were sintered at $1300^{\circ} \mathrm{C}$. Zhu reported in his literature to sinter the samples at $1200^{\circ} \mathrm{C}$ for $10 \mathrm{~h}$ with a sintering atmosphere of air ${ }^{23}$. Samples were sintered at different temperatures to determine the effect of sintering temperature in the kinetic properties of the LSCF samples. During the sintering, the pellets are placed in a ceramic tray that is previously cleaned using ethanol to ensure no contamination. The tray with the pellets was placed in the middle of the furnace tube. Once the sintering process is completed, measurements of the new pellet dimensions were taken. The density was calculated again, and the relative density is calculated to make sure that the pellets are fully dense. When the density of the pellets has been checked to be satisfactory, the next step in the process is to cut the circular sample into two rectangles.

The machine used for cutting the samples is a Techcut 4 Precision Low Seed Saw from Allied. The saw used a 6" wafering blade, diamond metal bond. The circular sintered samples were glued to a metal block in order to fix them and cut them precisely. The cutting process consisted of performing 3 parallel cuts on the samples and 2 cuts perpendicular to the first 3 cuts. Every sample would produce 2 different rectangular sized samples that were measured individually. Once the cutting was performed, the samples were polished if there was any surface imperfection on them. However, if no polishing was needed, the next step was to wire the samples. Wiring the samples was essential for this experiment. During the electrical conductivity relaxation method, current was applied to the samples to obtain a voltage response from them. Therefore, wiring the samples was a process quite important to ensure a proper characterization of the samples. The samples were wired using 4 pieces of gold ( $\mathrm{Au}$ ) wire $(0.1 \mathrm{~mm})$, and conductor Au SC print. First, the 4 wires are wrapped around the sample as it can be seen in the following figure: 


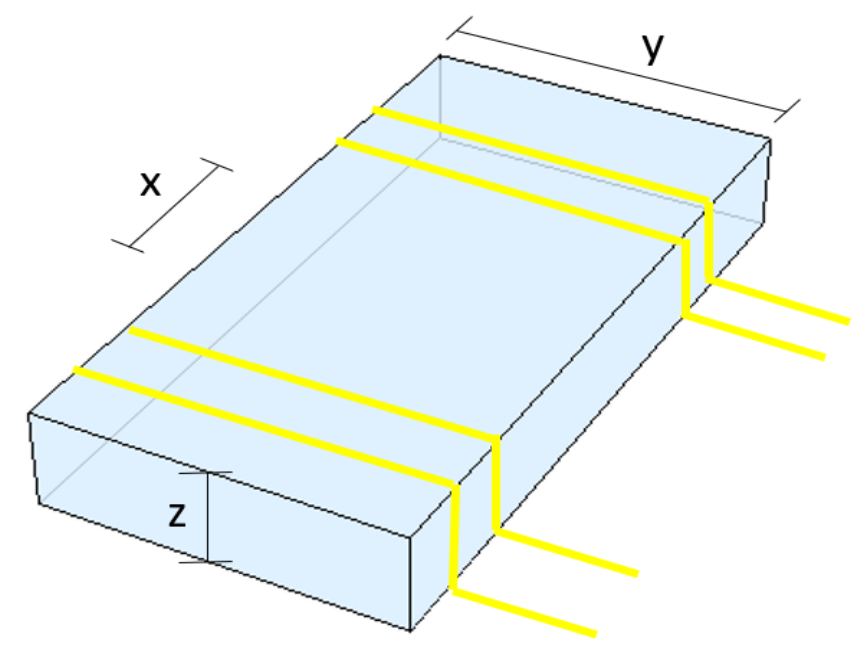

Figure 6 Computer Modeled LSCF Wired Sample

The 4 wires are placed parallel to each other and close to the sides of the sample. The 2 furthest wires to the sides were the ones where the current is applied. The 2 wires that are in the middle were used to measure the voltage response from the sample. The reason why the wires are placed towards the sides of the samples was to maximize the sample surface between the voltage wires. The goal was to ensure that the voltage response that was obtained from the sample was covering as much sample as possible. Once the wires were firmly wrapped around the sample, the gold paste was applied on top of the wires. The conductor Au print ensured the contact between the wires and the sample and prevented the wires from falling off the sample during the experiment.

\subsection{LSCF Surface Modified Sample Preparation}

The purpose of this thesis was to determine the impact of surface modification on the LSCF baseline samples. During the preparation for surface modified samples, two main processes were used to prepare them: layer coated, and ink coated samples.

The samples that were prepared using the layer coating method were prepared the exact same way that the LSCF baseline is. The samples were pressed, sintered, cut, wired, and then the layer coating was applied to them. The layers that were applied to every sample were different. Some samples had more layers applied than others. This helped determine the 
impact that the thickness of the layers had on the samples. The materials applied through layer coating were $\mathrm{CoO}_{x}$ and Pt. Some samples had only $\mathrm{CoO}_{x}$ applied to them, while others had a mix between $\mathrm{CoO}_{x}$ and Pt. Mixing the coating allowed to determine whether a new coating on top of a previous coating has an impact on the performance of the sample. The coating was applied to the samples using the Atomic Layer Deposition (ALD) technique.

The samples that were prepared using the ink coating method were prepared in a different way that the LSCF baseline is. In this case, the samples were pressed and sintered. Once the sinter was performed on the samples, and the density had been checked, the coating was added. After adding the coating, the sample was sintered again to ensure proper contact between the coating and the sample. When the second sintering is completed, the samples are cut and wired the same way that the LSCF baseline is prepared. The materials used for the ink coating were $\mathrm{CoO}_{x}, \mathrm{MnO}_{x}$, and $\mathrm{Pr}_{2} \mathrm{O}_{\mathrm{x}}$. The ink coating materials were prepared previously by mixing them. Each material was mixed, then they were spun in a silicon bath for about 3 hours. The materials were calcined after being mixed. Calcining each material helped to remove substances that might be left after mixing. The calcination process used was the following: 


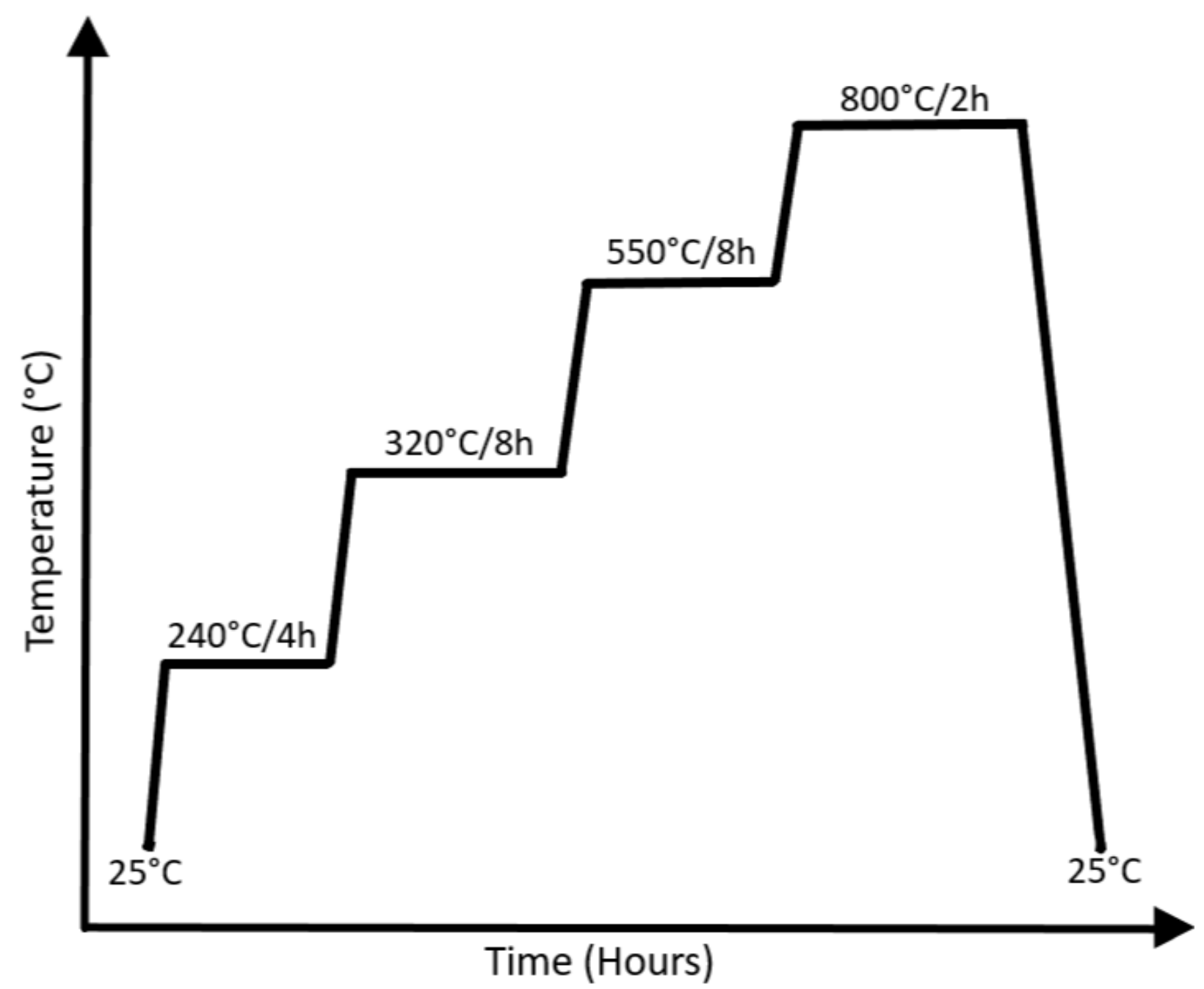

Figure 7 Heat-treatment Process for Coated LSCF

When the calcination process was completed, each material was mixed with Terpineol. The Terpineol was acting as a solvent while the powders were acting as a solute. After mixing well the powders and the Terpineol, an ink-based coating was obtained. This coating was liquid and could be applied to any surface. The machine that was used to apply the coating to the samples was an screen-printer. This device would hold the sample tight through a vacuum, while a squeegee spread the coating on top of the surface of the sample. The process of spreading the coating on top of the surface of the sample was performed twice to ensure that both sides of the samples were well coated. 


\subsection{Measurement Procedure}

Upon completion of the sample preparation process, the next step was to perform the Electrical Conductivity Relaxation method on the wired samples. However, it is crucial to make one more check of the surface of the samples before experimenting with them in the ECR set up. As it was mentioned before, the surface of the samples needs to remain smooth and uncontaminated. Especially the surface that is between the wires that read the voltage, since it will directly affect the measurement. The device that was used to check on the surface of the sample was an AxioCam Allied light microscope. The samples were placed under the microscope and checked that there were no cracks on top of the surface. When the check was completed, then ECR was performed on the sample.

The ECR setup requires different devices to experiment properly. These devices were connected to make a circuit. A simplified version of the setup is shown in the following image:

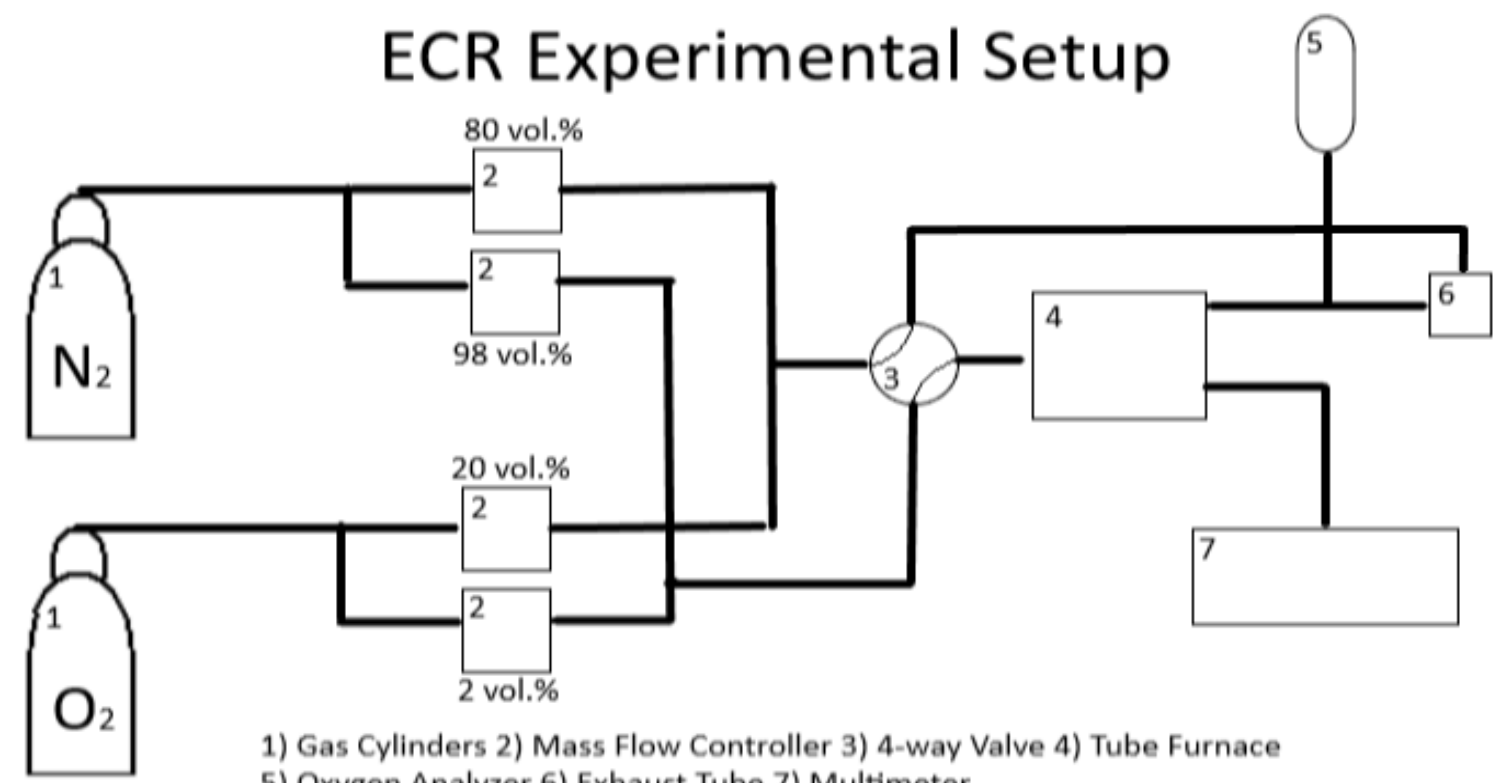

5) Oxygen Analyzer 6) Exhaust Tube 7) Multimeter

Figure 8 Experimental Setup of Electrical Conductivity Relaxation

The sample was placed in the tube furnace in the first place. The tube furnace counted with a sample holder that was wired. The sample was placed on top of the sample holder. The wires from the sample were connected to one end of the wires from the sample holder. The wires were connected carefully to ensure proper contact between the Au sample wires and the 
Ag sample holder wires. The wires from the sample holder needed to be connected in a way that the current was applied to the sample in the following way:

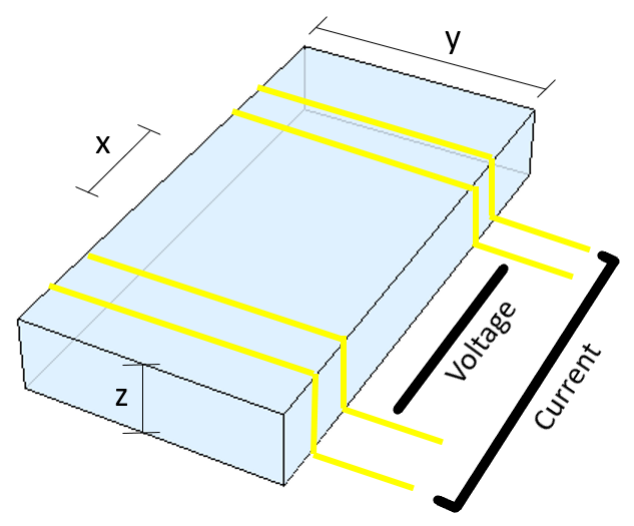

\section{Figure 9 Computer Modeled LSCF Current and Voltage Connections}

The other end of the wires from the sample holder was connected to the multimeter. Once the sample was secured on top of the sample holder, the sample holder was placed inside the tube furnace and locked using wrenches. The sample holder was bolted to the tube furnace to ensure no gas leaking.

When the sample holder had been locked, the gas cylinders were opened along with the mass flow controllers. Opening the gas cylinders at the beginning of the experiment ensured that the gas mixture would reach the same temperature as the sample. After opening the cylinders, the tube furnace was turned on in order to reach the desired temperature. The tube furnace was programmed to reach and stabilize at 2 temperatures for every measurement. The temperatures that were selected during the experiments were $650,700,750$, or $800{ }^{\circ} \mathrm{C}$. Those temperatures were selected based on the operating temperature of the SOFC's.

The tube furnace took around 1 hour for every experiment to reach the programmed temperature. Once this temperature was reached, data began to be collected. During the data collection process, the sample needed to reach different stabilization points. The first stabilization point was reached after reaching the programmed temperature with the furnace. When the temperature was reached, the sample needed to reach a resistance stabilization. The resistance of the sample varies depending on the temperature that the sample is found to be. 
Therefore, until the resistance of the sample was not stabilized, the change of $\mathrm{O}_{2}$ pressure could not be applied to the system. On the other hand, when the resistance of the sample reached the stabilization point, and it was not varying over time, the $\mathrm{O}_{2}$ pressure was increased from $2 \%$ to $20 \%$.

During the pressure increment process, the sample resistance dropped until it reached a new stabilization point for the new $\mathrm{O}_{2}$ pressure. After reaching the second stabilization point, the experiment was completed. However, as it was mentioned before, every experiment was performed for two temperatures. Consequently, the valve was switched again, and the programmed temperature was raised. The process was repeated until the second stabilization point was reached for the second temperature. After completing the experiment for both temperatures, the next step was to analyze the data and determine the kinetic properties.

\subsection{Analysis Procedure}

The data collection process was performed using a computer that received the signal from the digital multimeter and converted all the data into an excel file. The software that was used in the computer was LabView. This software had a customized program for the ECR experiment. As mentioned before, the software and the multimeter were connected. Therefore the multimeter was controlled from the computer. The program was set to make the multimeter apply a 0.1A current into the sample. Then the software would read the voltage signal that was sent from the multimeter to the computer and convert it into an excel file.

Upon completion of the experiment, the software delivered an excel file that contained the current and voltage readings, and the time that those readings were recorded. The excel file was used to determine the normalized conductance distribution. The normalized conductance distribution determined how long it would take for the sample to reach the stabilization phase, and to determine the kinetic properties of the sample ${ }^{35}$. The normalized conductance of the sample can be found through the following formula:

$$
\sigma_{n}=\frac{\sigma-\sigma_{o}}{\sigma_{s}-\sigma_{o}}
$$


The previous equation shows how the normalized conductance is calculated. The conductance measured by the multimeter is $\sigma$, the conductance achieved at the stabilization phase is $\sigma_{s}$, and the initial conductance is $\sigma_{0}$.

Once the normalized conductance was calculated for every measurement recorded during the experiment, the next step was to fit the normalized conductance into a solution of Fick's second law. The second law of Fick defines the rate of diffusion over a unit area. The equation that was used for this experiment was the following:

$$
\sigma_{n}=1-\sum_{n=1}^{\infty} \sum_{m=1}^{\infty} \sum_{i=1}^{\infty} \frac{2 * L_{\alpha}^{2} * e^{\left(\frac{-\alpha_{n}^{2} * D_{\text {chem }} * t}{x^{2}}\right)}}{\alpha_{n}^{2} *\left(\alpha_{n}^{2}+L_{\alpha}^{2}+L_{\alpha}\right)} \times \frac{2 * L_{\beta}^{2} * e^{\left(\frac{-\beta_{m}^{2} * D_{\text {chem }} * t}{y^{2}}\right)}}{\beta_{m}^{2} *\left(\beta_{m}^{2}+L_{\beta}^{2}+L_{\beta}\right)} \times \frac{2 * L_{\gamma}^{2} * e^{\left(\frac{-\gamma_{i}^{2} * D_{\text {chem }} * t}{z^{2}}\right)}}{\gamma_{i}^{2} *\left(\gamma_{i}^{2}+L_{\gamma}^{2}+L_{\gamma}\right)}
$$

The previous equation shows the relationship between Fick's second law and the normalized conductance. The ratio between half thickness to the characteristic length is shown as $L_{\alpha}, L_{\beta}$, and $L_{\gamma}$ for every dimension of the sample. The diffusion coefficient is shown as $D_{\text {chem. }}$ The time is shown as $t$. The dimensions of the sample are $x, y$, and $z$ for every dimension. Finally, $\alpha_{n}, \beta_{m}$, and $\gamma_{i}$ are eigenvalues ${ }^{23}$.

The characteristic length of the sample is defined by the following equation:

$$
L_{c}=\frac{D_{\text {chem }}}{k_{\text {chem }}}
$$

The characteristic length is fit to the half-thickness of each dimension of the sample to calculate the ratio between them. The ratio between these two parameters that were seen in Fick's second law is calculated by the following equation:

$$
L_{\alpha}=\frac{x * k_{\text {chem }}}{D_{\text {chem }}} ; \quad L_{\beta}=\frac{y * k_{\text {chem }}}{D_{\text {chem }}} ; \quad L_{\gamma}=\frac{z * k_{\text {chem }}}{D_{\text {chem }}}
$$

The eigenvalues shown in Fick's second law solution are calculated through the following equation for every dimension of the sample:

$$
\alpha_{n} * \tan \left(\alpha_{n}\right)=L_{\alpha} ; \quad \beta_{n} * \tan \left(\beta_{n}\right)=L_{\beta} ; \quad \gamma_{n} * \tan \left(\gamma_{n}\right)=L_{\gamma}
$$


The last equation shows the relationship between the eigenvalues and the ratio between the half-thickness and characteristic length of the sample for every dimension of the sample. The eigenvalues must be positive and non-zero roots. After conducting the experiment and calculating the normalized conductance of the sample, the following would be to calculate the kinetics parameters using the equations shown above. However, performing these calculations without computer software would be quite complex and would lead to errors. In order to avoid any mathematical errors while calculating the kinetic parameters, the conductance data was fitted and processed by a MATLAB program. The MATLAB program that was used required the normalized conductance and half the thickness of the dimensions of the sample to be input.

\subsection{Microstructure Characterization using Scanning Electron Microscopy}

The Scanning Electron Microscopy (SEM) was used to characterize the surface microstructure of the LSCF samples. The characterization with the SEM was only performed on samples that have previously been measured using the ECR. The samples that were characterized using the SEM have broken apart into a small piece that was glued with Silver $(\mathrm{Ag})$ on holders. The holders were placed inside the SEM machine and characterized using the electron beam at $10 \mathrm{kV}$. The images that were taken correspond to the plan view of each sample. The samples that were characterized by SEM consist of baseline and coated LSCF. The following images were taken for the following samples:

- Baseline LSCF sintered at 1200 and $1300{ }^{\circ} \mathrm{C}$ : 


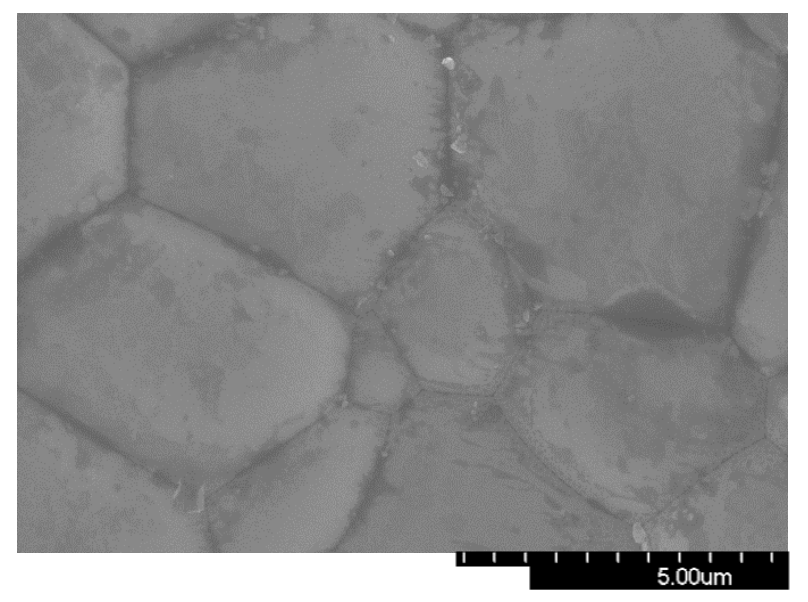

Figure 10 SEM LSCF Baseline $\left(\right.$ Sint $\left.=1300^{\circ} \mathrm{C}\right)$

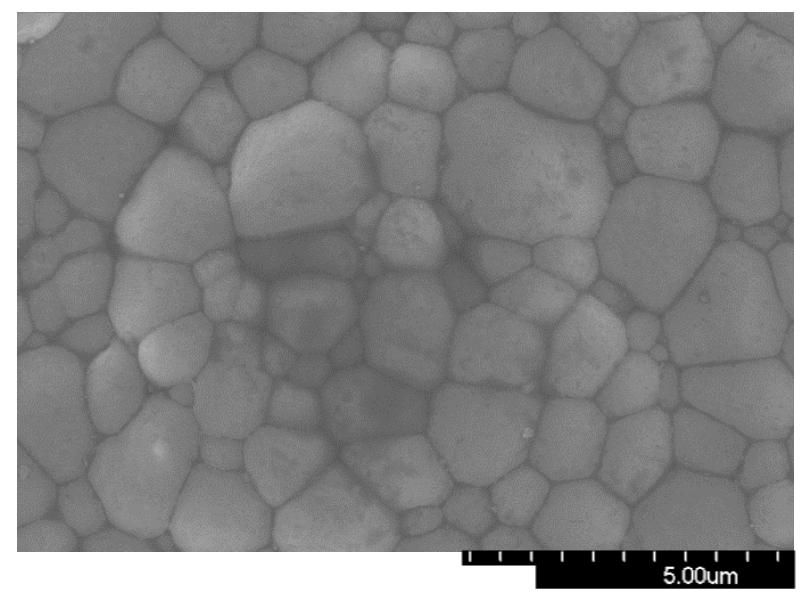

Figure 11 SEM LSCF Baseline $\left(\right.$ Sint $=1200^{\circ} \mathrm{C}$ )

Figures 10 and 11 show the plan view SEM images for baseline LSCF with a sintering temperature of 1300 and $1200{ }^{\circ} \mathrm{C}$ on the left and right, respectively. It is observed that lower sintering temperatures have a reduced grain size in comparison to larger sintering temperatures. Therefore, the average grain size of lower sintering temperature samples is reduced compared to the one from higher sintering temperature samples. In Asadis' et al study, it was found that a reduced average grain size in a MIEC would increase the oxygen permeation flux through the sample ${ }^{36}$. Therefore, it will be expected to see large oxygen transport kinetics in lower sintering temperature samples. However, it is also seen that the grain boundary area of higher sintering temperature samples is reduced in comparison to the grain boundary area of lower sintering temperature samples. Additionally, the study of Zeng's et al of the effects of sintering temperature on the performance of LSCF showed that the smaller the grain boundary area is in the perovskite oxide, the larger the electrical conductivity of the MIEC will be ${ }^{37}$. Higher electrical conductivity will result in a higher oxygen transport kinetics since the higher electrical conductivity will enhance the absorption of the oxygen molecules onto the surface of the MIEC.

To determine which sample offers higher oxygen transport kinetics, it will be necessary to perform ECR in both samples with different sintering temperatures. The reason for this is because the LSCF sample with higher sintering temperature has a reduced grain boundary area, which offers a larger electrical conductivity. On the other hand, the higher sintering 
temperature sample has a larger average grain size, which results in a lower oxygen permeation flux through the sample.

\subsection{Error Analysis}

The error bars were calculated for each measurement to determine the range of the measurements. The actual meaning of the bars is the range of the surface exchange and diffusion coefficient values at each temperature. Therefore, for each temperature the error bar was calculated including every measurement that was performed for such composition at such temperature. The error bars are the standard deviation of all the measurements at such temperature. The error bars were calculated using the following equation:

$$
\text { Error bar }= \pm \sqrt{\frac{\sum(x-\overline{\mathrm{x}})^{2}}{n}}
$$

The error bar equation calculates the standard deviation of each measurement with respect to an average. In the equation:

$x$ is the average

$\bar{x}$ is the value of each measurement

$\mathrm{n}$ is the number of samples 


\section{Chapter 3: Baseline LSCF}

\subsection{Crystal structure and physical properties of LSCF}

As mentioned above, the LSCF electrical properties and composition are a great fit for the cathode of SOFC's. The LSCF compound has been reported to have a rhombohedral perovskite structure ${ }^{38}$. As mentioned previously, fuel cells work by transforming chemical energy into electrical energy. This process is done by producing an electrochemical reaction that takes place in the electrolyte. The reactants of the electrochemical reaction are the oxygen atoms and hydrogen atoms that are fed into the electrolyte through the cathode and anode, respectively. To produce the oxygen dissociation at the cathode it is necessary that the material counts with a high electrical and ionic conductivity. Therefore, the perfect material to use as a cathode in the cell would be a mixed ion-electron conducting material such as LSCF. The reason for using a mixed ion-electron conducting material is because of the increased rate that the oxygen will be reduced. This will make the cell have increased active areas and more oxygen transported into the electrolyte ${ }^{39}$. The following figure shows a computer-modeled LSCF unit cell:

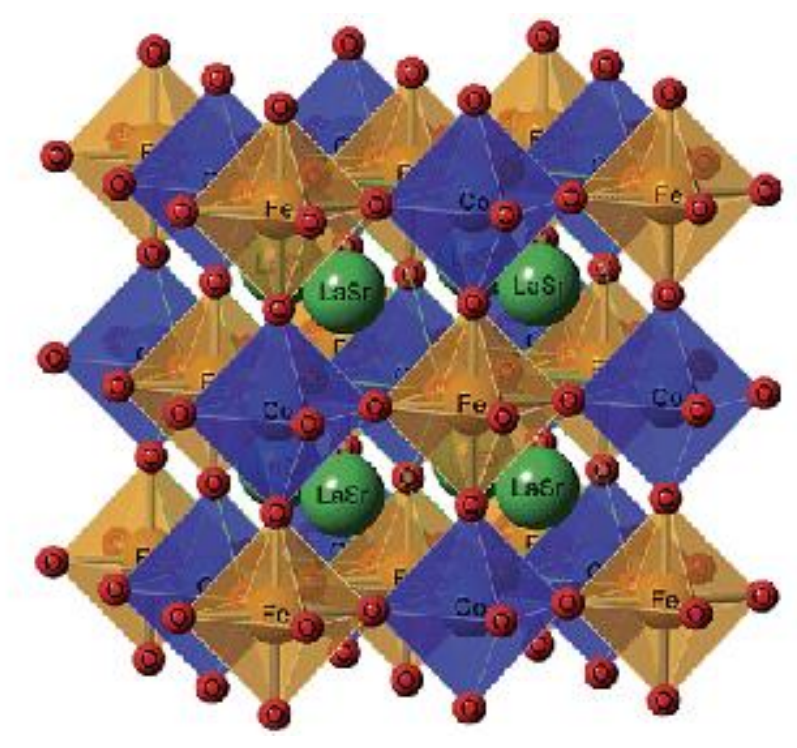

Figure 12 Computer Modeled LSCF Cubic Structure 40

The figure above shows a model for an 80 -atom unit cell. The composition is seen as 1 : 1 for La : Sr and $3: 1$ Fe : Co with a minimum distance between oxygen vacancies of $9.46 \AA$. 
LSCF $\left(\mathrm{La}_{0.60} \mathrm{Sr}_{0.40}\right)_{0.95} \mathrm{Co}_{0.20} \mathrm{Fe}_{0.80} \mathrm{O}_{3-\mathrm{x}}$ is one of the most frequently used materials for cathodes due to its electronic structure. The addition of the $\mathrm{Co}^{3+}$ increases the oxygen vacancy formation energy, which results in a lower amount of oxygen vacancies. Minimizing the amount of oxygen vacancies is crucial because it will strengthen the material and make it more durable.

Additionally, it will help improve the electronic conductivity, which will directly enhance the performance of the cathode in the SOFC.

\subsection{Kinetic Properties of Uncoated Baseline LSCF}

The first step within this research project was to characterize the kinetic properties of baseline LSCF properly. The kinetic properties of baseline LSCF will serve as a reference throughout this project. In this thesis, the kinetic properties of the coated samples were compared to the baseline ones. To ensure proper characterization of the baseline LSCF, the next needed to be met. The samples needed to be reproducible from one to another, meaning that the results will not vary sample after sample, hence the first objective was to dominate the manufacturing and experimental procedure of the samples. The samples for baseline LSCF were manufactured and analyzed, as it was explained in the previous chapter. However, for the baseline LSCF, two sets of samples were manufactured with the difference between them in the sintering temperature. One set of samples was sintered in an oxygen atmosphere at 1200 ${ }^{\circ} \mathrm{C}$ meanwhile the other one was sintered in an oxygen atmosphere at $1300{ }^{\circ} \mathrm{C}$. As mentioned in the previous chapter, only the samples with a relative density of $90 \%$ or higher were analyzed. Nevertheless, there were samples with a relative density that was higher than $90 \%$ that were not analyzed. The reason for this is that some samples have cracks that would create uncertainty while analyzing the diffusion process data and consequently would produce errors after the data analysis. Additionally, some of the samples had a large fitting error after processing the data through MATLAB. Therefore, they were discarded since those results were not reliable. Finally, some samples had connection problems during the measurement, and the data was excessively noisy.

After the manufacturing of the LSCF was completed, the analysis would proceed with the ECR experimental method, as explained in chapter 2 . Several LSCF baseline pellets with different sintering temperatures were tested through the ECR method: 
Table 1 Baseline LSCF Samples (Sintering $=1200^{\circ} \mathrm{C}$ )

\begin{tabular}{|c|c|c|c|c|c|c|c|}
\hline \multicolumn{8}{|c|}{ Baseline LSCF (sintering = $1200 \mathrm{C}$ ) } \\
\hline Sample & Temp. $\left({ }^{\circ} \mathrm{C}\right)$ & Temp. (K) & $1000 / \mathrm{T}(1 / \mathrm{K})$ & Surface Exchange $(\mathrm{k})(\mathrm{cm} / \mathrm{s})$ & Diffusion coefficient (D) $\left(\mathrm{cm}^{2} / \mathrm{s}\right)$ & $\ln (\mathbf{k})$ & $\ln (D)$ \\
\hline 21 & 800 & 1073.15 & 0.93 & $1.52 \mathrm{E}-03$ & 1.46E-06 & -6.49 & -13.44 \\
\hline 53.1 & 800 & 1073.15 & 0.93 & $7.25 \mathrm{E}-04$ & 7.86E-06 & -7.23 & -11.75 \\
\hline \multirow{2}{*}{53.2} & 650 & 923.15 & 1.08 & $1.79 \mathrm{E}-04$ & $1.84 \mathrm{E}-06$ & -8.63 & -13.21 \\
\hline & 700 & 973.15 & 1.03 & $2.42 \mathrm{E}-04$ & $3.41 \mathrm{E}-06$ & -8.33 & -12.59 \\
\hline \multirow{2}{*}{57.2} & 650 & 923.15 & 1.08 & $6.48 \mathrm{E}-04$ & 2.27E-06 & -7.34 & -12.99 \\
\hline & 700 & 973.15 & 1.03 & 7.50E-04 & 4.03E-06 & -7.19 & -12.42 \\
\hline 59.1 & 650 & 923.15 & 1.08 & $3.24 \mathrm{E}-04$ & $2.09 \mathrm{E}-06$ & -8.04 & -13.08 \\
\hline \multirow{2}{*}{59.2} & 650 & 923.15 & 1.08 & $3.26 \mathrm{E}-04$ & $1.44 \mathrm{E}-06$ & -8.03 & -13.45 \\
\hline & 700 & 973.15 & 1.03 & $6.55 \mathrm{E}-04$ & 2.34E-06 & -7.33 & -12.96 \\
\hline \multirow{2}{*}{60.1} & 750 & 1023.15 & 0.98 & $1.21 \mathrm{E}-03$ & $2.04 \mathrm{E}-06$ & -6.72 & -13.10 \\
\hline & 800 & 1073.15 & 0.93 & 4.94E-04 & 3.30E-06 & -7.61 & -12.62 \\
\hline 60.2 & 800 & 1073.15 & 0.93 & $4.28 \mathrm{E}-04$ & $3.21 \mathrm{E}-06$ & -7.76 & -12.65 \\
\hline 83.2 & 750 & 1023.15 & 0.98 & $1.73 \mathrm{E}-03$ & $1.50 \mathrm{E}-05$ & -6.36 & -11.11 \\
\hline
\end{tabular}

Table 2 Baseline LSCF Samples (Sintering $=1300{ }^{\circ} \mathrm{C}$ )

\begin{tabular}{|c|c|c|c|c|c|c|c|}
\hline \multicolumn{8}{|c|}{ Baseline LSCF (sintering = 1300 C) } \\
\hline Sample & Temp. $\left({ }^{\circ} \mathrm{C}\right)$ & Temp. (K) & $1000 / \mathrm{T}(1 / \mathrm{K})$ & Surface Exchange $(\mathrm{k})(\mathrm{cm} / \mathrm{s})$ & Diffusion coefficient (D) $\left(\mathrm{cm}^{2} / \mathrm{s}\right)$ & $\ln (k)$ & $\ln (D)$ \\
\hline 31 & 800 & 1073.15 & 0.93 & $6.85 \mathrm{E}-04$ & $8.32 \mathrm{E}-06$ & -7.29 & -11.70 \\
\hline 67.1 & 700 & 973.15 & 1.03 & $4.90 \mathrm{E}-04$ & $4.26 \mathrm{E}-06$ & -7.62 & -12.37 \\
\hline 73.2 & 800 & 1073.15 & 0.93 & $8.15 \mathrm{E}-04$ & $8.66 \mathrm{E}-06$ & -7.11 & -11.66 \\
\hline \multirow{2}{*}{81.2} & 750 & 1023.15 & 0.98 & 1.40E-03 & $1.27 \mathrm{E}-05$ & -6.57 & -11.27 \\
\hline & 800 & 1073.15 & 0.93 & $1.39 \mathrm{E}-03$ & $1.98 \mathrm{E}-05$ & -6.58 & -10.83 \\
\hline
\end{tabular}

The previous tables show the list of samples that were tested for baseline LSCF with sintering temperatures of $1200^{\circ} \mathrm{C}$ and $1300{ }^{\circ} \mathrm{C}$. The tables show the temperatures that the samples were tested for as well as the kinetic properties that were obtained at each given temperature for each sample.

Even though several samples were tested for baseline LSCF, only the highest results were taken from each sintering temperature because it means that such kinetic property is achievable for LSCF. The surface exchange coefficients obtained from baseline LSCF were plotted in a $\ln (k)$ vs $1000 / T$ graph as follows: 


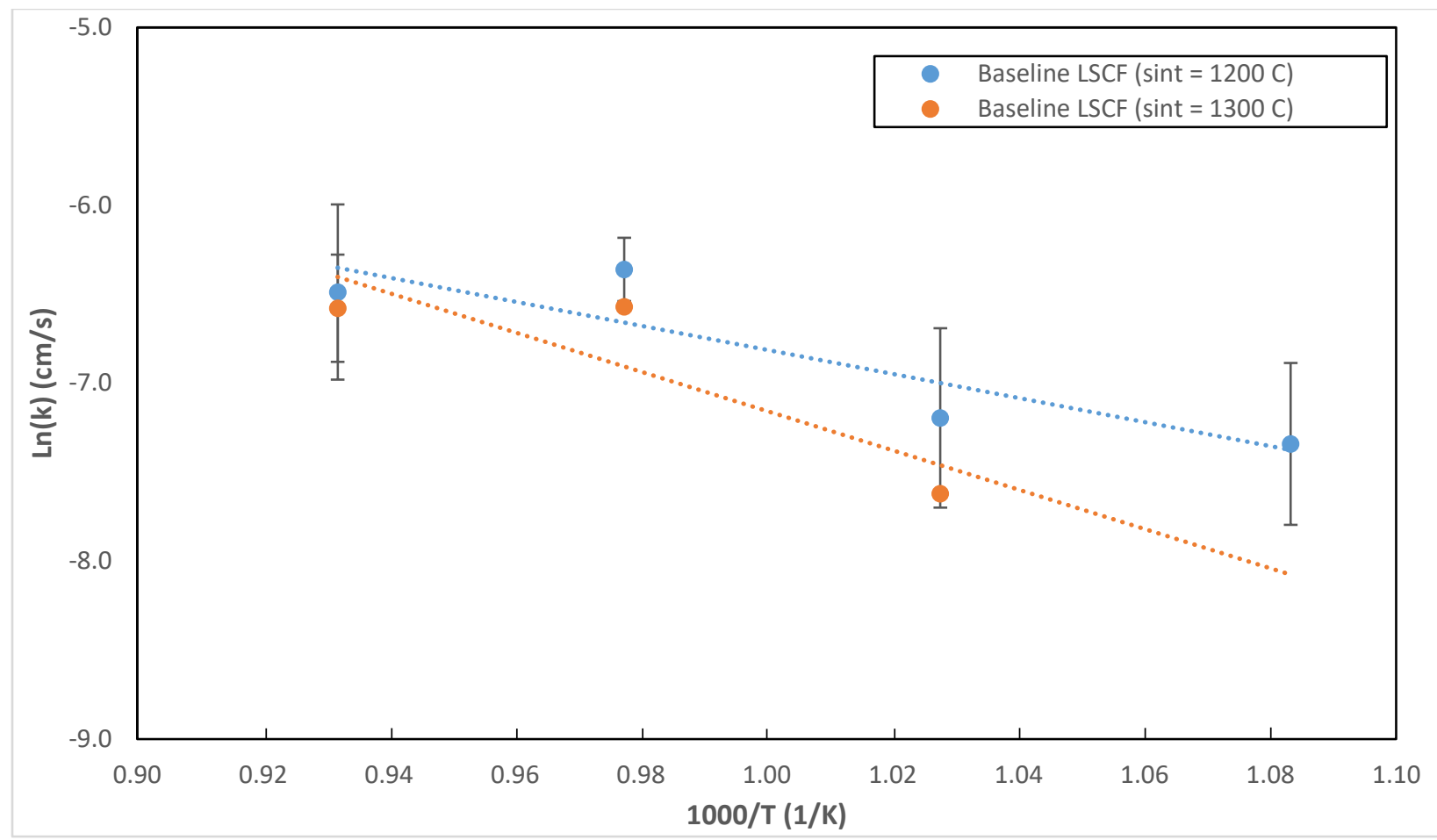

Figure 13 Surface Exchange vs Temperature - Baseline LSCF

In the previous figure, the $\ln (k)$ vs 1000/T graph was plotted for baseline LSCF sintered at $1200^{\circ} \mathrm{C}$ and $1300^{\circ} \mathrm{C}$. The surface exchange rate for LSCF increases as the temperature increases and decreases as the temperature reduces. Meaning that the surface exchange is inversely proportional to the conductance of the sample that increases as the temperature reduces. Furthermore, the surface exchange of baseline sintered at a temperature of $1200{ }^{\circ} \mathrm{C}$ is higher than the surface exchange of baseline sintered at a temperature of $1300^{\circ} \mathrm{C}$. To conclude why the surface exchange increases with reduced sintering temperature, it is necessary to recall from chapter one how the surface exchange process works. Surface exchange reaction processes function thanks to the vacancies that are found within the LSCF sample. Hence, the difference in surface exchange can be attributed to the fact that the samples with lower sintering temperatures are less compact and have a larger grain size than the samples with higher sintering temperatures. In the following images, a comparison between two baseline LSCF samples with different sintering temperature is shown: 


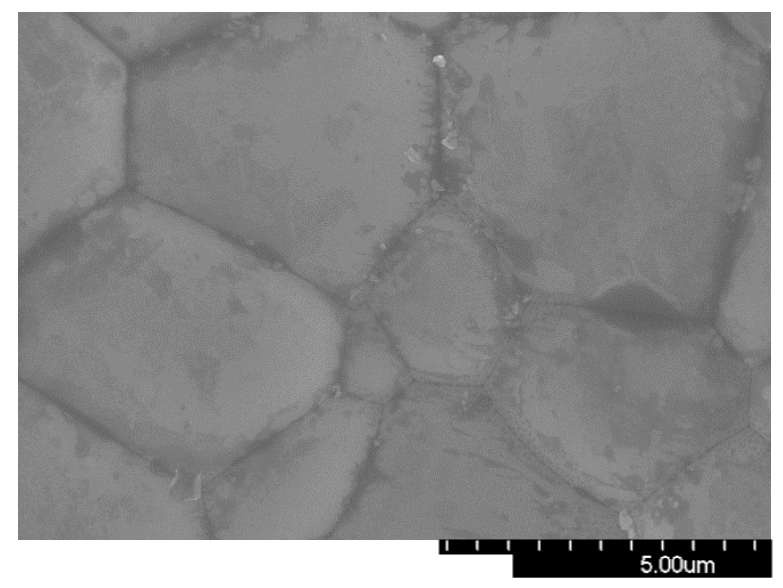

Figure 10 SEM LSCF Baseline $\left(\operatorname{Sint}=1300^{\circ} \mathrm{C}\right)$

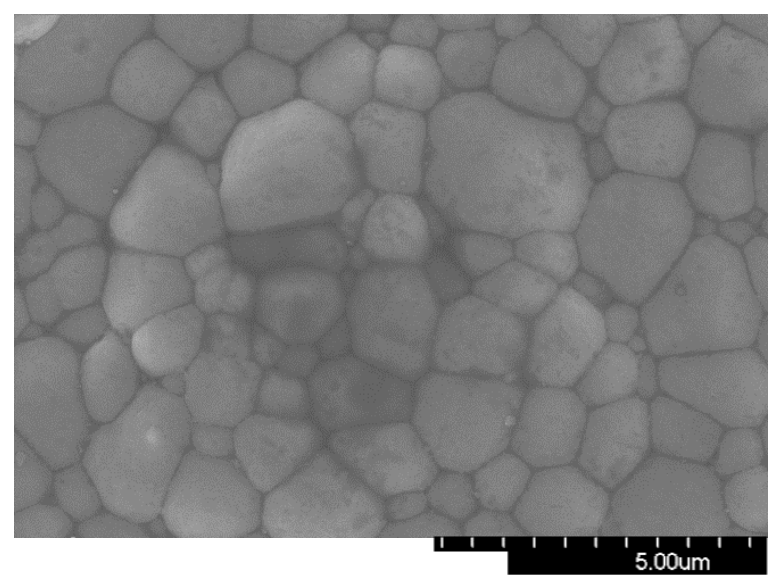

Figure 11 SEM LSCF Baseline $\left(\right.$ Sint $\left.=1200^{\circ} \mathrm{C}\right)$

The figure on the left shows an LSCF sample that was sintered at $1200{ }^{\circ} \mathrm{C}$ that has a smaller grain size than the figure on the right that shows an LSCF sample with a sintering temperature of $1300^{\circ} \mathrm{C}$.

The natural log surface exchange values plotted for the surface exchange vs temperature graph for baseline LSCF are shown in the following table for each temperature:

Table 3 Surface Exchange Values - Baseline LSCF

\begin{tabular}{cccccc}
\hline Composition of & Sintering Temp. & \multicolumn{4}{c}{$\mathbf{L n}(\mathbf{k})(\mathbf{c m} / \mathbf{s})$} \\
\cline { 3 - 6 } LSCF & $\left({ }^{\circ} \mathbf{C}\right)$ & $\mathbf{6 5 0}\left({ }^{\circ} \mathbf{C}\right)$ & $\mathbf{7 0 0}\left({ }^{\circ} \mathbf{C}\right)$ & $\mathbf{7 5 0}\left({ }^{\circ} \mathbf{C}\right)$ & $\mathbf{8 0 0}\left({ }^{\circ} \mathbf{C}\right)$ \\
\hline Baseline & 1200 & -7.34 & -7.19 & -6.36 & -6.49 \\
\hline Baseline & 1300 & 0.00 & -7.62 & -6.57 & -6.58 \\
\hline
\end{tabular}

Table 4 Surface Exchange \% Increase/Decrease - Baseline LSCF

\begin{tabular}{cccccc}
\hline $\begin{array}{c}\text { Composition of } \\
\text { LSCF }\end{array}$ & $\begin{array}{c}\text { Sintering Temp. } \\
\left({ }^{\circ} \mathrm{C}\right)\end{array}$ & \multicolumn{3}{c}{$\begin{array}{c}\% \text { Increase/Decrease in Surface Exchange } \\
\text { Compared to Baseline }\end{array}$} \\
\cline { 3 - 6 } & & $\mathbf{6 5 0}\left({ }^{\circ} \mathrm{C}\right)$ & $\mathbf{7 0 0}\left({ }^{\circ} \mathrm{C}\right)$ & $\mathbf{7 5 0}\left({ }^{\circ} \mathrm{C}\right)$ & $\mathbf{8 0 0}\left({ }^{\circ} \mathrm{C}\right)$ \\
\hline Baseline & 1300 & - & $-5.91 \%$ & $-3.30 \%$ & $-1.41 \%$ \\
\hline
\end{tabular}

In the previous table, the percentage increase/decrease of the surface exchange between the baselines is shown. It can be observed that the baseline with a sintering temperature of $1300^{\circ} \mathrm{C}$ has a significant reduction in the surface exchange with respect to the 
surface exchange of baseline with a sintering temperature of $1200^{\circ} \mathrm{C}$. The reduction in surface exchange is more pronounced for lower temperatures where there is about a $6 \%$ difference. However, for higher temperatures, the values become more similar, and the reduction seen is about $1.5 \%$ for the temperature of $800{ }^{\circ} \mathrm{C}$.

The surface exchange characterization was compared to the one reported by Zhu and others in Zhu's literature ${ }^{23}$. In the following figure, our surface exchange characterization was graphed with the surface exchange characterization done by Zhu for LSCF baseline samples:

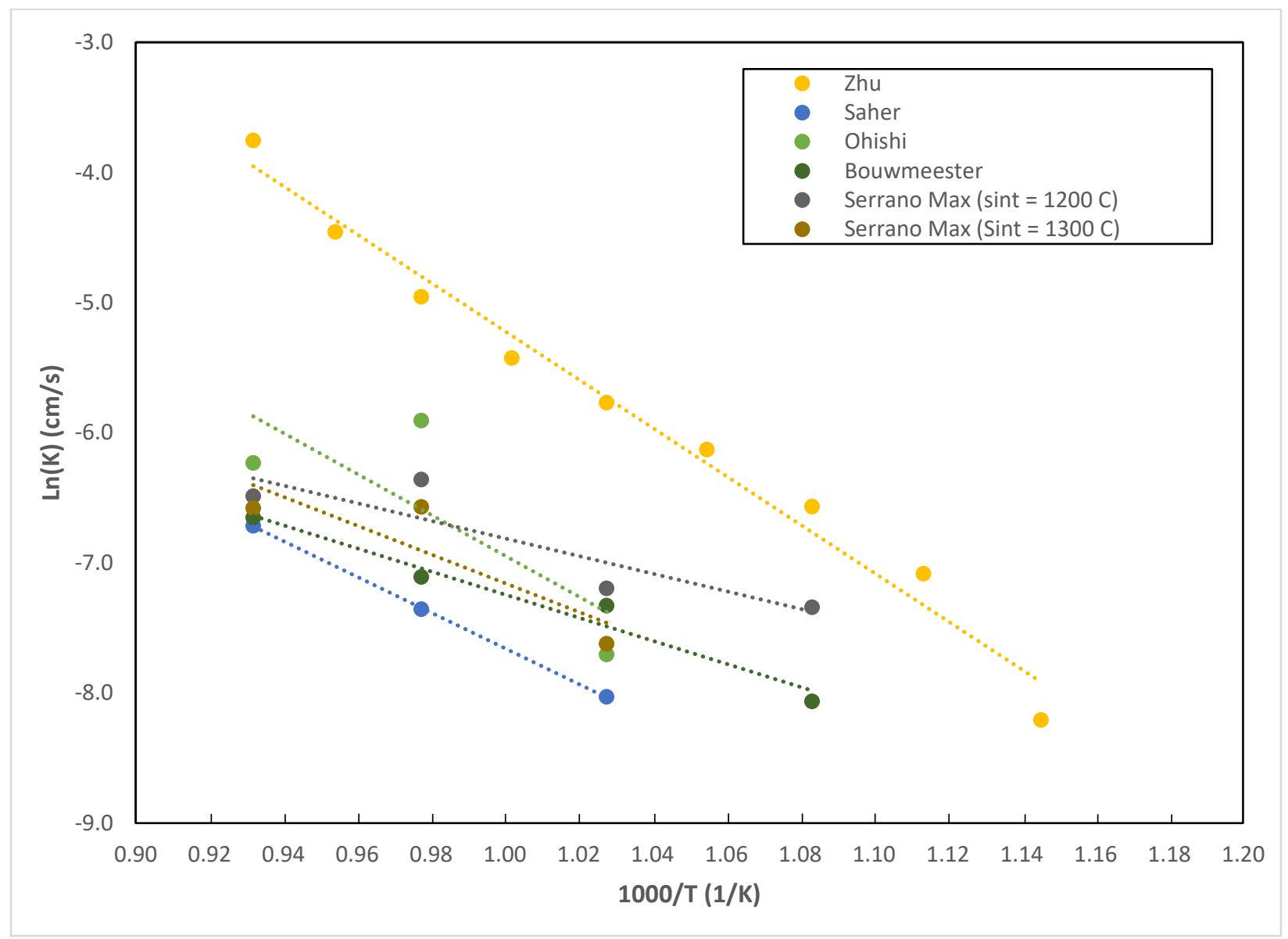

Figure 14 Surface Exchange Comparison with Literature - Baseline LSCF

It can be seen in the previous graph that Zhu reported the highest surface exchange coefficient. It can be attributed to the difference in sample preparation between his literature and this research project ${ }^{23}$. 
Moreover, the characterization of the bulk diffusion coefficient was also performed for baseline LSCF. The samples analyzed in this case are the same samples that were shown at the beginning of this section since the electrical conductivity relaxation method allows us to determine both oxygen transport kinetic properties simultaneously. The bulk diffusion coefficients obtained for baseline LSCF were plotted in a $\ln (D)$ vs $1000 / T$ graph as follows:

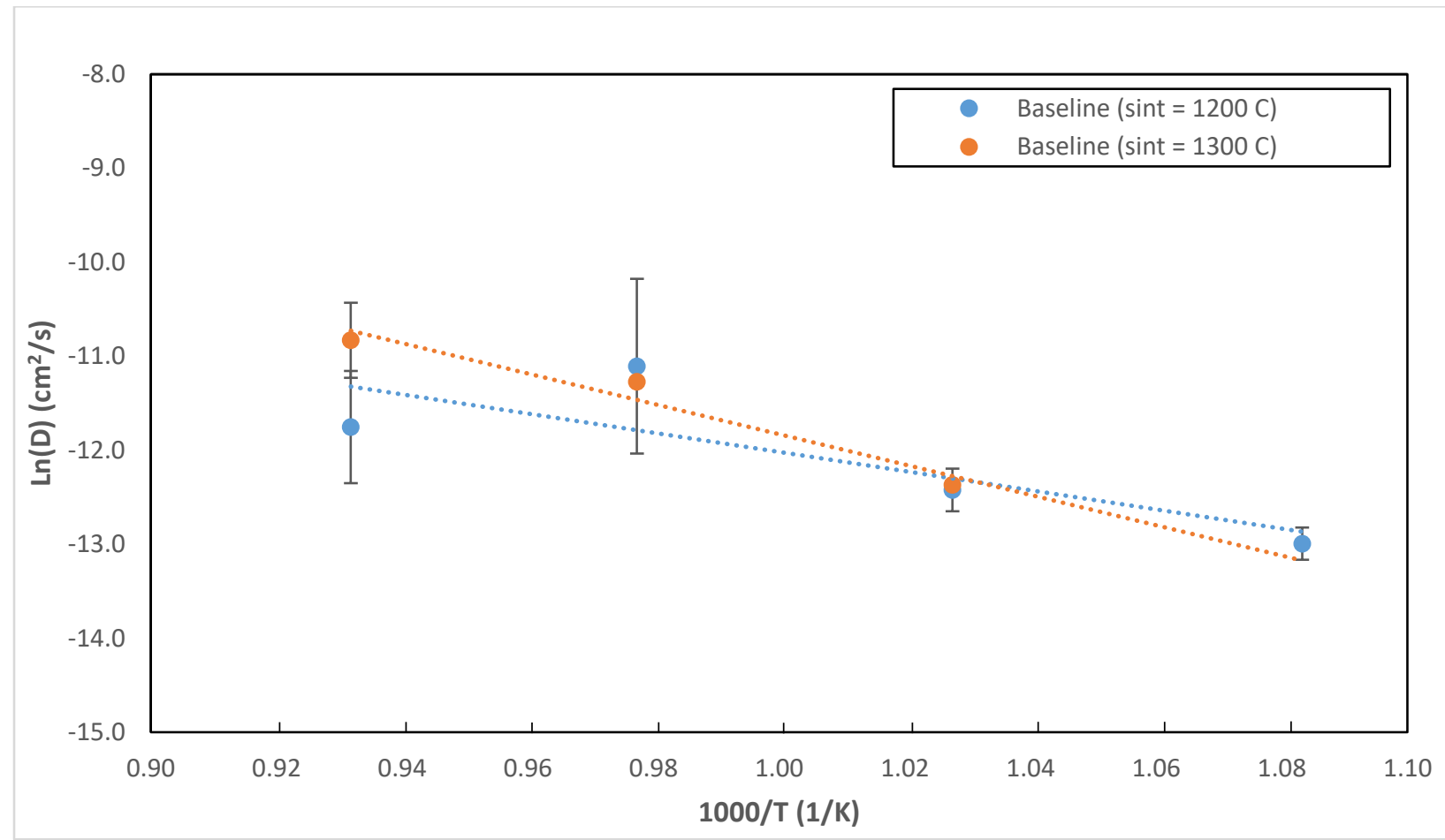

Figure 15 Bulk Diffusion Coefficient vs Temperature - Baseline LSCF

In the previous figure, the $\ln (D)$ vs $1000 / T$ was plotted for baseline LSCF with sintering temperature of $1200{ }^{\circ} \mathrm{C}$ and $1300{ }^{\circ} \mathrm{C}$. As it is expected, the diffusion coefficient follows the same trend as the surface exchange. The diffusion coefficient increases with increasing temperature and decreases as the temperature decreases. It can also be observed from the graph that the diffusion coefficient for baseline LSCF is not affected by the sintering temperature. The diffusion coefficient of both baselines is close to each other and cross each other at a temperature $700{ }^{\circ} \mathrm{C}$. Baseline LSCF with sintering temperature of $1200{ }^{\circ} \mathrm{C}$ shows an increasing diffusion coefficient concerning an increasing temperature except for temperature $800{ }^{\circ} \mathrm{C}$ that shows a smaller value. The value seen for that temperature on LSCF with sintering 
temperature of $1200{ }^{\circ} \mathrm{C}$ could potentially be wrong since it breaks the trend that the diffusion coefficient follows to temperature.

The reason that the diffusion coefficients of both baselines have a similar value is that the bulk is the same for every sample. Every sample has roughly about the same surface as the manufacturing process is the same for each sample independently of the coating and sintering. Therefore, the surface that is measured for each sample is about the same surface area, and the diffusion coefficient depends on the area of the bulk, hence the diffusion coefficient is not affected by the sintering temperature of the samples. However, it will be affected depending on the number of vacancies that are found in each sample because that number will determine how many oxygen ions the LSCF samples can incorporate into their stoichiometry. Also, the distance between such vacancies is a limiting factor on the speed that the ions are exchanged. Having vacancies close to each other will require less force from the electrons to move the oxygen ions from one vacancy to another, meaning that they will be moved faster, and consequently, the surface exchange and diffusion coefficient will increase.

In the following table, the natural log of the diffusion coefficient values that were plotted are shown for baseline LSCF with sintering temperature of 1200 and $1300{ }^{\circ} \mathrm{C}$ :

\section{Table 5 Bulk Diffusion Coefficient Values - Baseline LSCF}

\begin{tabular}{|c|c|c|c|c|c|}
\hline \multirow{2}{*}{$\begin{array}{l}\text { Composition of } \\
\text { LSCF }\end{array}$} & \multirow{2}{*}{$\begin{array}{l}\text { Sintering Temp. } \\
\left({ }^{\circ} \mathrm{C}\right)\end{array}$} & \multicolumn{4}{|c|}{$\operatorname{Ln}(D)(\mathrm{cm} 2 / \mathrm{s})$} \\
\hline & & $650\left({ }^{\circ} \mathrm{C}\right)$ & $700\left({ }^{\circ} \mathrm{C}\right)$ & $750\left({ }^{\circ} \mathrm{C}\right)$ & $800\left({ }^{\circ} \mathrm{C}\right)$ \\
\hline Baseline & 1200 & -12.99 & -12.42 & -11.11 & -11.75 \\
\hline Baseline & 1300 & 0.00 & -12.37 & -11.27 & -10.83 \\
\hline
\end{tabular}

Table 6 Bulk Diffusion Coefficient \% Increase/Decrease - Baseline LSCF

\begin{tabular}{cccccc}
\hline $\begin{array}{c}\text { Composition of } \\
\text { LSCF }\end{array}$ & $\begin{array}{c}\text { Sintering Temp. } \\
\left({ }^{\circ} \mathrm{C}\right)\end{array}$ & \multicolumn{3}{c}{$\begin{array}{c}\% \text { Increase/Decrease in Diffusion Coefficient } \\
\text { Compared to Baseline }\end{array}$} \\
\cline { 3 - 6 } & & $\mathbf{6 5 0}\left({ }^{\circ} \mathrm{C}\right)$ & $\mathbf{7 0 0}\left({ }^{\circ} \mathrm{C}\right)$ & $\mathbf{7 5 0}\left({ }^{\circ} \mathrm{C}\right)$ & $\mathbf{8 0 0}\left({ }^{\circ} \mathrm{C}\right)$ \\
\hline Baseline & 1300 & - & $0.45 \%$ & $-1.49 \%$ & $7.86 \%$ \\
\hline
\end{tabular}


In the previous table, the percentage increase/decrease of the diffusion coefficient between the baselines is shown. As it was mentioned before, the difference in diffusion coefficient between the baselines is not pronounced except for a temperature of $800{ }^{\circ} \mathrm{C}$. For temperatures of 700 and $750{ }^{\circ} \mathrm{C}$ there is about a $1.5 \%$ difference between the baselines, meanwhile for temperature $800{ }^{\circ} \mathrm{C}$ there is almost an $8 \%$ difference. However, the results seen for temperature $800{ }^{\circ} \mathrm{C}$ on the baseline with sintering $1200{ }^{\circ} \mathrm{C}$ do not follow the trend that the rest of the results follow, and the difference calculated at that temperature is not accurate.

The bulk diffusion coefficient characterization was also compared to the one reported by Zhu and others in Zhu's literature ${ }^{23}$. In the following figure, our bulk diffusion coefficient characterization was graphed with the bulk diffusion coefficient characterization done by Zhu for LSCF baseline samples:

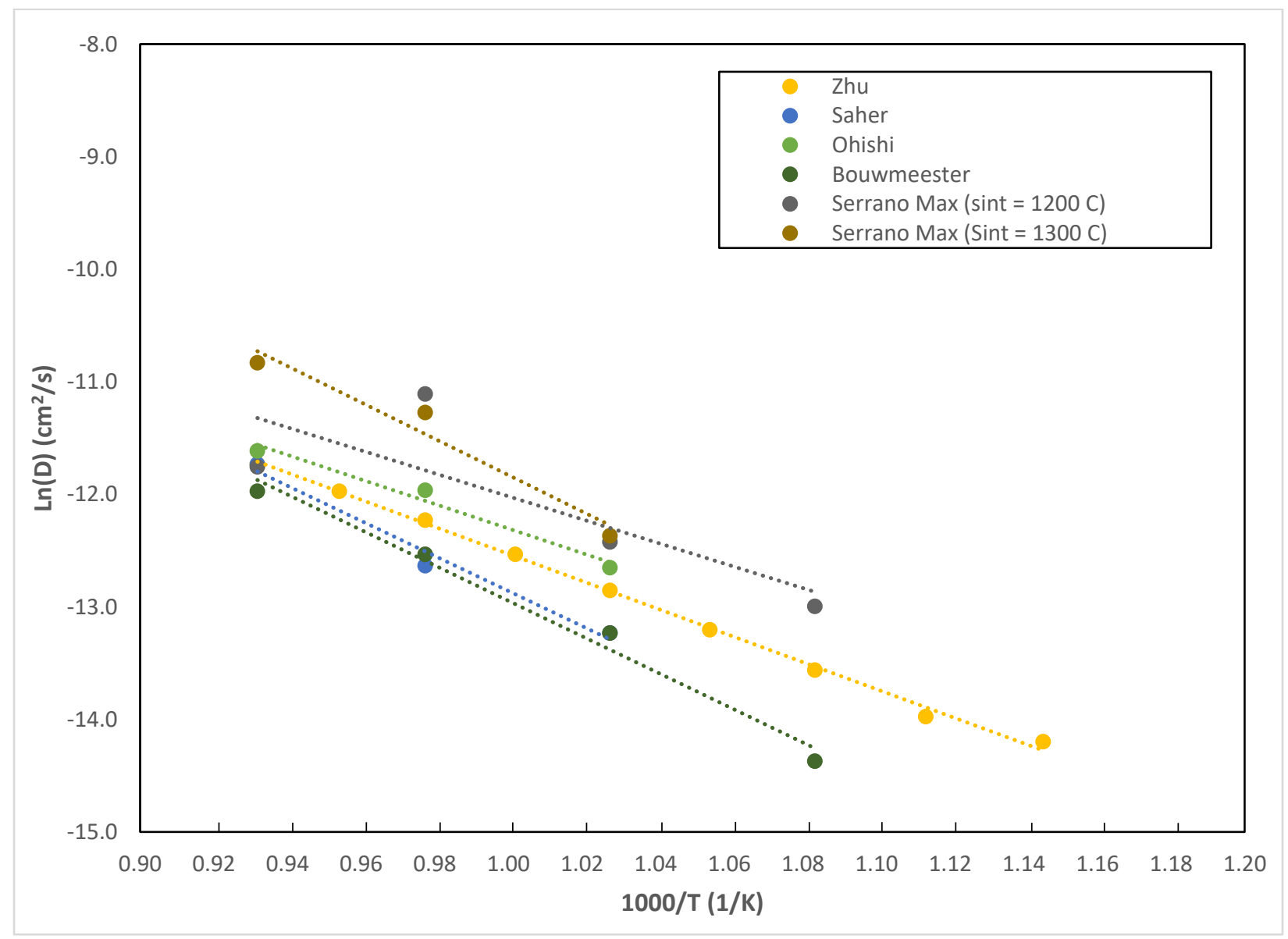

Figure 16 Bulk Diffusion Comparison with Literature - Baseline LSCF 
It is seen in the previous graph that our bulk diffusion characterization reported the highest values, and it can also be attributed to the difference in sample preparation between Zhu's report and this report ${ }^{23}$.

\subsection{Summary of Baseline LSCF Results}

The characterization of baseline LSCF was performed through the electrical conductivity relaxation technique, which allowed to determine both kinetic properties simultaneously. The oxygen transport kinetic properties that were determine were the surface exchange coefficient and the bulk diffusion coefficient. The kinetic properties exhibit an increased value with respect to increasing temperature and reduced with respect to a reducing temperature. Furthermore, the effects of sintering on the kinetic properties of baseline LSCF were analyzed. Higher sintering temperatures will have a larger grain size, which will lead to a smaller number of vacancies in the sample, consequently resulting in a smaller surface exchange coefficient of the baseline LSCF. On the other hand, the diffusion coefficient was observed not to be affected by the sintering temperature of baseline LSCF. 


\section{Chapter 4: ALD Coated LSCF}

\subsection{Conductivity and catalytic properties of $\mathrm{CoO}_{x}$}

The coatings that were chosen for this project are metal oxides with high electrical conductivity and ionic conductivity for oxygen. $\mathrm{CoO}_{x}$ in an inorganic compound that has a wide variety of uses. It has been reported that nanoparticles of $\mathrm{CoO}_{\mathrm{x}}$ are used in a variety of fields where the main ones are electronics and ceramics ${ }^{41}$. Inside the ceramic application, it can be used in many ways; for example, as a catalyst or as an active electrode material. Among the various materials for infiltration, the $\mathrm{CoO}_{x}$ was considered to be a promising catalyst for ORR ${ }^{42}$. However, the effect of $\mathrm{CoO}_{x}$ infiltration on the SOFC performance is reported to be controversial ${ }^{43,44}$. While the $\mathrm{CoO}_{x}$ has been reported to enhance the performance of LSM/YSZ cathodes ${ }^{45}$, there are also evidence showing the addition of $\mathrm{CoO}_{\mathrm{x}}$ had a negligible effect on both the $V$-I curve and the impedance spectrum. For the thin film $\mathrm{La}_{0.6} \mathrm{Sr}_{0.4} \mathrm{CoO}_{3-\delta}$, performance degradation was even observed upon coating $\mathrm{CO}_{3} \mathrm{O}_{4}$ by atomic layer deposition (ALD) 46, 47, 48, 49, $50,51,52,53,54$ In addition to those controversial reports, it is believed that the activity of $\mathrm{CO}_{3} \mathrm{O}_{4}$ nanoparticles are subjected to fast coarsening at elevated temperatures, thus diminishing the activity quickly. To suppress the coarsening, the infiltration composite consisting of $\mathrm{CeO}_{2}$ and $\mathrm{SrCrO}_{3}$ were developed to prevent the $\mathrm{CO}_{3} \mathrm{O}_{4}{ }^{55}$.

For this work $\mathrm{CoO}_{\mathrm{x}}$ will be characterized as a catalyst of LSCF to increase the surface exchange coefficient and bulk diffusion of the perovskite oxide. In this project, $\mathrm{CoO}_{\mathrm{x}}$ nanoparticles will be used for the $\mathrm{CoO}_{x}-\mathrm{ALD}$ coating. The nanoparticles of the catalyst are applied to the surface of the perovskite oxide to increase the absorption rate of oxygen ions and incorporation of the ions to the MIEC membrane. The structure that the $\mathrm{CoO}_{\mathrm{x}}$ nanoparticles are reported to have is a spinel structure ${ }^{41}$. On the other hand, the $\mathrm{CoO}_{x}$ ink that will be reported in chapter 5 is reported to have a periclase structure ${ }^{56}$. The difference in using $\mathrm{CoO}_{\mathrm{x}^{-}}$ $\mathrm{ALD}$ and $\mathrm{CoO}_{x}$-ink coatings is obviously found on the structure of the material, as explained above. However, another remarkable difference between the two coatings is the layer thickness that is on top of the LSCF after applying the catalyst coating. The ALD coating has a layer thickness of 4-12 $\mathrm{nm}$ meanwhile, the ink coating is about $150 \mu \mathrm{m}$. The difference in the 
thickness is quite noticeable, and it could affect the incorporation of the oxygen ions into the MIEC membrane.

The thickness of the layer could affect the $\mathrm{O}_{2}$ ions incorporation to the perovskite oxide membrane. The electrical conductivity of Co is reported to be $1.7 \times 10^{7} \mathrm{~S} / \mathrm{m}^{57}$. The main property that will determine whether the coating will produce an enhancement on the oxygen transport properties of the LSCF is the electrical conductivity of the catalyst.

\subsection{Conductivity and catalytic properties of Pt}

Amongst the various electrocatalysts, precious metal Pt remains to be one of the most efficient oxygen reduction catalysts employed for various fuel cells operated at different temperatures, while the high cost of Pt prevents its large-scale applications. In recent years, chemical vapor based Atomic Layer Deposition (ALD) $58,59,60$ is demonstrated to be able to create a conformal and uniform surface coating layer with thickness down to the atomic scale. Such an approach could lead to the minimum loading of catalyst into the cathode of asfabricated cells to further improve the SOFC performance ${ }^{61}$. For the ALD coated samples, Pt was chosen to be added on top of the $\mathrm{CoO}_{x}$ coating to form a composite coating. Pt was chosen due to its high electrical conductivity that is reported to be $9.4 \times 10^{6} \mathrm{~S} / \mathrm{m}^{62}$. The electrical conductivity of Pt is lower than Co and will overall reduce the electrical conductivity of the composite coating. The reduction in electrical conductivity of the composite coating may result in a decrease in the absorption rate of oxygen ions since the ions are separated from the air thanks to the electron flow through the material.

Platinum is mainly used in industry nowadays, but it has a wide variety of uses, which include jewelry, electronics, investment, and catalyst for car engines and ceramics ${ }^{63}$. The ceramic catalyst application is what will be characterized in this research project. Like all the coatings that are covered in this project, the main goal is to serve as a catalyst that can increase the chemical reactions that occur in a SOFC.

Since the early $19^{\text {th }}$ century, platinum has been reported widely as a catalyst material ${ }^{64}$. As it was mentioned above, the main catalyst application that it has is cars, which enhances the rate at which the car engine completes the combustion process. Even though platinum mainly 
serves as a catalyst for the combustion process of car engines, it can also serve as a catalyst in the petroleum industry and hydrogenation of vegetable oils ${ }^{64}$. Since Pt serves as a catalyst for many different areas, it could serve as a catalyst for fuel cells to increase the oxygen reduction rate.

\subsection{Effect of ALD $\mathrm{CoO}_{x}$ Coating on the Kinetic Properties of LSCF}

The next step within this research project was to apply a coating to the LSCF baseline samples. On chapter 4, the results for the Atomic Layer Deposition (ALD) coating will be presented and compared to the LSCF Baseline results. In this section, the baselines samples had a thin layer of $\mathrm{CoO}_{x}$ added on top of their surface. The thickness of the layer that was added on top of the LSCF samples ranged depending on the number of cycles that the ALD machine was used for. The range of cycles for the $\mathrm{CoO}_{x}$ ALD coated samples is 60 to 120 cycles in increments of 30 cycles. Such a number of cycles delivered a thin layer of $\mathrm{CoO}_{x}$ with a thickness between 4$12 \mathrm{~nm}$. The coating was added to baseline LSCF samples that were sintered in an oxygen atmosphere at 1200 and $1300{ }^{\circ} \mathrm{C}$.

The list of samples that were analyzed using a $\mathrm{CoO}_{x}-\mathrm{ALD}$ coating and the abovementioned sintering temperatures is as follows:

Table $7 \mathrm{CoO}_{x}-$ ALD Coated LSCF Samples $\left(\operatorname{Sint}=1200^{\circ} \mathrm{C}\right)$

\begin{tabular}{|c|c|c|c|c|c|c|c|}
\hline \multicolumn{8}{|c|}{ CoO-ALD Coated LSCF (sintering $=1200 \mathrm{C}$ ) } \\
\hline Sample & Temp. $\left({ }^{\circ} \mathrm{C}\right)$ & Temp. (K) & $1000 / \mathrm{T}(1 / \mathrm{K})$ & Surface Exchange $(\mathrm{k})(\mathrm{cm} / \mathrm{s})$ & Diffusion coefficient (D) $\left(\mathrm{cm}^{2} / \mathrm{s}\right)$ & $\ln (\mathbf{k})$ & $\ln (D)$ \\
\hline 54.1 ( 60 cycles $\mathrm{CoO})$ & 700 & 973.15 & 1.03 & $4.18 \mathrm{E}-03$ & 4.00E-06 & -5.48 & -12.43 \\
\hline 54.2 (90 cycles $\mathrm{CoO})$ & 650 & 923.15 & 1.08 & $2.22 \mathrm{E}-04$ & 9.87E-07 & -8.41 & -13.83 \\
\hline \multirow{2}{*}{55.1 ( 120 cycles $\mathrm{CoO})$} & 650 & 923.15 & 1.08 & $1.32 \mathrm{E}-03$ & $2.12 \mathrm{E}-06$ & -6.63 & -13.07 \\
\hline & 700 & 973.15 & 1.03 & $3.96 \mathrm{E}-04$ & 4.17E-06 & -7.83 & -12.39 \\
\hline 84.1 ( 60 cycles $\mathrm{CoO})$ & 700 & 973.15 & 1.03 & $1.08 \mathrm{E}-03$ & $6.56 \mathrm{E}-06$ & -6.83 & -11.93 \\
\hline \multirow{3}{*}{$\begin{array}{c}85.1 \text { (90 cycles } \mathrm{CoO}+30 \\
\text { cycles } \mathrm{CoO})\end{array}$} & 650 & 923.15 & 1.08 & $2.13 \mathrm{E}-03$ & 4.66E-06 & -6.15 & -12.28 \\
\hline & 700 & 973.15 & 1.03 & $1.91 \mathrm{E}-03$ & 7.94E-06 & -6.26 & -11.74 \\
\hline & 750 & 1023.15 & 0.98 & $2.02 \mathrm{E}-03$ & $1.23 \mathrm{E}-05$ & -6.20 & -11.31 \\
\hline
\end{tabular}

Table $8 \mathrm{CoO}_{x}-\mathrm{ALD}$ Coated LSCF Samples (Sint $=1300^{\circ} \mathrm{C}$ )

\begin{tabular}{|c|c|c|c|c|c|c|c|}
\hline \multicolumn{8}{|c|}{ CoO-ALD Coated LSCF (sintering = 1300 C) } \\
\hline Sample & Temp. $\left({ }^{\circ} \mathrm{C}\right)$ & Temp. (K) & $1000 / \mathrm{T}(1 / \mathrm{K})$ & Surface Exchange $(k)(\mathrm{cm} / \mathrm{s})$ & Diffusion coefficient (D) $\left(\mathrm{cm}^{2} / \mathrm{s}\right)$ & $\ln (\mathbf{k})$ & $\ln (D)$ \\
\hline \multirow{2}{*}{74.1 (60 cycles $\mathrm{CoO})$} & 650 & 923.15 & 1.08 & $4.86 \mathrm{E}-04$ & 1.23E-06 & -7.63 & -13.61 \\
\hline & 700 & 973.15 & 1.03 & $4.88 \mathrm{E}-04$ & $2.20 \mathrm{E}-06$ & -7.63 & -13.03 \\
\hline \multirow{2}{*}{74.2 (90 cycles $\mathrm{CoO})$} & 750 & 1023.15 & 0.98 & $6.64 \mathrm{E}-04$ & $6.01 \mathrm{E}-06$ & -7.32 & -12.02 \\
\hline & 800 & 1073.15 & 0.93 & $5.40 \mathrm{E}-04$ & 4.97E-06 & -7.52 & -12.21 \\
\hline \multirow{2}{*}{$\begin{array}{c}75.1 \text { (90 cycles } \mathrm{CoO}+30 \\
\text { cycles } \mathrm{CoO})\end{array}$} & 650 & 923.15 & 1.08 & $4.78 \mathrm{E}-04$ & $8.08 \mathrm{E}-07$ & -7.65 & -14.03 \\
\hline & 700 & 973.15 & 1.03 & $3.87 \mathrm{E}-04$ & $2.69 \mathrm{E}-06$ & -7.86 & -12.83 \\
\hline
\end{tabular}


The previous tables show the list of samples that were tested with a $\mathrm{CoO}_{x}-\mathrm{ALD}$ coating on their surface and sintering temperatures of $1200^{\circ} \mathrm{C}$ and $1300^{\circ} \mathrm{C}$. The sample name shows the number of $\mathrm{CoO}_{x}$ cycles that were added to the baseline LSCF samples. Additionally, the tables show the temperatures that the samples were tested for as well as the kinetic properties that were obtained for each sample at each given temperature. The surface exchange coefficients obtained from the $\mathrm{CoO}_{x}$-ALD coated samples were plotted in a $\ln (\mathrm{k})$ vs 1000/T graph along the LSCF baseline with the same sintering temperature as follows:

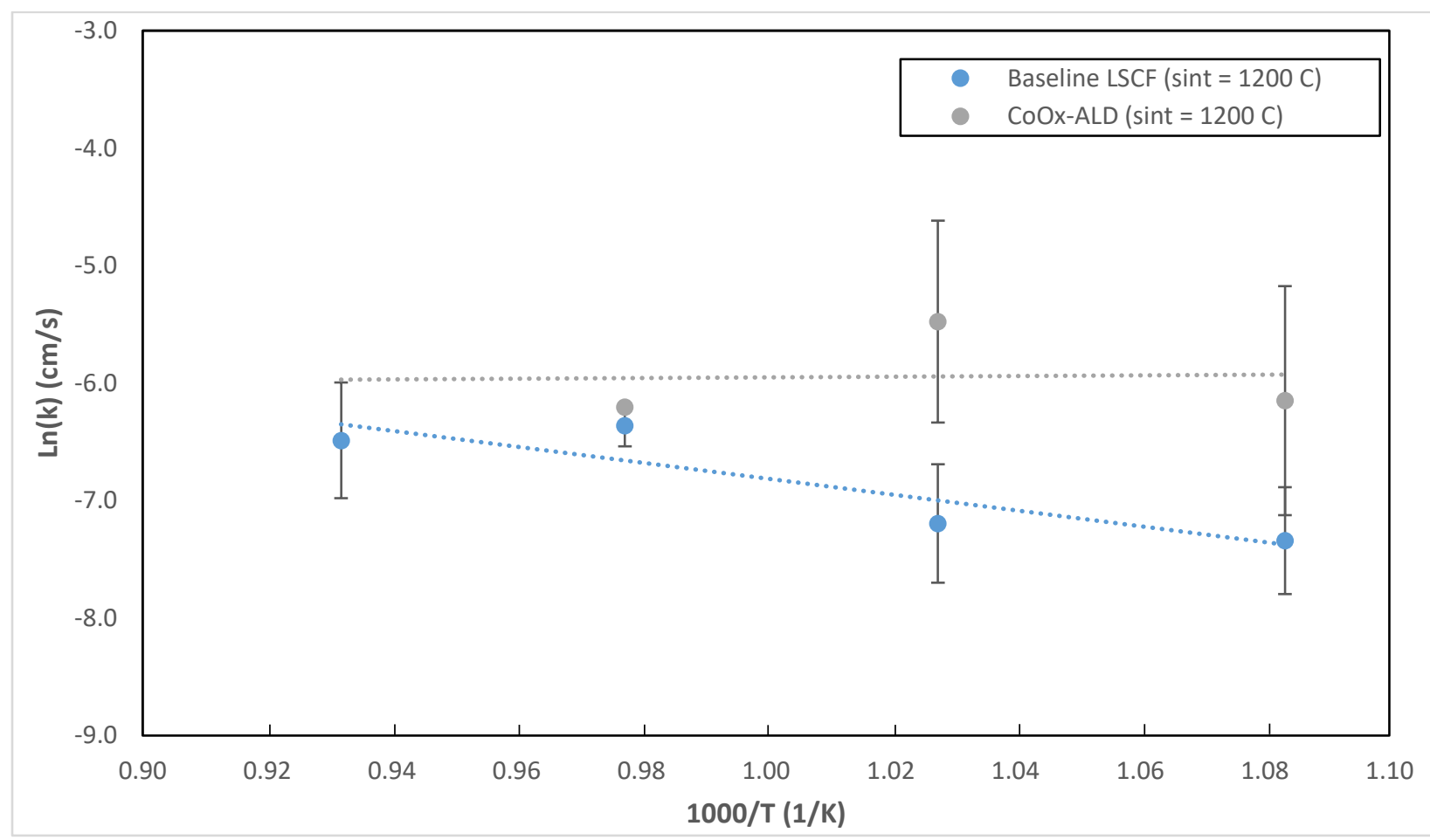

Figure 17 Surface Exchange vs Temperature $-\operatorname{CoO} x-A L D\left(\operatorname{Sint}=1200^{\circ} \mathrm{C}\right)$

In the previous figure, the $\ln (k)$ vs $1000 / T$ graph was plotted for $\mathrm{CoO}_{x}$-ALD coated, and baseline LSCF sintered at $1200^{\circ} \mathrm{C}$. The surface exchange rate for LSCF increases as the temperature increases and decreases as the temperature reduces, as it was seen in the previous chapter. On the other hand, the surface exchange rate for $\mathrm{CoO}_{x}-\mathrm{ALD}$ coated samples does not follow the same trend as the LSCF baseline due to the uncertainty of the measurements obtained at $800{ }^{\circ} \mathrm{C}$. However, the $\mathrm{CoO}_{x}-\mathrm{ALD}$ coated samples have a higher surface exchange than the LSCF baseline samples sintered at $1200^{\circ} \mathrm{C}$. Hence, the $\mathrm{CoO}_{\mathrm{x}}-\mathrm{ALD}$ 
coating enhances the surface exchange of LSCF, allowing it to transport oxygen ions through the surface faster than the baseline LSCF itself.

The natural log surface exchange values that were graphed for the surface exchange vs temperature graph for $\mathrm{CoO}_{\mathrm{x}}$-ALD coated and baseline LSCF with sintering temperature of 1200 ${ }^{\circ} \mathrm{C}$ are shown in the following table for each temperature:

Table 9 Surface Exchange Values $-\mathrm{CoO}_{x}-\operatorname{ALD}\left(\operatorname{Sint}=1200{ }^{\circ} \mathrm{C}\right)$

\begin{tabular}{cccccc}
\hline $\begin{array}{c}\text { Composition of } \\
\text { LSCF }\end{array}$ & $\begin{array}{c}\text { Sintering Temp. } \\
\left({ }^{\circ} \mathbf{C}\right)\end{array}$ & \multicolumn{4}{c}{ Ln (k) (cm/s) } \\
\cline { 3 - 6 } & 1200 & -7.34 & -7.19 & -6.36 & -6.49 \\
\hline Baseline & 1200 & -6.15 & -5.48 & -6.20 & 0.00 \\
\hline CoO $_{\mathbf{x}}(\mathrm{ALD})$ & $1200\left({ }^{\circ} \mathbf{C}\right)$ & $\mathbf{7 5 0}\left({ }^{\circ} \mathbf{C}\right)$ & $\mathbf{8 0 0}\left({ }^{\circ} \mathbf{C}\right)$ \\
\hline
\end{tabular}

Table 10 Surface Exchange \% Increase/Decrease $-\operatorname{CoO}_{x}-A L D\left(\operatorname{Sint}=1200^{\circ} \mathrm{C}\right)$

\begin{tabular}{cccccc}
\hline $\begin{array}{c}\text { Composition of } \\
\text { LSCF }\end{array}$ & $\begin{array}{c}\text { Sintering Temp. } \\
\left({ }^{\circ} \mathrm{C}\right)\end{array}$ & \multicolumn{3}{c}{$\begin{array}{c}\% \text { Increase/Decrease in Surface Exchange } \\
\text { Compared to Baseline }\end{array}$} \\
\cline { 3 - 6 } & & $\mathbf{6 5 0}\left({ }^{\circ} \mathrm{C}\right)$ & $\mathbf{7 0 0}\left({ }^{\circ} \mathrm{C}\right)$ & $\mathbf{7 5 0}\left({ }^{\circ} \mathrm{C}\right)$ & $\mathbf{8 0 0}\left({ }^{\circ} \mathrm{C}\right)$ \\
\hline $\mathrm{CoO}_{x}(\mathrm{ALD})$ & 1200 & $16.23 \%$ & $23.88 \%$ & $2.46 \%$ & - \\
\hline
\end{tabular}

In the previous table, the percentage increase/decrease of the surface exchange between the $\mathrm{CoO}_{x}-\mathrm{ALD}$ coated and baseline samples with a sintering temperature of $1200{ }^{\circ} \mathrm{C}$ is shown. It can be observed that the $\mathrm{CoO}_{x}-\mathrm{ALD}$ samples have a much higher surface exchange than the baseline for low temperatures. The $\mathrm{CoO}_{x}$ coating enhances the surface exchange of the baseline LSCF, however, for higher temperatures such as 750 and $800{ }^{\circ} \mathrm{C}$ there is not an improvement. As mentioned above, the measurements for the samples with $\mathrm{CoO}_{x}-\mathrm{ALD}$ at 800 ${ }^{\circ} \mathrm{C}$ are not reliable; therefore, they were not taken into consideration. Also, the measurement at $750{ }^{\circ} \mathrm{C}$ is not completely reliable because it does not follow the trend of increasing as the temperature increases. Therefore there is not much improvement with respect to the baseline LSCF. 
Furthermore, the $\mathrm{CoO}_{x}-\mathrm{ALD}$ samples were also prepared, measured, and analyzed with a sintering temperature of $1300{ }^{\circ} \mathrm{C}$. The natural log of the surface exchange versus the inverse of the temperature was plotted in the following graph and compared to baseline LSCF for samples with sintering temperature of $1300^{\circ} \mathrm{C}$ :

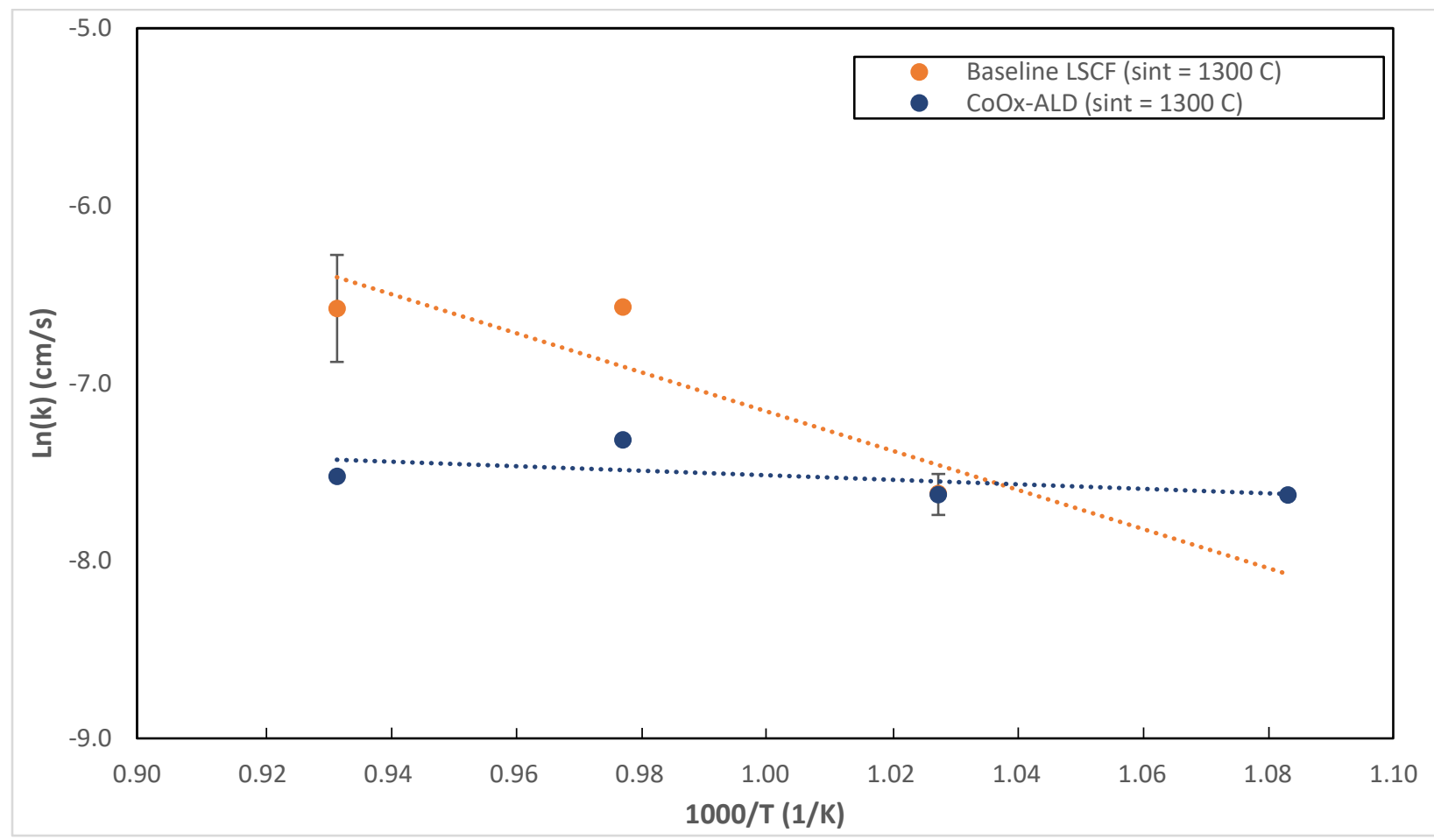

Figure 18 Surface Exchange vs Temperature $-\operatorname{CoO}_{x}-\operatorname{ALD}\left(\operatorname{Sint}=1300^{\circ} \mathrm{C}\right)$

The graph above shows the surface exchange of the $\mathrm{CoO}_{x}-\mathrm{ALD}$ coated samples compared to the LSCF baseline samples with a sintering temperature of $1300^{\circ} \mathrm{C}$. In contrast to the samples with a sintering temperature of $1200^{\circ} \mathrm{C}$, the $\mathrm{CoO}_{\mathrm{x}}-\mathrm{ALD}$ does not enhance the surface exchange of baseline LSCF for sintering temperatures of $130{ }^{\circ} \mathrm{C}$. As seen in chapter 3 , the sintering temperature of $1300^{\circ} \mathrm{C}$ has a larger grain size, meaning that the number of vacancies is reduced in the sample, and consequently, the surface exchange is also reduced. Even though the addition of $\mathrm{CoO}_{x}$ enhances the surface kinetics of the LSCF for sintering temperatures of $1200{ }^{\circ} \mathrm{C}$, it does not enhance it for sintering temperatures of $1300{ }^{\circ} \mathrm{C}$ because of the reduced number of vacancies is limiting the rate that the LSCF can transport the oxygen ions. Therefore, the oxygen ions will not be able to move to the vacancies because the vacancies found in LSCF are already filled by oxygen ions. 
The natural log surface exchange values that were graphed for the surface exchange vs temperature graph for $\mathrm{CoO}_{\mathrm{x}}$-ALD coated and baseline LSCF with sintering temperature of 1300 ${ }^{\circ} \mathrm{C}$ are shown in the following table for each temperature:

Table 11 Surface Exchange Values $-\operatorname{CoO}_{x}-\operatorname{ALD}\left(\operatorname{Sin} t=1300^{\circ} \mathrm{C}\right)$

\begin{tabular}{cccccc}
\hline $\begin{array}{c}\text { Composition of } \\
\text { LSCF }\end{array}$ & $\begin{array}{c}\text { Sintering Temp. } \\
\left({ }^{\circ} \mathrm{C}\right)\end{array}$ & \multicolumn{4}{c}{ Ln (k) (cm/s) } \\
\cline { 3 - 6 } & 1300 & $\mathbf{6 5 0}\left({ }^{\circ} \mathrm{C}\right)$ & $\mathbf{7 0 0}\left({ }^{\circ} \mathrm{C}\right)$ & $\mathbf{7 5 0}\left({ }^{\circ} \mathrm{C}\right)$ & $\mathbf{8 0 0}\left({ }^{\circ} \mathbf{C}\right)$ \\
\hline Baseline & 1300 & -7.63 & -7.63 & -7.32 & -7.52 \\
\hline CoO $_{\mathbf{x}}(\mathrm{ALD})$ & 1300 & & -7.62 & -6.57 & -6.58 \\
\hline
\end{tabular}

Table 12 Surface Exchange \% Increase/Decrease $-\operatorname{CoO} x-A L D\left(\operatorname{Sint}=1300^{\circ} \mathrm{C}\right)$

\begin{tabular}{cccccc}
\hline $\begin{array}{c}\text { Composition of } \\
\text { LSCF }\end{array}$ & $\begin{array}{c}\text { Sintering Temp. } \\
\left({ }^{\circ} \mathrm{C}\right)\end{array}$ & \multicolumn{3}{c}{$\begin{array}{c}\% \text { Increase/Decrease in Surface Exchange } \\
\text { Compared to Baseline }\end{array}$} \\
\cline { 3 - 6 } & & $\mathbf{6 5 0}\left({ }^{\circ} \mathrm{C}\right)$ & $\mathbf{7 0 0}\left({ }^{\circ} \mathrm{C}\right)$ & $\mathbf{7 5 0}\left({ }^{\circ} \mathrm{C}\right)$ & $\mathbf{8 0 0}\left({ }^{\circ} \mathrm{C}\right)$ \\
\hline $\mathrm{CoO}_{\mathbf{x}}(\mathrm{ALD})$ & 1300 & - & $-0.08 \%$ & $-11.38 \%$ & $-14.36 \%$ \\
\hline
\end{tabular}

In the previous table, the percentage increase/decrease of the surface exchange between the $\mathrm{CoO}_{x}-\mathrm{ALD}$ coated and baseline samples with a sintering temperature of $1300{ }^{\circ} \mathrm{C}$ is shown. It can be observed that the surface exchange coefficient of the $\mathrm{CoO}_{\mathrm{x}}$-ALD samples is reduced compared to the LSCF baseline at high temperatures. Meanwhile, at low temperatures, the surface exchange coefficient between the $\mathrm{CoO}_{x}-\mathrm{ALD}$ and the baseline samples is about the same magnitude due to an uncertain result obtained for LSCF baseline at $800^{\circ} \mathrm{C}$.

Moreover, the characterization of the bulk diffusion coefficient was also performed for $\mathrm{CoO}_{x}$-ALD coated samples and compared to baseline LSCF. The samples analyzed in this case are the same samples that were shown at the beginning of this section since the electrical conductivity relaxation method allows us to determine both oxygen transport kinetic properties simultaneously. The bulk diffusion coefficients obtained for $\mathrm{CoO}_{x}-\mathrm{ALD}$ coated samples and baseline LSCF with sintering temperature of $1200^{\circ} \mathrm{C}$ were plotted in a $\ln (\mathrm{D})$ vs $1000 / \mathrm{T}$ graph as follows: 


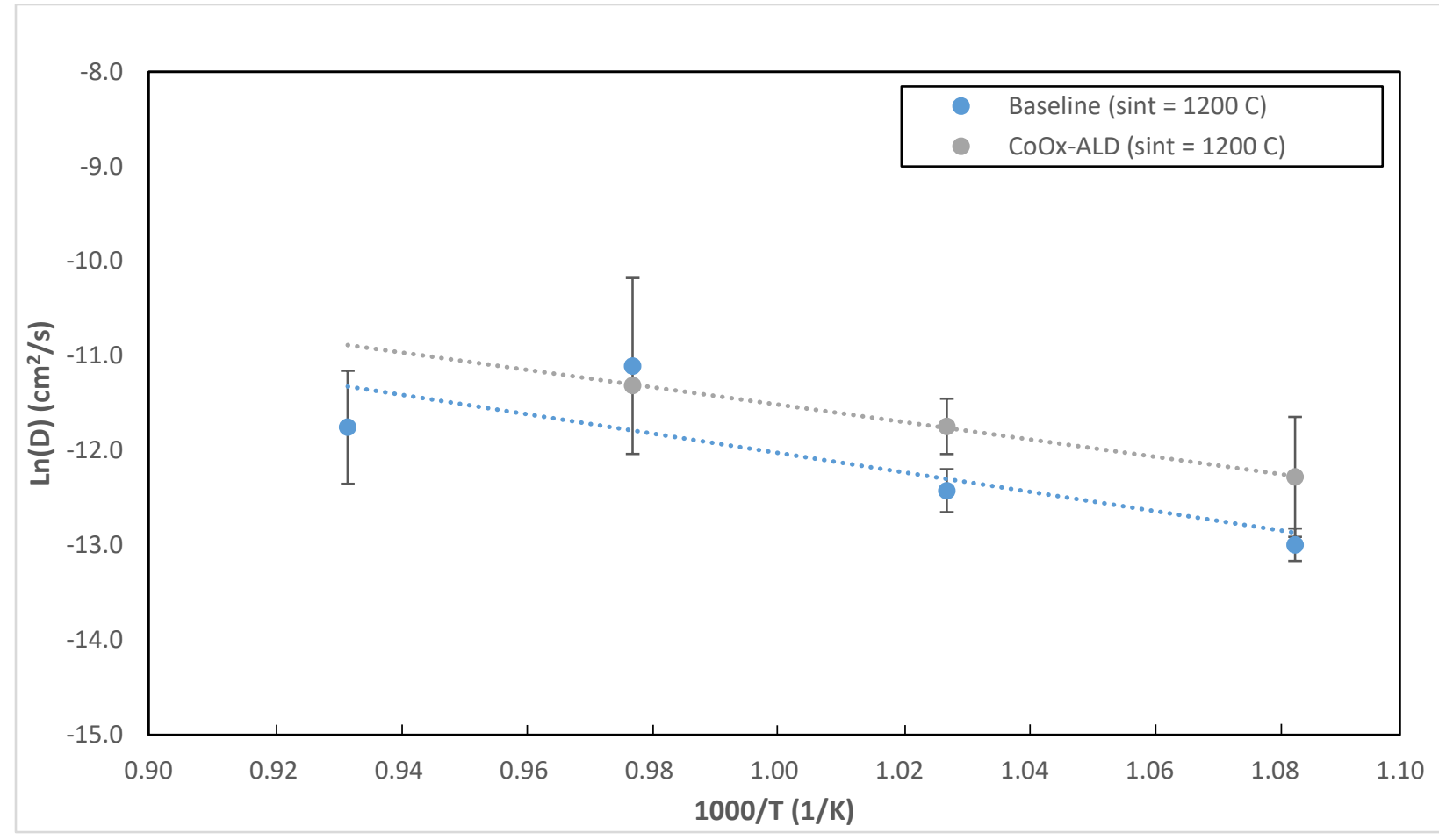

Figure 19 Bulk Diffusion Coefficient vs Temperature $-\mathrm{CoO}_{x^{-}}-\mathrm{ALD}\left(\operatorname{Sint}=1200^{\circ} \mathrm{C}\right)$

In the previous figure, the $\ln (D)$ vs $1000 / T$ was plotted for $\mathrm{CoO}_{x}-\mathrm{ALD}$ samples and baseline LSCF with sintering temperature of $1200^{\circ} \mathrm{C}$. As it was shown in the previous chapter, the diffusion coefficient follows the same trend that the surface exchange does. The diffusion coefficient increases with increasing temperature and decreases as the temperature decreases. It can also be observed from the graph that the diffusion coefficient for $\mathrm{CoO}_{\mathrm{x}}-\mathrm{ALD}$ samples and LSCF baseline is about the same magnitude. There are not high variations between them since some LSCF baseline measurements are higher than the $\mathrm{CoO}_{\mathrm{x}}-\mathrm{ALD}$ samples ones and vice versa. Therefore, it can be concluded that the addition of $\mathrm{CoO}_{x}-\mathrm{ALD}$ to LSCF does not make a large enhancement in the diffusion coefficient, but it has a larger enhancement in the surface exchange of LSCF as it was shown in the previous graphs.

As it was explained in the previous chapter, the bulk is the same for every sample due to the manufacturing process. The only factor that will alter the diffusion coefficient is the number of vacancies that are found in each sample. Also, the distance between the vacancies will alter the diffusion coefficient and surface exchange. Every sample has roughly about the same surface as the manufacturing process is the same for each sample independently of the coating 
and sintering. Therefore, the surface that is measured for each sample is about the same surface area, and the diffusion coefficient depends on the area of the bulk, hence the diffusion coefficient is not affected by the sintering temperature of the samples.

In the following table, the natural log of the diffusion coefficient values that were plotted are shown for $\mathrm{CoO}_{x}-\mathrm{ALD}$ and baseline LSCF with sintering temperature of $120{ }^{\circ} \mathrm{C}$ :

Table 13 Bulk Diffusion Coefficient Values $-\operatorname{CoO}_{x}-A L D\left(\operatorname{Sint}=1200^{\circ} \mathrm{C}\right)$

\begin{tabular}{cccccc}
\hline $\begin{array}{c}\text { Composition of } \\
\text { LSCF }\end{array}$ & $\begin{array}{c}\text { Sintering Temp. } \\
\left({ }^{\circ} \mathrm{C}\right)\end{array}$ & \multicolumn{4}{c}{ Ln (D) (cm2/s) } \\
\cline { 2 - 6 } & 1200 & $\mathbf{6 5 0}\left({ }^{\circ} \mathrm{C}\right)$ & $\mathbf{7 0 0}\left({ }^{\circ} \mathrm{C}\right)$ & $\mathbf{7 5 0}\left({ }^{\circ} \mathrm{C}\right)$ & $\mathbf{8 0 0}\left({ }^{\circ} \mathrm{C}\right)$ \\
\hline Baseline & 1200 & -12.99 & -12.42 & -11.11 & -11.75 \\
\hline $\mathrm{CoO}_{\mathbf{x}}$ (ALD) & -12.28 & -11.74 & -11.31 & 0.00 \\
\hline
\end{tabular}

Table 14 Bulk Diffusion Coefficient \% Increase/Decrease $-\mathrm{CoO}_{x}-\mathrm{ALD}\left(\operatorname{Sint}=1200{ }^{\circ} \mathrm{C}\right)$

\begin{tabular}{cccccc}
\hline $\begin{array}{c}\text { Composition of } \\
\text { LSCF }\end{array}$ & $\begin{array}{c}\text { Sintering Temp. } \\
\left({ }^{\circ} \mathrm{C}\right)\end{array}$ & \multicolumn{3}{c}{$\begin{array}{c}\text { \% Increase/Decrease in Diffusion Coefficient } \\
\text { Compared to Baseline }\end{array}$} \\
\cline { 3 - 6 } & & $\mathbf{6 5 0}\left({ }^{\circ} \mathrm{C}\right)$ & $\mathbf{7 0 0}\left({ }^{\circ} \mathrm{C}\right)$ & $\mathbf{7 5 0}\left({ }^{\circ} \mathrm{C}\right)$ & $\mathbf{8 0 0}\left({ }^{\circ} \mathrm{C}\right)$ \\
\hline $\mathrm{CoO}_{\mathbf{x}}(\mathrm{ALD})$ & 1200 & $5.51 \%$ & $5.46 \%$ & $-1.84 \%$ & - \\
\hline
\end{tabular}

In the previous table, the percentage increase/decrease of the diffusion coefficient between the $\mathrm{CoO}_{\mathrm{x}}-\mathrm{ALD}$ and baseline LSCF samples with a sintering temperature of $1200{ }^{\circ} \mathrm{C}$ is shown. The addition of $\mathrm{CoO}_{x}-A L D$ to the surface of the LSCF with a sintering temperature of $1200{ }^{\circ} \mathrm{C}$ slightly increases the diffusion coefficient of the LSCF about $5 \%$ for low temperatures. However, for higher temperatures, there is a reduction at $750{ }^{\circ} \mathrm{C}$, and no value was found for $\mathrm{CoO}_{x}$-ALD coting at $800^{\circ} \mathrm{C}$. However, if $\mathrm{CoO}_{\mathrm{x}}$-ALD follows the trend, there should be a higher diffusion coefficient at $800{ }^{\circ} \mathrm{C}$ for $\mathrm{CoO}_{x}$-ALD compared to baseline LSCF. Even though an enhancement in the diffusion coefficient could happen for $\mathrm{CoO}_{x}-A L D$ coated LSCF, the improvement should not be greater than the $5 \%$ seen at low temperatures for samples with a sintering temperature of $1200^{\circ} \mathrm{C}$.

Furthermore, the $\mathrm{CoO}_{\mathrm{x}}-\mathrm{ALD}$ samples were also prepared, measured, and analyzed with a sintering temperature of $1300{ }^{\circ} \mathrm{C}$. The natural log of the diffusion coefficient versus the inverse 
of the temperature was plotted in the following graph and compared to baseline LSCF for samples with sintering temperature of $1300^{\circ} \mathrm{C}$ :

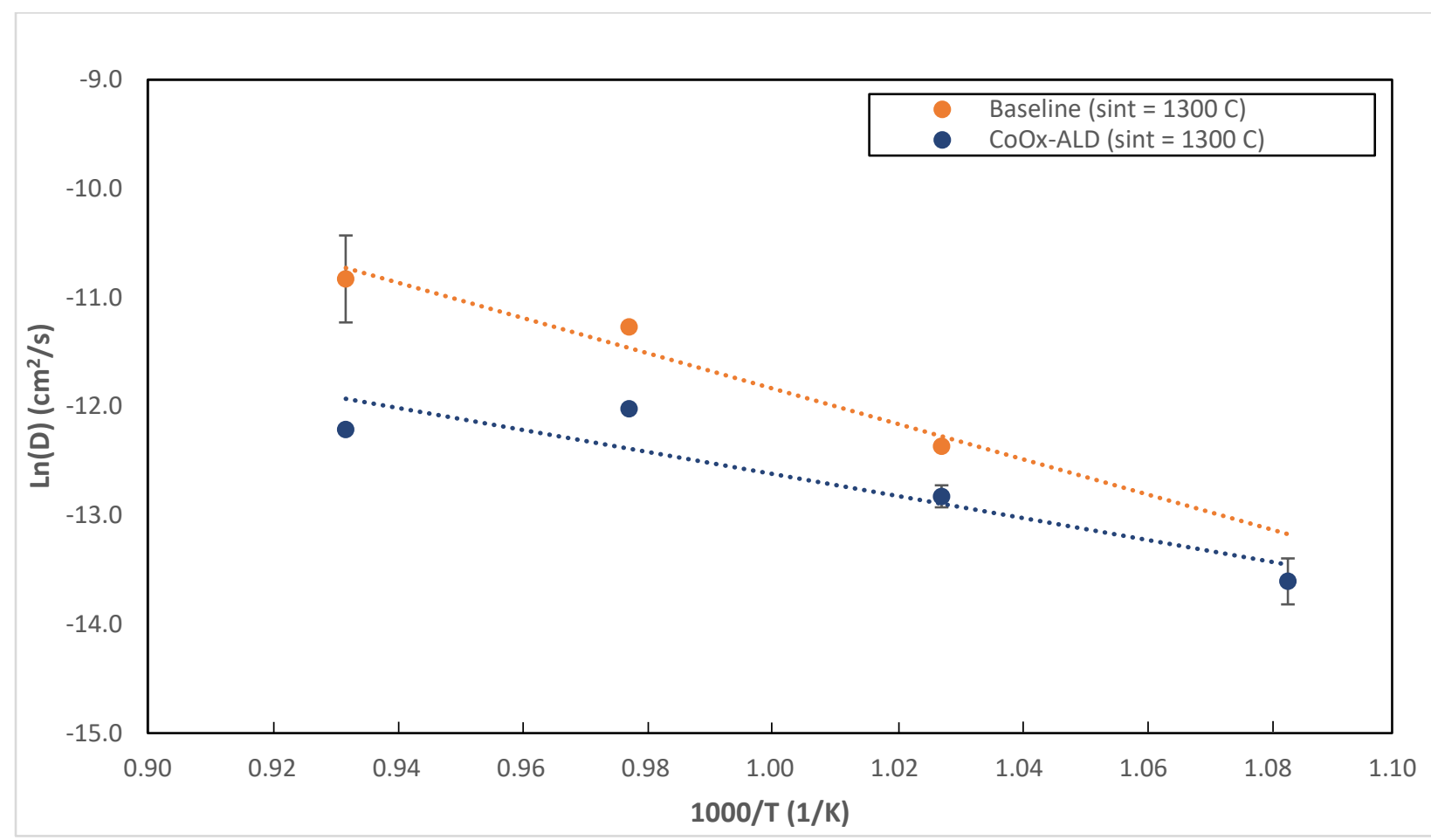

Figure 20 Bulk Diffusion Coefficient vs Temperature $-\operatorname{CoO}_{x}-A L D\left(\operatorname{Sint}=1300^{\circ} \mathrm{C}\right)$

In the previous figure, the $\ln (\mathrm{D})$ vs $1000 / \mathrm{T}$ was plotted for $\mathrm{CoO}_{x}-\mathrm{ALD}$ and baseline LSCF with sintering temperature of $1300^{\circ} \mathrm{C}$. In contrast with the results seen before, the addition of $\mathrm{CoO}_{x}-A L D$ coating to LSCF with a sintering temperature of $1300^{\circ} \mathrm{C}$ slightly reduces the diffusion coefficient of LSCF. This is due to the smaller number of vacancies found in samples with higher sintering temperatures. A higher sintering temperature will make the samples to be more compacted and consequently have fewer defects in their structure. Therefore, the enhancement of the addition of $\mathrm{CoO}_{x}-A L D$ is limited to the number of vacancies and will decrease if the number of defects in the material is reduced.

In the following table, the natural log of the diffusion coefficient values that were plotted are shown for $\mathrm{CoO}_{x}-\mathrm{ALD}$ and baseline LSCF with sintering temperature of $1300^{\circ} \mathrm{C}$ : 
Table 15 Bulk Diffusion Coefficient Values $-\operatorname{CoO}_{x}-\operatorname{ALD}\left(\operatorname{Sint}=1300^{\circ} \mathrm{C}\right)$

\begin{tabular}{cccccc}
\hline $\begin{array}{c}\text { Composition of } \\
\text { LSCF }\end{array}$ & $\begin{array}{c}\text { Sintering Temp. } \\
\left({ }^{\circ} \mathrm{C}\right)\end{array}$ & \multicolumn{4}{c}{$\operatorname{Ln}(\mathbf{D})(\mathbf{c m 2} / \mathbf{s})$} \\
\cline { 3 - 6 } & 1300 & $\mathbf{6 5 0}\left({ }^{\circ} \mathbf{C}\right)$ & $\mathbf{7 0 0}\left({ }^{\circ} \mathbf{C}\right)$ & $\mathbf{7 5 0}\left({ }^{\circ} \mathbf{C}\right)$ & $\mathbf{8 0 0}\left({ }^{\circ} \mathbf{C}\right)$ \\
\hline Baseline & 0.00 & -12.37 & -11.27 & -10.83 \\
\hline CoO $_{x}$ (ALD) & 1300 & -13.61 & -12.83 & -12.02 & -12.02 \\
\hline
\end{tabular}

Table 16 Bulk Diffusion Coefficient \% Increase/Decrease $-\operatorname{CoO} x-A L D\left(\right.$ Sint $\left.=1300{ }^{\circ} \mathrm{C}\right)$

\begin{tabular}{cccccc}
\hline $\begin{array}{c}\text { Composition of } \\
\text { LSCF }\end{array}$ & $\begin{array}{c}\text { Sintering Temp. } \\
\left({ }^{\circ} \mathrm{C}\right)\end{array}$ & \multicolumn{4}{c}{$\begin{array}{c}\text { \% Increase/Decrease in Diffusion Coefficient } \\
\text { Compared to Baseline }\end{array}$} \\
\cline { 3 - 6 } & & $\mathbf{6 5 0}\left({ }^{\circ} \mathrm{C}\right)$ & $\mathbf{7 0 0}\left({ }^{\circ} \mathrm{C}\right)$ & $\mathbf{7 5 0}\left({ }^{\circ} \mathrm{C}\right)$ & $\mathbf{8 0 0}\left({ }^{\circ} \mathrm{C}\right)$ \\
\hline $\mathrm{CoO}_{x}$ (ALD) & 1300 & - & $-3.72 \%$ & $-6.66 \%$ & $-11.00 \%$ \\
\hline
\end{tabular}

In the previous table, the percentage increase/decrease of the diffusion coefficient between the $\mathrm{CoO}_{x}-\mathrm{ALD}$ and baseline LSCF samples with a sintering temperature of $1300^{\circ} \mathrm{C}$ is shown. The addition of $\mathrm{CoO}_{\mathrm{x}}$-ALD to the surface of the LSCF with sintering temperature of 1300 ${ }^{\circ} \mathrm{C}$, slightly decreases the diffusion coefficient of the LSCF. The reduction of the diffusion coefficient is more pronounced at high temperatures where the diffusion coefficient is reduced by $11 \%$ at $800^{\circ} \mathrm{C}$. It is observed that the reduction of the diffusion coefficient between the $\mathrm{CoO}_{x}-\mathrm{ALD}$ and baseline LSCF is decreased as the temperature drops.

\subsection{Effect of ALD CoO + Pt Coating on the Kinetic Properties of LSCF}

In contrast with the last section, where the baselines samples had a thin layer of $\mathrm{CoO}_{x}$ added on top of their surface, on this section, the samples also had a layer of Pt added through ALD. As mentioned before, the thickness of the layer that was added on top of the LSCF samples ranged depending on the number of cycles that the ALD machine was used for. The range of cycles for the $\mathrm{CoO}_{x}+$ Pt-ALD coated samples is 60 to 150 cycles in increments of 30 cycles. Such number of cycles delivered a thin layer of $\mathrm{CoO}_{x}$ with a thickness between 4-15 nm. The coating was added to baseline LSCF samples that were sintered in an oxygen atmosphere at 1200 and $1300^{\circ} \mathrm{C}$.

The list of samples that were analyzed using a $\mathrm{CoO}_{x}+\mathrm{Pt}-\mathrm{ALD}$ coating and the abovementioned sintering temperatures is as follows: 
Table $17 \mathrm{CoO}_{x}+$ Pt-ALD Coated LSCF Samples (Sint $=1200{ }^{\circ} \mathrm{C}$ )

\begin{tabular}{|c|c|c|c|c|c|c|c|}
\hline \multicolumn{8}{|c|}{ CoO + Pt-ALD Coated LSCF (sintering $=1200 \mathrm{C}$ ) } \\
\hline Sample & Temp. $\left({ }^{\circ} \mathrm{C}\right)$ & Temp. (K) & $1000 / \mathrm{T}(1 / \mathrm{K})$ & Surface Exchange $(k)(\mathrm{cm} / \mathrm{s})$ & Diffusion coefficient (D) $\left(\mathrm{cm}^{2} / \mathrm{s}\right)$ & $\ln (\mathbf{k})$ & $\ln (D)$ \\
\hline \multirow{2}{*}{55.2 ( 60 cycles $\mathrm{CoO}+\mathrm{Pt}$ ) } & 650 & 923.15 & 1.08 & $2.16 \mathrm{E}-03$ & $2.44 \mathrm{E}-06$ & -6.14 & -12.92 \\
\hline & 700 & 973.15 & 1.03 & $2.84 \mathrm{E}-03$ & 3.37E-06 & -5.86 & -12.60 \\
\hline \multirow{2}{*}{56.2 (90 cycles CoO+Pt) } & 650 & 923.15 & 1.08 & $1.21 \mathrm{E}-03$ & $2.36 \mathrm{E}-06$ & -6.72 & -12.96 \\
\hline & 700 & 973.15 & 1.03 & $1.31 \mathrm{E}-03$ & 4.37E-06 & -6.64 & -12.34 \\
\hline $\begin{array}{c}57.1 \text { (120 cycles } \\
\text { CoO+Pt) }\end{array}$ & 700 & 973.15 & 1.03 & $1.06 \mathrm{E}-03$ & 1.03E-05 & -6.85 & -11.49 \\
\hline $\begin{array}{c}85.2 \text { (60 cycles } \mathrm{CoO}+30 \\
\text { cycles } \mathrm{Pt})\end{array}$ & 750 & 1023.15 & 0.98 & $3.20 \mathrm{E}-03$ & $5.81 \mathrm{E}-06$ & -5.74 & -12.06 \\
\hline $\begin{array}{c}86.1 \text { (30 cycles } \mathrm{Pt}+90 \\
\text { cycles } \mathrm{CoO})\end{array}$ & 650 & 923.15 & 1.08 & $2.60 \mathrm{E}-03$ & $3.12 \mathrm{E}-06$ & -5.95 & -12.68 \\
\hline 86.2 ( 30 cycles Pt +90 & 750 & 1023.15 & 0.98 & $1.46 \mathrm{E}-03$ & $2.46 \mathrm{E}-06$ & -6.53 & -12.92 \\
\hline cycles $\mathrm{CoO}+30$ cycles & 800 & 1073.15 & 0.93 & $1.52 \mathrm{E}-03$ & 3.37E-06 & -6.49 & -12.60 \\
\hline
\end{tabular}

Table $18 \mathrm{CoO}_{x}+$ Pt-ALD Coated LSCF Samples $\left(\right.$ Sint $\left.=1300^{\circ} \mathrm{C}\right)$

\begin{tabular}{|c|c|c|c|c|c|c|c|}
\hline \multicolumn{8}{|c|}{ CoO + Pt-ALD Coated LSCF (sintering $=1300 \mathrm{C}$ ) } \\
\hline Sample & Temp. $\left({ }^{\circ} \mathrm{C}\right)$ & Temp. (K) & $1000 / \mathrm{T}(1 / \mathrm{K})$ & Surface Exchange $(k)(\mathrm{cm} / \mathrm{s})$ & Diffusion coefficient (D) $\left(\mathrm{cm}^{2} / \mathrm{s}\right)$ & $\ln (\mathbf{k})$ & $\ln (D)$ \\
\hline $\begin{array}{c}67.2(30 \text { cycles } \mathrm{Pt}+30 \\
\text { cycles } \mathrm{CoO}+30 \text { cycles } \\
\mathrm{Pt})\end{array}$ & 750 & 1023.15 & 0.98 & 1.07E-03 & $5.88 \mathrm{E}-06$ & -6.84 & -12.04 \\
\hline $75.2(60$ cycles $\mathrm{CoO}+30$ & 750 & 1023.15 & 0.98 & $1.55 \mathrm{E}-03$ & $3.27 \mathrm{E}-06$ & -6.47 & -12.63 \\
\hline cycles Pt) & 800 & 1073.15 & 0.93 & $8.62 \mathrm{E}-04$ & $5.06 \mathrm{E}-06$ & -7.06 & -12.19 \\
\hline $\begin{array}{c}76.1 \text { (30 cycles Pt + } 90 \\
\text { cycles } \mathrm{CoO})\end{array}$ & 700 & 973.15 & 1.03 & $8.05 \mathrm{E}-04$ & 4.19E-06 & -7.12 & -12.38 \\
\hline 76.2 ( 30 cycles $\mathrm{Pt}+90$ & 700 & 973.15 & 1.03 & $1.90 \mathrm{E}-03$ & $6.70 \mathrm{E}-06$ & -6.27 & -11.91 \\
\hline cycles $\mathrm{CoO}+30$ cycles & 750 & 1023.15 & 0.98 & $1.73 \mathrm{E}-03$ & $1.05 \mathrm{E}-05$ & -6.36 & -11.46 \\
\hline $\mathrm{CoO})$ & 800 & 1073.15 & 0.93 & $1.55 \mathrm{E}-03$ & $1.66 \mathrm{E}-05$ & -6.47 & -11.00 \\
\hline
\end{tabular}

The previous tables show the list of samples that were tested with a $\mathrm{CoO}_{\mathrm{x}}+\mathrm{Pt}-\mathrm{ALD}$ coating on their surface and sintering temperatures of $1200{ }^{\circ} \mathrm{C}$ and $1300{ }^{\circ} \mathrm{C}$. The sample name shows the number of $\mathrm{CoO}_{x}$ and Pt cycles that were added to the baseline LSCF samples.

Additionally, the tables show the temperatures that the samples were tested for as well as the kinetic properties that were obtained for each sample at each given temperature.

The surface exchange coefficients obtained from the $\mathrm{CoO}_{x}+\mathrm{Pt}-\mathrm{ALD}$ coated samples were plotted in a $\ln (k)$ vs $1000 / T$ graph along the LSCF baseline with the same sintering temperature as follows: 


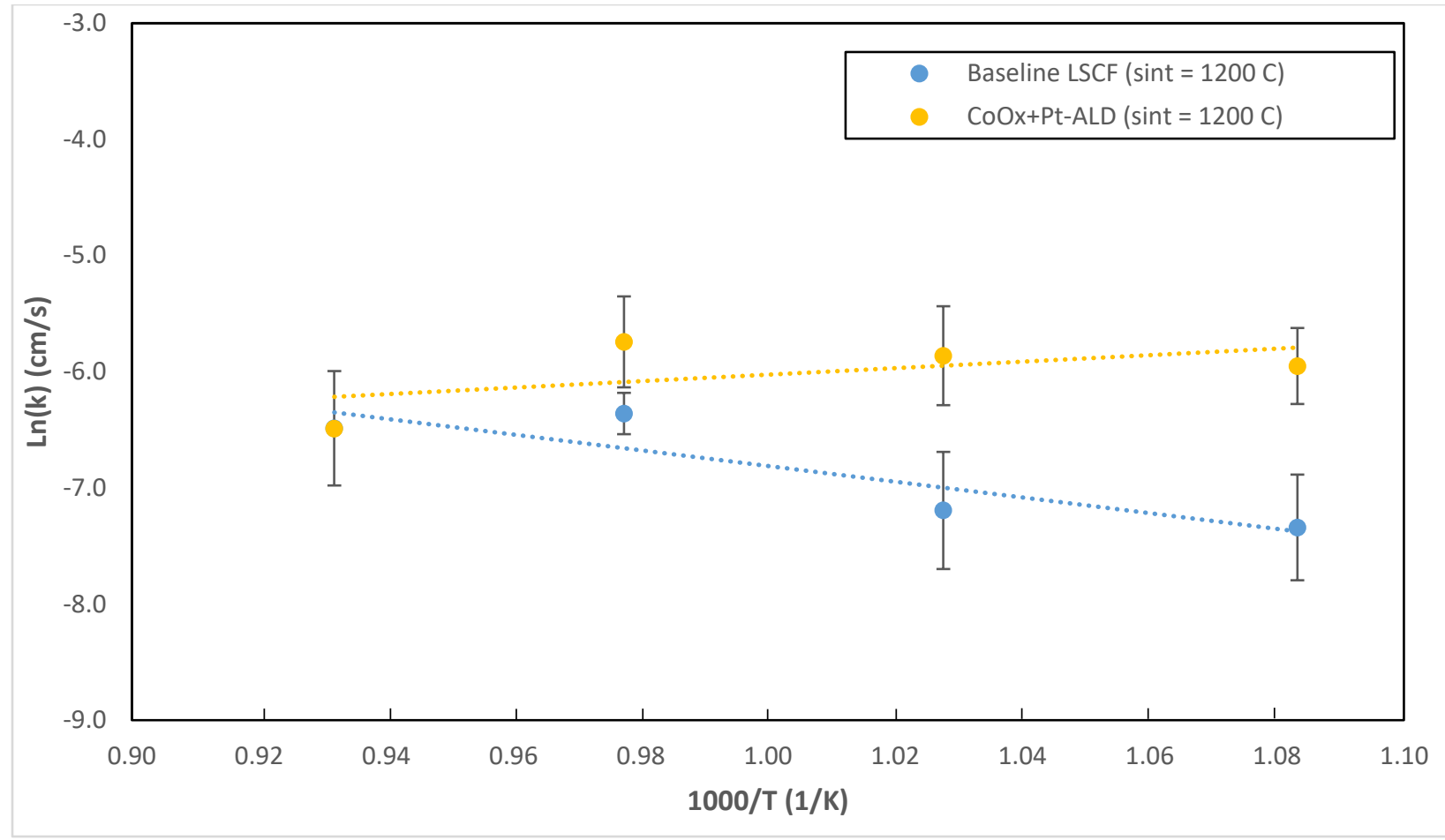

Figure 21 Surface Exchange vs Temperature $-\operatorname{CoO}_{x}+P t-A L D\left(\operatorname{Sint}=1200^{\circ} \mathrm{C}\right)$

In the previous figure, the $\ln (k)$ vs $1000 / T$ graph was plotted for $\mathrm{CoO}_{x}+\mathrm{Pt}-\mathrm{ALD}$ coated, and baseline LSCF sintered at $1200^{\circ} \mathrm{C}$. The surface exchange rate for LSCF increases as the temperature increases and reduces with as the temperature reduces as it was seen in the previous chapter. On the other hand, the surface exchange rate for $\mathrm{CoO}_{x}+\mathrm{Pt}-\mathrm{ALD}$ coated samples does not follow the same trend as the LSCF baseline due to the uncertainty of the measurements obtained at $800^{\circ} \mathrm{C}$. The enhancement of this coating on the LSCF surface exchange is more pronounced at lower temperatures than it is at higher temperatures. However, the $\mathrm{CoO}_{x}+\mathrm{Pt}-\mathrm{ALD}$ coated samples have a higher surface exchange for the LSCF baseline samples in general. Therefore, the $\mathrm{CoO}_{x}+\mathrm{Pt}$-ALD has an enhancement in the surface exchange of the LSCF.

The natural log surface exchange values that were graphed for the surface exchange vs temperature graph for $\mathrm{CoO}_{x}+\mathrm{Pt}-\mathrm{ALD}$ coated and baseline LSCF with sintering temperature of $1200^{\circ} \mathrm{C}$ are shown in the following table for each temperature: 
Table 19 Surface Exchange Values $-\mathrm{CoO}_{x}+\operatorname{Pt}-\mathrm{ALD}\left(\operatorname{Sint}=1200^{\circ} \mathrm{C}\right)$

\begin{tabular}{cccccc}
\hline $\begin{array}{c}\text { Composition of } \\
\text { LSCF }\end{array}$ & $\begin{array}{c}\text { Sintering Temp. } \\
\left({ }^{\circ} \mathrm{C}\right)\end{array}$ & \multicolumn{5}{c}{$\mathbf{L n}(\mathbf{k})(\mathbf{c m} / \mathbf{s})$} \\
\cline { 3 - 6 } & 1200 & $\mathbf{6 5 0}\left({ }^{\circ} \mathbf{C}\right)$ & $\mathbf{7 0 0}\left({ }^{\circ} \mathbf{C}\right)$ & $\mathbf{7 5 0}\left({ }^{\circ} \mathbf{C}\right)$ & $\mathbf{8 0 0}\left({ }^{\circ} \mathbf{C}\right)$ \\
\hline Baseline & -7.34 & -7.19 & -6.36 & -6.49 \\
\hline $\mathbf{C o O}_{\mathbf{x}}+\mathrm{Pt}(\mathrm{ALD})$ & 1200 & -5.95 & -5.86 & -5.74 & -6.49 \\
\hline
\end{tabular}

Table 20 Surface Exchange \% Increase/Decrease $-\operatorname{CoO}_{x}+P t-A L D\left(\operatorname{Sint}=1200^{\circ} \mathrm{C}\right)$

\begin{tabular}{cccccc}
\hline $\begin{array}{c}\text { Composition of } \\
\text { LSCF }\end{array}$ & $\begin{array}{c}\text { Sintering Temp. } \\
\left({ }^{\circ} \mathrm{C}\right)\end{array}$ & \multicolumn{4}{c}{$\%$ Increase/Decrease in Surface Exchange } \\
\cline { 3 - 6 } & & $\mathbf{6 5 0}\left({ }^{\circ} \mathrm{C}\right)$ & $\mathbf{7 0 0}\left({ }^{\circ} \mathrm{C}\right)$ & $\mathbf{7 5 0}\left({ }^{\circ} \mathrm{C}\right)$ & $\mathbf{8 0 0}\left({ }^{\circ} \mathrm{C}\right)$ \\
\hline $\mathrm{CoO}_{\mathrm{x}}+\mathrm{Pt}$ (ALD) & 1200 & $18.93 \%$ & $18.52 \%$ & $9.70 \%$ & $-0.04 \%$ \\
\hline
\end{tabular}

In the previous table, the percentage increase/decrease of the surface exchange between the $\mathrm{CoO}_{x}+\mathrm{Pt}-\mathrm{ALD}$ coated and baseline samples with a sintering temperature of $1200^{\circ} \mathrm{C}$ is shown. It can be observed that the $\mathrm{CoO}_{x}+\mathrm{Pt}-\mathrm{ALD}$ samples have a much higher surface exchange than the baseline for 650 and $700{ }^{\circ} \mathrm{C}$ temperatures with an enhancement of about $18 \%$. The surface exchange of the $\mathrm{CoO}_{x}+\mathrm{Pt}-\mathrm{ALD}$ samples is also pronounced for temperature $750^{\circ} \mathrm{C}$ with an enhancement of almost $10 \%$ when comparing it to the baseline samples. On the other hand, the surface exchange obtained at $800^{\circ} \mathrm{C}$ for $\mathrm{CoO}_{x}+\mathrm{Pt}-\mathrm{ALD}$ samples is not enhanced when compared to the baseline samples due to an uncertain measurement at that temperature. It is seen in the graph above that the surface exchange measured at $800^{\circ} \mathrm{C}$ for $\mathrm{CoO}_{x}+\mathrm{Pt}-\mathrm{ALD}$ samples does not follow the same trend that all the surface exchange measurements follow. Therefore, the measurement at $800{ }^{\circ} \mathrm{C}$ should be repeated for $\mathrm{CoO}_{x}+\mathrm{Pt}-$ ALD samples.

Furthermore, the $\mathrm{CoO}_{x}+\mathrm{Pt}-\mathrm{ALD}$ samples were also prepared, measured, and analyzed with a sintering temperature of $1300^{\circ} \mathrm{C}$. The natural log of the surface exchange versus the inverse of the temperature was plotted in the following graph and compared to baseline LSCF for samples with a sintering temperature of $1300^{\circ} \mathrm{C}$ : 


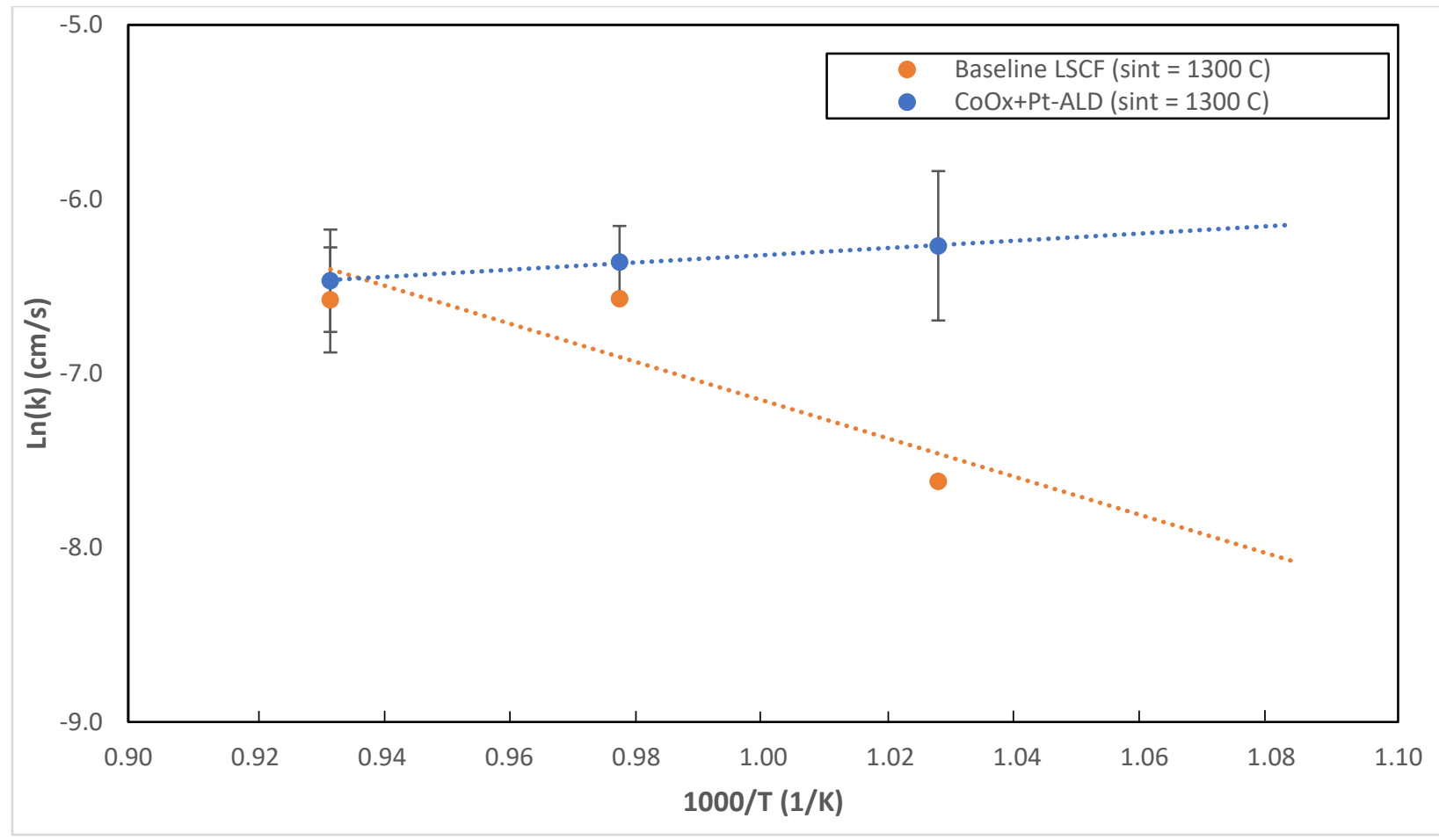

Figure 22 Surface Exchange vs Temperature $-\operatorname{CoO}_{x}+P t-A L D\left(\operatorname{Sint}=1300^{\circ} \mathrm{C}\right)$

The graph above shows the surface exchange of the $\mathrm{CoO}_{x}+\mathrm{Pt}-\mathrm{ALD}$ coated samples compared to the LSCF baseline samples with a sintering temperature of $1300{ }^{\circ} \mathrm{C}$. The $\mathrm{CoO}_{\mathrm{x}}+\mathrm{Pt}$ ALD coating with a sintering temperature of $1300^{\circ} \mathrm{C}$ follows the same trend than the one with sintering temperature at $1200^{\circ} \mathrm{C}$. The enhancement is pronounced at lower temperatures, but the measurement at $800{ }^{\circ} \mathrm{C}$ is uncertain, and there is no enhancement at that temperature. In general, the $\mathrm{CoO}_{x}+\mathrm{Pt}$-ALD coating increases the surface exchange of LSCF. However, the enhancement is smaller than the one seen for the samples with a sintering temperature of $1200{ }^{\circ} \mathrm{C}$.

The natural log surface exchange values that were graphed for the surface exchange vs temperature graph for $\mathrm{CoO}_{x}+\mathrm{Pt}-\mathrm{ALD}$ coated and baseline LSCF with sintering temperature of $1300^{\circ} \mathrm{C}$ are shown in the following table for each temperature:

Table 21 Surface Exchange Values $-\mathrm{CoO}_{x}+P t-A L D\left(\right.$ Sint $\left.=1300^{\circ} \mathrm{C}\right)$

\begin{tabular}{cccccc}
\hline $\begin{array}{c}\text { Composition of } \\
\text { LSCF }\end{array}$ & $\begin{array}{c}\text { Sintering Temp. } \\
\left({ }^{\circ} \mathrm{C}\right)\end{array}$ & \multicolumn{4}{c}{$\operatorname{Ln}(\mathbf{k})(\mathrm{cm} / \mathrm{s})$} \\
\cline { 3 - 6 } & 1300 & $\mathbf{6 5 0}\left({ }^{\circ} \mathrm{C}\right)$ & $\mathbf{7 0 0}\left({ }^{\circ} \mathrm{C}\right)$ & $\mathbf{7 5 0}\left({ }^{\circ} \mathrm{C}\right)$ & $\mathbf{8 0 0}\left({ }^{\circ} \mathrm{C}\right)$ \\
\hline Baseline & 0.00 & -7.62 & -6.57 & -6.58 \\
\hline
\end{tabular}




\begin{tabular}{|c|c|c|c|c|c|}
\hline $\mathrm{CoO}_{\mathrm{x}}+\mathrm{Pt}(\mathrm{ALD})$ & 1300 & 0.00 & -6.27 & -6.36 & -6.47 \\
\hline \multicolumn{6}{|c|}{ Table 22 Surface Exchange \% Increase/Decrease $-\mathrm{CoO}_{x}+P t-A L D\left(\operatorname{Sint}=1300^{\circ} \mathrm{C}\right)$} \\
\hline \multirow[t]{2}{*}{$\begin{array}{l}\text { Composition of } \\
\text { LSCF }\end{array}$} & \multirow[t]{2}{*}{$\begin{array}{l}\text { Sintering Temp. } \\
\left({ }^{\circ} \mathrm{C}\right)\end{array}$} & \multicolumn{4}{|c|}{$\begin{array}{l}\text { \% Increase/Decrease in Surface Exchange } \\
\text { Compared to Baseline }\end{array}$} \\
\hline & & $650\left({ }^{\circ} \mathrm{C}\right)$ & $700\left({ }^{\circ} \mathrm{C}\right)$ & $750\left({ }^{\circ} \mathrm{C}\right)$ & $800\left({ }^{\circ} \mathrm{C}\right)$ \\
\hline $\mathrm{CoO}_{\mathrm{x}}+\mathrm{Pt}(\mathrm{ALD})$ & 1300 & - & $17.75 \%$ & $3.19 \%$ & $1.67 \%$ \\
\hline
\end{tabular}

In the previous table, the percentage increase/decrease of the surface exchange between the $\mathrm{CoO}_{x}+\mathrm{Pt}-\mathrm{ALD}$ coated and baseline samples with a sintering temperature of $1300{ }^{\circ} \mathrm{C}$ is shown. It can be observed that the surface exchange coefficient of the $\mathrm{CoO}_{x}+\mathrm{Pt}-\mathrm{ALD}$ samples is reduced compared to the LSCF baseline at high temperatures. The difference between the $\mathrm{CoO}_{\mathrm{x}}+\mathrm{Pt}-\mathrm{ALD}$ and the baseline samples at 750 and $800^{\circ} \mathrm{C}$ is not larger than $3 \%$. However, for temperature of $700^{\circ} \mathrm{C}$ the enhancement that the $\mathrm{CoO}_{x}+\mathrm{Pt}-\mathrm{ALD}$ coating has on the LSCF is more pronounced and is increased by almost an $18 \%$.

Moreover, the characterization of the bulk diffusion coefficient was also performed for $\mathrm{CoO}_{x}+\mathrm{Pt}$-ALD coated samples and compared to baseline LSCF. The samples analyzed in this case are the same samples that were shown at the beginning of this section since the electrical conductivity relaxation method allows to determine both oxygen transport kinetic properties simultaneously. The bulk diffusion coefficients obtained for $\mathrm{CoO}_{x}+\mathrm{Pt}-\mathrm{ALD}$ coated samples and baseline LSCF with sintering temperature of $1200{ }^{\circ} \mathrm{C}$ were plotted in a $\ln (\mathrm{D})$ vs $1000 / \mathrm{T}$ graph as follows: 


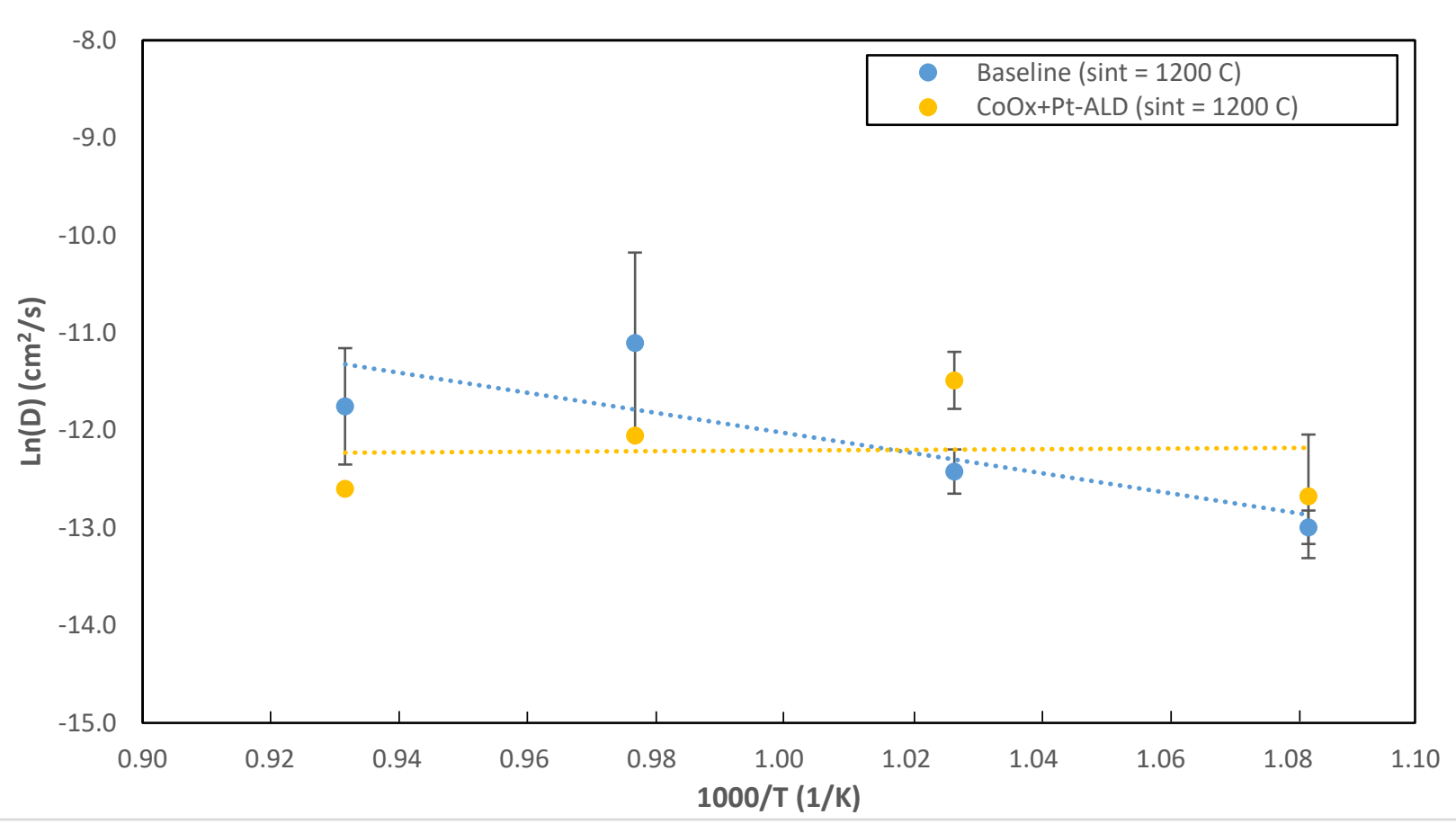

Figure 23 Bulk Diffusion Coefficient vs Temperature $-\mathrm{CoO}_{x}+P t-A L D\left(\operatorname{Sint}=1200^{\circ} \mathrm{C}\right)$

In the previous figure, the $\ln (\mathrm{D})$ vs $1000 / \mathrm{T}$ was plotted for $\mathrm{CoO}_{\mathrm{x}}+\mathrm{Pt}-\mathrm{ALD}$ samples and baseline LSCF with sintering temperature of $1200^{\circ} \mathrm{C}$. The diffusion coefficient obtained for the $\mathrm{CoO}_{\mathrm{x}}+\mathrm{Pt}-\mathrm{ALD}$ samples is higher at low temperatures and lower at higher temperatures compared to the baseline LSCF. In contrast with the results seen for the surface exchange coefficients, the diffusion coefficient measurement seems to not be altered as much when compared to the baseline samples. Also, when comparing the diffusion coefficient values seen for $\mathrm{CoO}_{\mathrm{x}}+\mathrm{Pt}-\mathrm{ALD}$ samples with the values seen for $\mathrm{CoO}_{\mathrm{x}}-\mathrm{ALD}$ samples in section 4.3 , it is observed that the addition on Pt on top of the $\mathrm{CoO}_{x}$ reduces the diffusion coefficient of LSCF

In the following table, the natural log of the diffusion coefficient values that were plotted are shown for $\mathrm{CoO}_{x}+\mathrm{Pt}-\mathrm{ALD}$ and baseline LSCF with sintering temperature of $120{ }^{\circ} \mathrm{C}$ :

Table 23 Bulk Diffusion Coefficient Values $-\operatorname{CoO}_{x}+P t\left(\operatorname{Sint}=1200^{\circ} \mathrm{C}\right)$

\begin{tabular}{cccccc}
\hline $\begin{array}{c}\text { Composition of } \\
\text { LSCF }\end{array}$ & $\begin{array}{c}\text { Sintering Temp. } \\
\left({ }^{\circ} \mathrm{C}\right)\end{array}$ & \multicolumn{4}{c}{$\operatorname{Ln}(\mathrm{D})(\mathbf{c m} 2 / \mathrm{s})$} \\
\cline { 3 - 6 } & 1200 & -12.950 & -12.42 & -11.11 & -11.75 \\
\hline Baseline & 1200 & -12.68 & -11.49 & -12.06 & -12.60 \\
\hline $\mathrm{CoO}_{x}+\mathrm{Pt}(\mathrm{ALD})$ & $120\left({ }^{\circ} \mathrm{C}\right)$ & $\mathbf{7 5 0}\left({ }^{\circ} \mathrm{C}\right)$ & $\mathbf{8 0 0}\left({ }^{\circ} \mathrm{C}\right)$ \\
\hline
\end{tabular}


Table 24 Bulk Diffusion Coefficient \% Increase/Decrease $-\mathrm{CoO}_{x}+\mathrm{Pt}\left(\operatorname{Sint}=1200^{\circ} \mathrm{C}\right)$

\begin{tabular}{cccccc}
\hline $\begin{array}{c}\text { Composition of } \\
\text { LSCF }\end{array}$ & $\begin{array}{c}\text { Sintering Temp. } \\
\left({ }^{\circ} \mathrm{C}\right)\end{array}$ & \multicolumn{3}{c}{$\%$ Increase/Decrease in Diffusion Coefficient } \\
& & $\mathbf{6 5 0}\left({ }^{\circ} \mathrm{C}\right)$ & $\mathbf{7 0 0}\left({ }^{\circ} \mathrm{C}\right)$ & $\mathbf{7 5 0}\left({ }^{\circ} \mathrm{C}\right)$ & $\mathbf{8 0 0}\left({ }^{\circ} \mathrm{C}\right)$ \\
\hline $\mathrm{CoO}_{\mathrm{x}}+\mathrm{Pt}(\mathrm{ALD})$ & 1200 & $2.44 \%$ & $7.53 \%$ & $-8.55 \%$ & $-7.21 \%$ \\
\hline
\end{tabular}

In the previous table, the percentage increase/decrease of the diffusion coefficient between the $\mathrm{CoO}_{x}+\mathrm{Pt}$-ALD and baseline LSCF samples with sintering temperature of $1200{ }^{\circ} \mathrm{C}$ is shown. As mentioned above, the diffusion coefficient for $\mathrm{CoO}_{x}+\mathrm{Pt}-\mathrm{ALD}$ coated samples is reduced for 750 and $800{ }^{\circ} \mathrm{C}$ and is increased for 650 and $700{ }^{\circ} \mathrm{C}$ temperatures. However, the difference between the values when compared to the baseline LSCF is not larger than $10 \%$ meaning that the diffusion coefficients are about the same magnitude in comparison.

Furthermore, the $\mathrm{CoO}_{\mathrm{x}}+\mathrm{Pt}-\mathrm{ALD}$ samples were also prepared, measured and analyzed with a sintering temperature of $1300^{\circ} \mathrm{C}$. The natural log of the diffusion coefficient versus the inverse of the temperature was plotted in the following graph and compared to baseline LSCF for samples with sintering temperature of $1300{ }^{\circ} \mathrm{C}$ : 


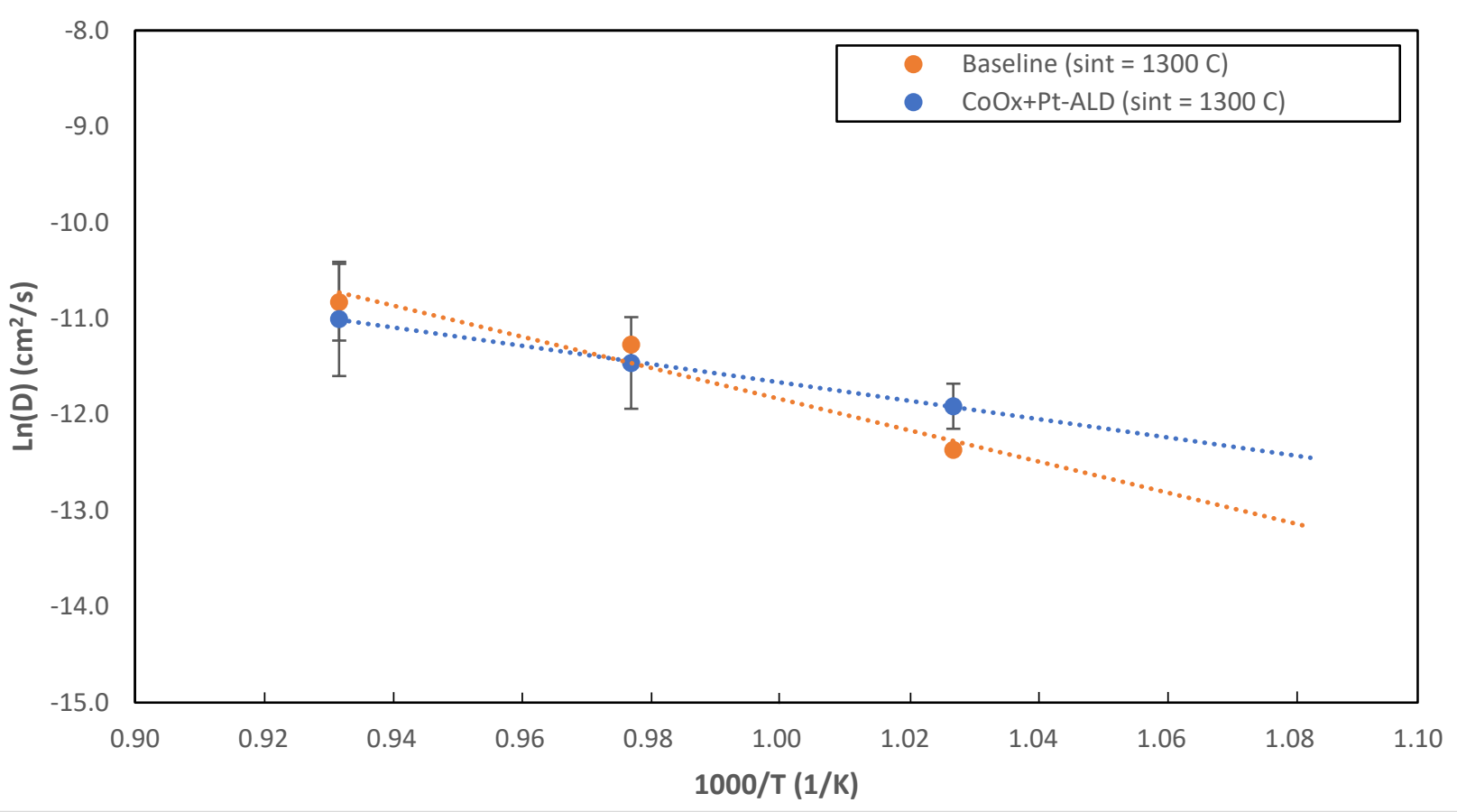

Figure 24 Bulk Diffusion Coefficient vs Temperature $-\mathrm{CoO}_{x}+P t-A L D\left(\operatorname{Sint}=1300^{\circ} \mathrm{C}\right)$

In the previous figure, the $\ln (\mathrm{D})$ vs $1000 / T$ was plotted for $\mathrm{CoO}_{\mathrm{x}}+\mathrm{Pt}-\mathrm{ALD}$ and baseline LSCF with sintering temperature of $1300^{\circ} \mathrm{C}$. Similarly, to the results seen for the samples with sintering temperature of $1200^{\circ} \mathrm{C}$, the diffusion coefficient of the $\mathrm{CoO}_{\mathrm{x}}+\mathrm{Pt}-\mathrm{ALD}$ is higher at some temperatures and lower at other temperatures. There is no enhancement of the diffusion coefficient of LSCF given by the $\mathrm{CoO}_{x}+\mathrm{Pt}-\mathrm{ALD}$ coating. In comparison with the $\mathrm{CoO}_{\mathrm{x}}-\mathrm{ALD}$ coating with sintering temperature of $1300^{\circ} \mathrm{C}$ from section 4.3 , the addition of Pt enhances the diffusion coefficient.

In the following table, the natural log of the diffusion coefficient values that were plotted are shown for $\mathrm{CoO}_{x}+\mathrm{Pt}-\mathrm{ALD}$ and baseline LSCF with sintering temperature of $1300^{\circ} \mathrm{C}$ :

Table 25 Bulk Diffusion Coefficient Values $-\mathrm{CoO}_{x}+\mathrm{Pt}\left(\mathrm{Sint}=1300^{\circ} \mathrm{C}\right)$

\begin{tabular}{cccccc}
\hline $\begin{array}{c}\text { Composition of } \\
\text { LSCF }\end{array}$ & $\begin{array}{c}\text { Sintering Temp. } \\
\left({ }^{\circ} \mathrm{C}\right)\end{array}$ & \multicolumn{4}{c}{$\operatorname{Ln}(\mathrm{D})(\mathbf{c m} 2 / \mathrm{s})$} \\
\cline { 2 - 6 } & 1300 & $\mathbf{6 5 0}\left({ }^{\circ} \mathrm{C}\right)$ & $\mathbf{7 0 0}\left({ }^{\circ} \mathrm{C}\right)$ & $\mathbf{7 5 0}\left({ }^{\circ} \mathrm{C}\right)$ & $\mathbf{8 0 0}\left({ }^{\circ} \mathrm{C}\right)$ \\
\hline Baseline & 1300 & 0.00 & -12.37 & -11.27 & -10.83 \\
\hline $\mathbf{C o O}_{\mathbf{x}}+\mathrm{Pt}(\mathrm{ALD})$ & 0.00 & -11.91 & -11.46 & -11.00 \\
\hline
\end{tabular}


Table 26 Bulk Diffusion Coefficient \% Increase/Decrease $-\operatorname{CoO} x+\operatorname{Pt}-A L D\left(\operatorname{Sint}=1300^{\circ} \mathrm{C}\right)$

\begin{tabular}{cccccc}
\hline $\begin{array}{c}\text { Composition of } \\
\text { LSCF }\end{array}$ & $\begin{array}{c}\text { Sintering Temp. } \\
\left({ }^{\circ} \mathrm{C}\right)\end{array}$ & \multicolumn{3}{c}{$\%$ Increase/Decrease in Diffusion Coefficient } \\
& & $\mathbf{6 5 0}\left({ }^{\circ} \mathrm{C}\right)$ & $\mathbf{7 0 0}\left({ }^{\circ} \mathrm{C}\right)$ & $\mathbf{7 5 0}\left({ }^{\circ} \mathrm{C}\right)$ & $\mathbf{8 0 0}\left({ }^{\circ} \mathrm{C}\right)$ \\
\hline $\mathrm{CoO}_{x}+\mathrm{Pt}(\mathrm{ALD})$ & 1300 & - & $3.67 \%$ & $-1.70 \%$ & $-1.60 \%$ \\
\hline
\end{tabular}

In the previous table, the percentage increase/decrease of the diffusion coefficient between the $\mathrm{CoO}_{x}+\mathrm{Pt}-\mathrm{ALD}$ and baseline LSCF samples with sintering temperature of $1300^{\circ} \mathrm{C}$ is shown. As mentioned before the addition of $\mathrm{CoO}_{x}+\mathrm{Pt}-\mathrm{ALD}$ coating to LSCF does not alter the diffusion coefficient. The difference between one another is not larger than $4 \%$.

\subsection{Summary of $\mathrm{CoO}_{x}-\mathrm{ALD}$ and $\mathrm{CoO}_{x}+$ Pt-ALD Coated LSCF Results}

The characterization of $\mathrm{CoO}_{x}-\mathrm{ALD}$ and $\mathrm{CoO}_{x}+\mathrm{Pt}-\mathrm{ALD}$ coated LSCF was performed for pellets with sintering temperatures of 1200 and $1300{ }^{\circ} \mathrm{C}$. It was observed that the addition of $\mathrm{CoO}_{x}$-ALD coating on top of the LSCF surface enhances the surface exchange of the perovskite oxide. The diffusion coefficient of the perovskite oxide was increased for sintering temperature $1200^{\circ} \mathrm{C}$ and decreased for sintering temperature of $1300^{\circ} \mathrm{C}$. On the other hand, the addition of Pt-ALD on top of the $\mathrm{CoO}_{x}$-ALD coating, maintains the enhancement of the surface exchange that is seen for the $\mathrm{CoO}_{x}$-ALD coating alone. However, the addition of Pt-ALD on top of the $\mathrm{CoO}_{x}$-ALD does not alter the diffusion coefficient of LSCF. 


\section{Chapter 5: Characterization of Ink Coated LSCF}

\subsection{Conductivity and catalytic properties of $\mathrm{MnO}_{x}$}

For the ink coated samples, $\mathrm{MnO}_{2}$ was one of the three metal oxides that were used in this project as a catalyst to enhance the oxygen transport kinetics of LSCF. MnO ${ }_{x}$ is an inorganic compound that is used as a colorant for diverse items, and as a catalyst for batteries ${ }^{65}$. Therefore, it could potentially serve as a catalyst for the cathode of a SOFC due to the electrical conductivity of the manganese. The electrical conductivity of manganese has been reported to be $6.2 \times 10^{5} \mathrm{~S} / \mathrm{m}^{66}$. Manganese has lower electrical conductivity than the ones seen in chapter 3 for platinum and cobalt. Therefore, it could be expected that the enhancement of the absorption rate of ions from this compound is reduced when compared to the other coating compounds.

Furthermore, $\mathrm{MnO}_{\mathrm{x}}$ has also been reported to be a polymorphous material that can adopt different crystal structures. However, this coating compound crystallizes in the rutile crystal structure with a tetragonal structure ${ }^{67}$.

\subsection{Conductivity and catalytic properties of $\mathrm{Pr}_{2} \mathrm{O}_{x}$}

$\mathrm{Pr}_{2} \mathrm{O}_{x}$ was the last coating in this project. This coating also goes by the name of Praseodymium (III) oxide. It was also chosen by its electrical conductivity and ionic conductivity for oxygen ions. The electrical conductivity of this compound has been reported to be $1.4 \times 10^{6}$ $\mathrm{S} / \mathrm{m}^{68}$. The electrical conductivity of this material is lower than the ones seen for $\mathrm{Co}$ and $\mathrm{Pt}$, however, it is higher than the electrical conductivity of manganese and could be expected to deliver a better performance than $\mathrm{MnO}_{\mathrm{x}}$ coating.

Praseodymium oxide is a compound that is transparent and is used for several applications. This compound is widely used in optics due to the transparency of the material. Also, it is a hard and insoluble material that fits perfectly for optical coating ${ }^{69}$. However, there are other applications for this material, such as dielectric material combined with silicon and to block infrared radiation ${ }^{70}$. This material has been reported to have a hexagonal crystal structure. 


\subsection{Effect of Ink $\mathrm{CoO}_{x}$ Coating on the Kinetic Properties of LSCF}

On chapter 5, several coatings were applied on top of the LSCF samples by using an inkbased coating. Such coatings were added on top of the surface of the LSCF using a screen printer to add a uniform layer on top of the surface. $\mathrm{CoO}_{\mathrm{x}}$ was the first ink coating that was used on the LSCF. On section 5.3, the results seen for the $\mathrm{CoO}_{x}$-ink coated samples will be shown and discussed. The results seen for the $\mathrm{CoO}_{x}$-ink coating will also be compared to the ones seen on section 4.3 for the $\mathrm{CoO}_{\mathrm{x}}$-ALD coating. This comparison between the ink-based and the ALD coatings will determine which one provides a better enhancement for the oxygen transport kinetics of LSCF. The $\mathrm{CoO}_{\mathrm{x}}$-ink coating samples were fabricated with sintering temperatures of 1200 and $1300{ }^{\circ} \mathrm{C}$.

The list of samples that were analyzed using a $\mathrm{CoO}_{x}$-ink coating and the abovementioned sintering temperatures is as follows:

Table $27 \mathrm{CoO}_{x^{-}}$Ink Coated LSCF Samples (Sint $=1200^{\circ} \mathrm{C}$ )

\begin{tabular}{|c|c|c|c|c|c|c|c|}
\hline \multicolumn{8}{|c|}{ CoO Ink-Coated LSCF (sintering $=1200 \mathrm{C}$ ) } \\
\hline Sample & Temp. $\left({ }^{\circ} \mathrm{C}\right)$ & Temp. (K) & $1000 / \mathrm{T}(1 / \mathrm{K})$ & Surface Exchange $(\mathrm{k})(\mathrm{cm} / \mathrm{s})$ & Diffusion coefficient (D) $\left(\mathrm{cm}^{2} / \mathrm{s}\right)$ & $\ln (\mathbf{k})$ & $\ln (D)$ \\
\hline 56.1 (CoO Ink) & 650 & 923.15 & 1.08 & 1.30E-03 & $1.25 \mathrm{E}-05$ & -6.64 & -11.29 \\
\hline $58.1(\mathrm{CoO}$ Ink) & 750 & 1023.15 & 0.98 & $2.04 \mathrm{E}-03$ & $6.71 \mathrm{E}-06$ & -6.20 & -11.91 \\
\hline \multirow{2}{*}{58.2 ( $\mathrm{CoO}$ Ink) } & 750 & 1023.15 & 0.98 & $2.98 \mathrm{E}-03$ & $9.48 \mathrm{E}-06$ & -5.82 & -11.57 \\
\hline & 800 & 1073.15 & 0.93 & $5.04 \mathrm{E}-03$ & $1.33 \mathrm{E}-05$ & -5.29 & -11.23 \\
\hline $62.2(\mathrm{CoO}$ Ink) & 750 & 1023.15 & 0.98 & $1.52 \mathrm{E}-03$ & 3.03E-06 & -6.49 & -12.71 \\
\hline
\end{tabular}

Table $28 \mathrm{CoO}^{-}$-Ink Coated LSCF Samples (Sint $=1300^{\circ} \mathrm{C}$ )

\begin{tabular}{|c|c|c|c|c|c|c|c|}
\hline \multicolumn{8}{|c|}{ CoO Ink-Coated LSCF (sintering = 1300 C) } \\
\hline Sample & Temp. $\left({ }^{\circ} \mathrm{C}\right)$ & Temp. (K) & $1 / \mathrm{T}(1 / \mathrm{K})$ & Surface Exchange $(k)(\mathrm{cm} / \mathrm{s})$ & Diffusion coefficient (D) $\left(\mathrm{cm}^{2} / \mathrm{s}\right)$ & $\ln (\mathbf{k})$ & $\ln (D)$ \\
\hline \multirow{2}{*}{$99.2(\mathrm{CoO}$ Ink) } & 750 & 1023.15 & 0.98 & $1.12 \mathrm{E}-03$ & $2.57 \mathrm{E}-06$ & -6.79 & -12.87 \\
\hline & 800 & 1073.15 & 0.93 & $1.12 \mathrm{E}-03$ & $3.21 \mathrm{E}-06$ & -6.79 & -12.65 \\
\hline 100.1 (CoO Ink) & 700 & 973.15 & 1.03 & $6.08 \mathrm{E}-04$ & $8.26 \mathrm{E}-07$ & -7.40 & -14.01 \\
\hline \multirow{2}{*}{101.1 ( CoO Ink) } & 750 & 1023.15 & 0.98 & $3.08 \mathrm{E}-04$ & $3.72 \mathrm{E}-06$ & -8.08 & -12.50 \\
\hline & 800 & 1073.15 & 0.93 & $4.58 \mathrm{E}-04$ & $4.80 \mathrm{E}-06$ & -7.69 & -12.25 \\
\hline
\end{tabular}

The previous tables show the list of samples that were tested with a $\mathrm{CoO}_{x}$-ink coating on their surface and sintering temperatures of $1200{ }^{\circ} \mathrm{C}$ and $1300^{\circ} \mathrm{C}$. The tables show the temperatures that the samples were tested for as well as the kinetic properties that were obtained for each sample at each given temperature.

To keep the same trend as the LSCF baseline, only the highest results were taken from each sintering temperature because it means that such kinetic parameter is achievable. The 
surface exchange coefficients obtained from the $\mathrm{CoO}_{\mathrm{x}}$-ink coated samples were plotted in a $\ln (k)$ vs 1000/T graph along the LSCF baseline with the same sintering temperature as follows:

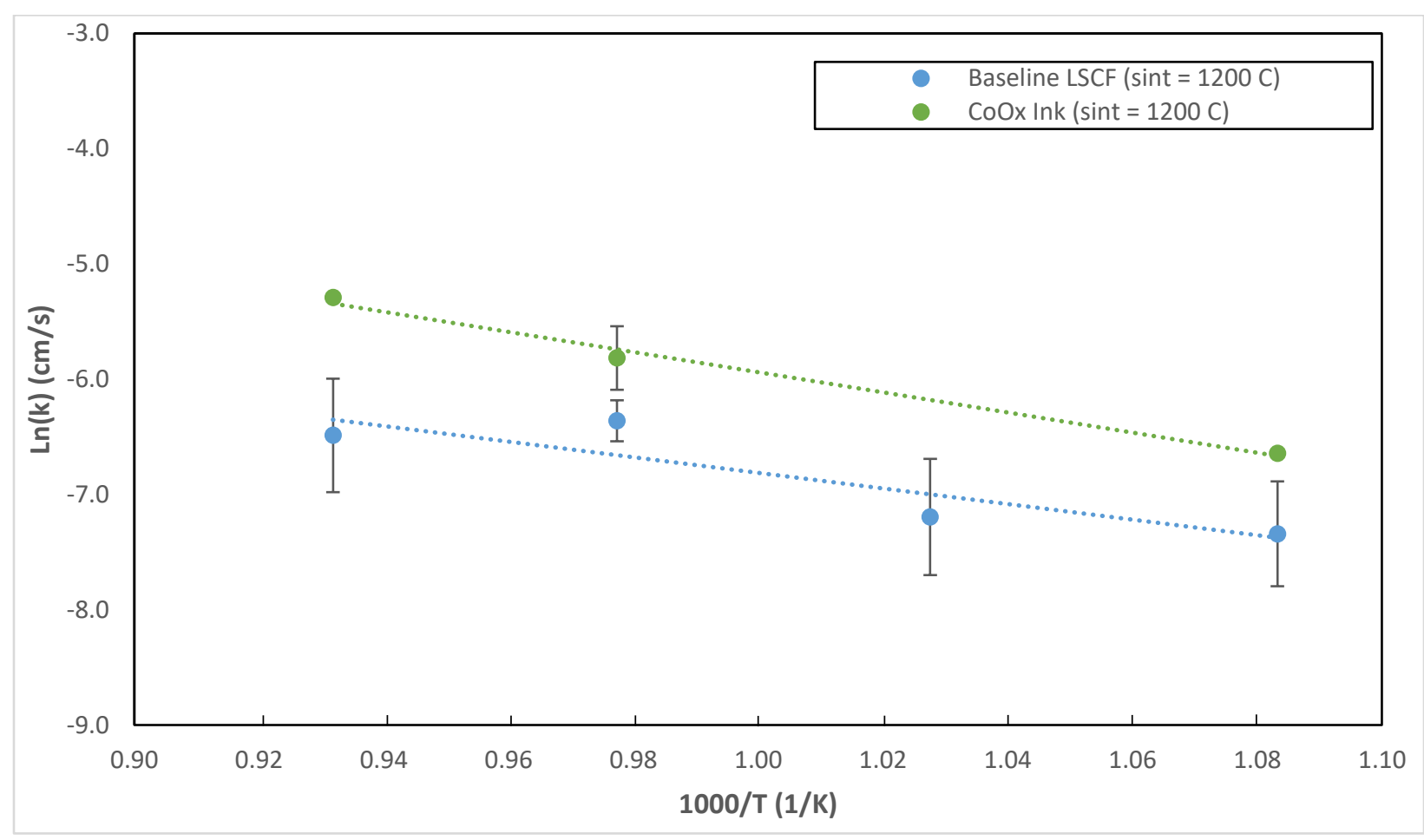

Figure 25 Surface Exchange vs Temperature $-\mathrm{CoO}_{x}-\operatorname{Ink}\left(\operatorname{Sint}=1200^{\circ} \mathrm{C}\right)$

In the previous figure, the $\ln (k)$ vs $1000 / T$ graph was plotted for $\mathrm{CoO}_{x}$-ink coated, and baseline LSCF sintered at $1200^{\circ} \mathrm{C}$. The surface exchange rate for LSCF and the $\mathrm{CoO}_{\mathrm{x}}$-ink coated samples increases as the temperature increases and reduced with as the temperature reduces, following the trend seen in previous chapters. The surface exchange of the $\mathrm{CoO}_{\mathrm{x}}$-ink coated samples were determined for temperatures 650,750 , and $800{ }^{\circ} \mathrm{C}$, but for temperature $700{ }^{\circ} \mathrm{C}$ it was not possible to determine it due to uncertainty. However, the three measurements are enough to determine that the $\mathrm{CoO}_{x}$-ink coating enhances the surface exchange of LSCF with a sintering temperature of $1200^{\circ} \mathrm{C}$. The difference between the surface exchange of LSCF and the $\mathrm{CoO}_{x}$-ink samples is about a whole order of magnitude.

The natural log surface exchange values that were graphed for the surface exchange vs temperature graph for $\mathrm{CoO}_{x}$-ink coated and baseline LSCF with sintering temperature of 1200 ${ }^{\circ} \mathrm{C}$ are shown in the following table for each temperature: 
Table 29 Surface Exchange Values $-\mathrm{CoO}_{x}$-Ink $\left(\operatorname{Sint}=1200^{\circ} \mathrm{C}\right)$

\begin{tabular}{ccccccc}
\hline $\begin{array}{c}\text { Composition of } \\
\text { LSCF }\end{array}$ & $\begin{array}{c}\text { Sintering Temp. } \\
\left({ }^{\circ} \mathrm{C}\right)\end{array}$ & $\mathbf{6 5 0}\left({ }^{\circ} \mathrm{C}\right)$ & $\mathbf{7 0 0}\left({ }^{\circ} \mathrm{C}\right)$ & $\mathbf{7 5 0}\left({ }^{\circ} \mathrm{C}\right)$ & $\mathbf{8 0 0}\left({ }^{\circ} \mathrm{C}\right)$ \\
\hline Baseline & 1200 & -7.34 & -7.19 & -6.36 & -6.49 \\
\hline CoO $_{\mathbf{x}}($ Ink $)$ & 1200 & -6.64 & 0.00 & -5.82 & -5.29 \\
\hline
\end{tabular}

Table 30 Surface Exchange \% Increase/Decrease $-\operatorname{CoO}_{x}$-Ink $\left(\operatorname{Sint}=1200{ }^{\circ} \mathrm{C}\right)$

\begin{tabular}{cccccc}
\hline $\begin{array}{c}\text { Composition of } \\
\text { LSCF }\end{array}$ & $\begin{array}{c}\text { Sintering Temp. } \\
\left({ }^{\circ} \mathrm{C}\right)\end{array}$ & \multicolumn{4}{c}{$\begin{array}{c}\text { \% Increase/Decrease in Surface Exchange } \\
\text { Compared to Baseline }\end{array}$} \\
\cline { 3 - 6 } & & $\mathbf{6 5 0}\left({ }^{\circ} \mathrm{C}\right)$ & $\mathbf{7 0 0}\left({ }^{\circ} \mathrm{C}\right)$ & $\mathbf{7 5 0}\left({ }^{\circ} \mathrm{C}\right)$ & $\mathbf{8 0 0}\left({ }^{\circ} \mathrm{C}\right)$ \\
\hline $\mathrm{CoO}_{\mathrm{x}}$ (Ink) & 1200 & $9.50 \%$ & - & $8.56 \%$ & $18.44 \%$ \\
\hline
\end{tabular}

In the previous table, the percentage increase/decrease of the surface exchange between the $\mathrm{CoO}_{x}$-ink coated and baseline samples with a sintering temperature of $1200^{\circ} \mathrm{C}$ is shown. It can be observed that the enhancement that the $\mathrm{CoO}_{x}$ ink has on the surface exchange of LSCF is significant, with a percentage increase of about $10 \%$. As it was seen in section 4.3 , the $\mathrm{CoO}_{x}$ coating enhances the surface exchange of LSCF about a whole order of magnitude. The $\mathrm{CoO}_{x}$-ALD coated samples seen in section 4.3 have a higher percentage increase at lower temperatures. Meanwhile the percentage increase in such samples is not as noticeable for higher temperatures. The characterization of the $\mathrm{CoO}_{x}$-ink coated samples confirms that the $\mathrm{CoO}_{x}$ coating enhances the surface exchange coefficient of LSCF. The enhancement produced by $\mathrm{CoO}_{x}$ can be attributed to the faster transportation of oxygen ions thanks to the electrical conductivity of $\mathrm{CoO}_{x}$.

Furthermore, the $\mathrm{CoO}_{\mathrm{x}}$-ink samples were also prepared, measured, and analyzed with a sintering temperature of $1300^{\circ} \mathrm{C}$. The natural log of the surface exchange versus the inverse of the temperature was plotted in the following graph and compared to baseline LSCF for samples with a sintering temperature of $1300^{\circ} \mathrm{C}$ : 


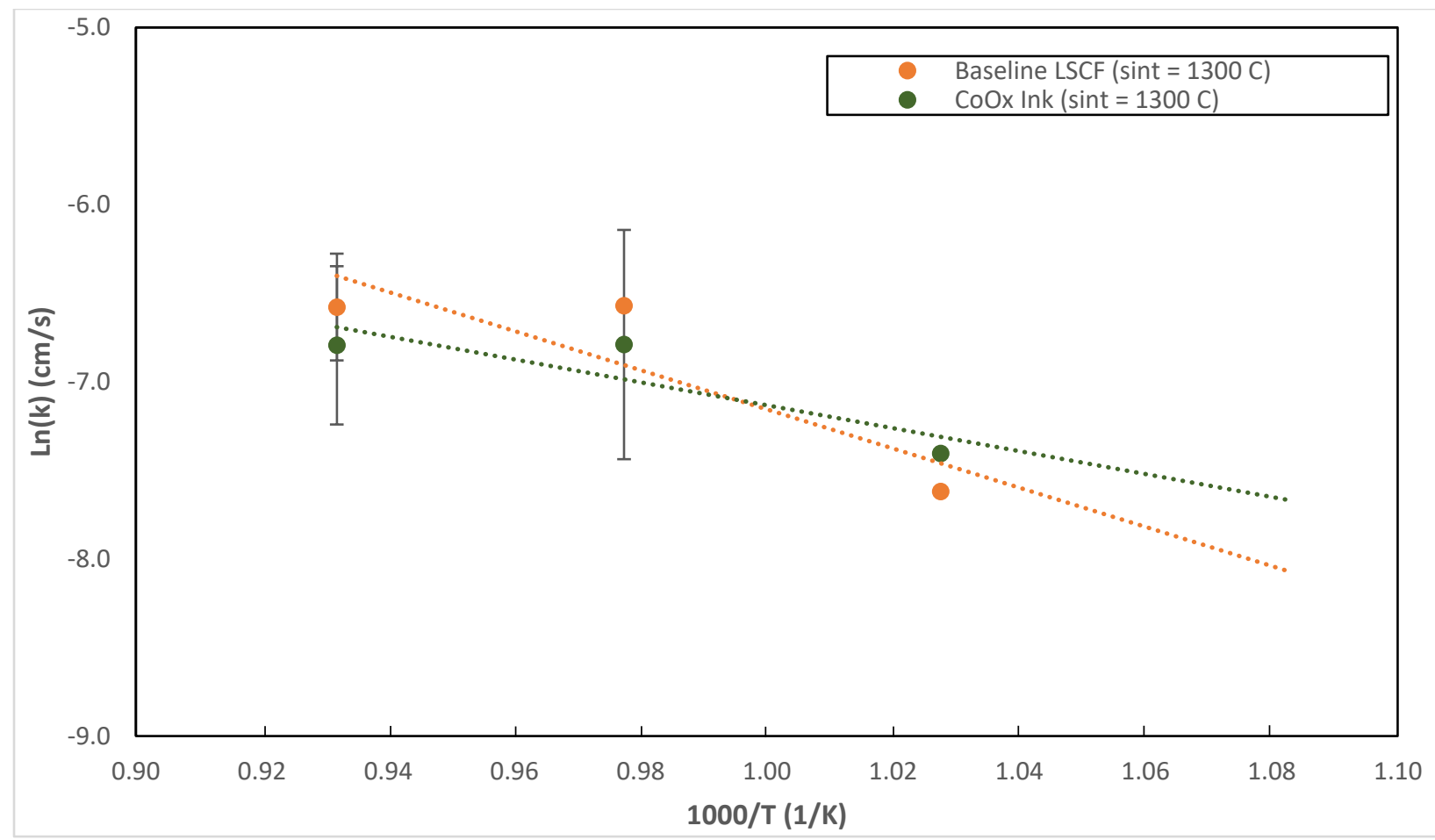

Figure 26 Surface Exchange vs Temperature $-\mathrm{CoO}_{x}-\operatorname{Ink}\left(\operatorname{Sint}=1300{ }^{\circ} \mathrm{C}\right)$

The graph above shows the surface exchange of the $\mathrm{CoO}_{\mathrm{x}}$-ink coated samples compared to the LSCF baseline samples with a sintering temperature of $1300^{\circ} \mathrm{C}$. The surface exchange of the $\mathrm{CoO}_{x}$-ink and the baseline LSCF samples is roughly the same for all the temperatures. In contrast with the $\mathrm{CoO}_{\mathrm{x}}$-ink samples with a sintering temperature of $1200^{\circ} \mathrm{C}$, the ones with a sintering temperature of $1300^{\circ} \mathrm{C}$ do not enhance the surface exchange of LSCF. This can be attributed to the fewer number of vacancies presented in samples with higher sintering temperatures. Since there are fewer vacancies, the $\mathrm{CoO}_{x}$ will not be able to enhance the surface exchange because the LSCF will not be able to incorporate more ions into its structure. These results agree with the results seen for $\mathrm{CoO}_{x}-\mathrm{ALD}$ coated samples with a sintering temperature of $1300{ }^{\circ} \mathrm{C}$ in section 4.3 .

The natural log surface exchange values that were graphed for the surface exchange vs temperature graph for $\mathrm{CoO}_{\mathrm{x}}$-ink coated and baseline LSCF with sintering temperature of 1300 ${ }^{\circ} \mathrm{C}$ are shown in the following table for each temperature: 
Table 31 Surface Exchange Values $-\mathrm{CoO}_{x}-\operatorname{Ink}\left(\operatorname{Sint}=1300^{\circ} \mathrm{C}\right)$

\begin{tabular}{cccccc}
\hline $\begin{array}{c}\text { Composition of } \\
\text { LSCF }\end{array}$ & $\begin{array}{c}\text { Sintering Temp. } \\
\left({ }^{\circ} \mathrm{C}\right)\end{array}$ & $\mathbf{5 5 0}\left({ }^{\circ} \mathrm{C}\right)$ & $\mathbf{7 0 0}\left({ }^{\circ} \mathrm{C}\right)$ & $\mathbf{7 5 0}\left({ }^{\circ} \mathrm{C}\right)$ & $\mathbf{8 0 0}\left({ }^{\circ} \mathrm{C}\right)$ \\
\hline Baseline & 1300 & 0.00 & -7.62 & -6.57 & -6.58 \\
\hline CoO $_{\mathbf{x}}($ Ink $)$ & 1300 & 0.00 & -7.40 & -6.79 & -6.79 \\
\hline
\end{tabular}

Table 32 Surface Exchange \% Increase/Decrease $-\operatorname{CoO}_{x}$-Ink $\left(\operatorname{Sint}=1300{ }^{\circ} \mathrm{C}\right)$

\begin{tabular}{cccccc}
\hline $\begin{array}{c}\text { Composition of } \\
\text { LSCF }\end{array}$ & $\begin{array}{c}\text { Sintering Temp. } \\
\left({ }^{\circ} \mathrm{C}\right)\end{array}$ & \multicolumn{4}{c}{$\begin{array}{c}\text { \% Increase/Decrease in Surface Exchange } \\
\text { Compared to Baseline }\end{array}$} \\
\cline { 3 - 6 } & & $\mathbf{6 5 0}\left({ }^{\circ} \mathrm{C}\right)$ & $\mathbf{7 0 0}\left({ }^{\circ} \mathrm{C}\right)$ & $\mathbf{7 5 0}\left({ }^{\circ} \mathrm{C}\right)$ & $\mathbf{8 0 0}\left({ }^{\circ} \mathrm{C}\right)$ \\
\hline $\mathrm{CoO}_{x}($ Ink $)$ & 1300 & - & $2.83 \%$ & $-3.35 \%$ & $-3.29 \%$ \\
\hline
\end{tabular}

In the previous table, there is percentage change of the surface exchange between the $\mathrm{CoO}_{x}$-ink coated and baseline samples with a sintering temperature of $1300{ }^{\circ} \mathrm{C}$. As mentioned above, there is not much improvement seen in the surface exchange of LSCF. The $\mathrm{CoO}_{x}$-ink coated samples have higher surface exchange than LSCF for $700{ }^{\circ} \mathrm{C}$ and lower surface exchange for temperatures 750 and $800{ }^{\circ} \mathrm{C}$. However, the difference between the surface exchanges does not exceed $4 \%$. Therefore, the reduced number of vacancies seen in samples with a sintering temperature of $1300^{\circ} \mathrm{C}$ is limiting the enhancement from the $\mathrm{CoO}_{x}$ coating.

Moreover, the characterization of the bulk diffusion coefficient was also performed for $\mathrm{CoO}_{x}$-ink coated samples and compared to baseline LSCF. The samples analyzed in this case are the same samples that were shown at the beginning of this section since the electrical conductivity relaxation method allows us to determine both oxygen transport kinetic properties simultaneously. The bulk diffusion coefficients obtained for $\mathrm{CoO}_{x}$-ink coated samples and baseline LSCF with sintering temperature of $1200^{\circ} \mathrm{C}$ were plotted in a $\ln (\mathrm{D})$ vs $1000 / \mathrm{T}$ graph as follows: 
Figure 27 Bulk Diffusion Coefficient vs Temperature $-\mathrm{CoO}_{x^{-}}$Ink (Sint $\left.=1200^{\circ} \mathrm{C}\right)$

In the previous figure, the $\ln (\mathrm{D})$ vs $1000 / \mathrm{T}$ was plotted for $\mathrm{CoO}_{\mathrm{x}}$-ink samples and baseline LSCF with sintering temperature of $1200^{\circ} \mathrm{C}$. It can be observed that the diffusion coefficient values seen for $\mathrm{CoO}_{x}$-ink do not follow the same trend that the baseline LSCF values do. This can be attributed to the uncertainty seen in the measurements for $\mathrm{CoO}_{\mathrm{x}}$-ink coated samples at high temperatures. However, the diffusion coefficient of the $\mathrm{CoO}_{x}$-ink samples seen for temperature $650^{\circ} \mathrm{C}$ is enhanced compared to the baseline one.

In the following table, the natural log of the diffusion coefficient values that were plotted are shown for $\mathrm{CoO}_{x}$-ink and baseline LSCF with sintering temperature of $1200^{\circ} \mathrm{C}$ :

Table 33 Bulk Diffusion Coefficient Values $-\mathrm{CoO}_{x}-\operatorname{Ink}\left(\operatorname{Sint}=1200^{\circ} \mathrm{C}\right)$

\begin{tabular}{cccccc}
\hline $\begin{array}{c}\text { Composition of } \\
\text { LSCF }\end{array}$ & $\begin{array}{c}\text { Sintering Temp. } \\
\left({ }^{\circ} \mathrm{C}\right)\end{array}$ & \multicolumn{4}{c}{$\operatorname{Ln}(\mathrm{D})(\mathbf{c m} 2 / \mathrm{s})$} \\
\cline { 3 - 6 } & 1200 & $\mathbf{6 5 0}\left({ }^{\circ} \mathrm{C}\right)$ & $\mathbf{7 0 0}\left({ }^{\circ} \mathrm{C}\right)$ & $\mathbf{7 5 0}\left({ }^{\circ} \mathrm{C}\right)$ & $\mathbf{8 0 0}\left({ }^{\circ} \mathbf{C}\right)$ \\
\hline Baseline & 1200 & -11.29 & -12.42 & -11.11 & -11.75 \\
\hline CoO $_{x}($ Ink $)$ & 12.99 & 0.00 & -11.57 & -11.23 \\
\hline
\end{tabular}


Table 34 Bulk Diffusion Coefficient \% Increase/Decrease $-\mathrm{CoO}_{x}-\operatorname{Ink}\left(\operatorname{Sin} t=1200{ }^{\circ} \mathrm{C}\right)$

\begin{tabular}{cccccc}
\hline $\begin{array}{c}\text { Composition of } \\
\text { LSCF }\end{array}$ & $\begin{array}{c}\text { Sintering Temp. } \\
\left({ }^{\circ} \mathrm{C}\right)\end{array}$ & \multicolumn{3}{c}{$\%$ Increase/Decrease in Diffusion Coefficient } \\
& & \multicolumn{3}{c}{ Compared to Baseline } \\
\cline { 2 - 6 } & 1200 & $\mathbf{6 5 0}\left({ }^{\circ} \mathrm{C}\right)$ & $\mathbf{7 0 0}\left({ }^{\circ} \mathrm{C}\right)$ & $\mathbf{7 5 0}\left({ }^{\circ} \mathrm{C}\right)$ & $\mathbf{8 0 0}\left({ }^{\circ} \mathrm{C}\right)$ \\
\hline $\mathrm{CoO}_{\mathrm{x}}($ Ink $)$ & $13.14 \%$ & - & $-4.14 \%$ & $4.47 \%$ \\
\hline
\end{tabular}

The diffusion coefficient of the $\mathrm{CoO}_{x}$-ink samples is enhanced when compared to the baseline LSCF samples. The enhancement is not large as it was seen in section 4.3 for $\mathrm{CoO}_{\mathrm{x}}-\mathrm{ALD}$ coated samples with a sintering temperature of $1200^{\circ} \mathrm{C}$. Furthermore, the $\mathrm{CoO}_{x}$-ink samples were also prepared, measured, and analyzed with a sintering temperature of $1300{ }^{\circ} \mathrm{C}$. The natural log of the diffusion coefficient versus the inverse of the temperature was plotted in the following graph and compared to baseline LSCF for samples with a sintering temperature of $1300^{\circ} \mathrm{C}$ :

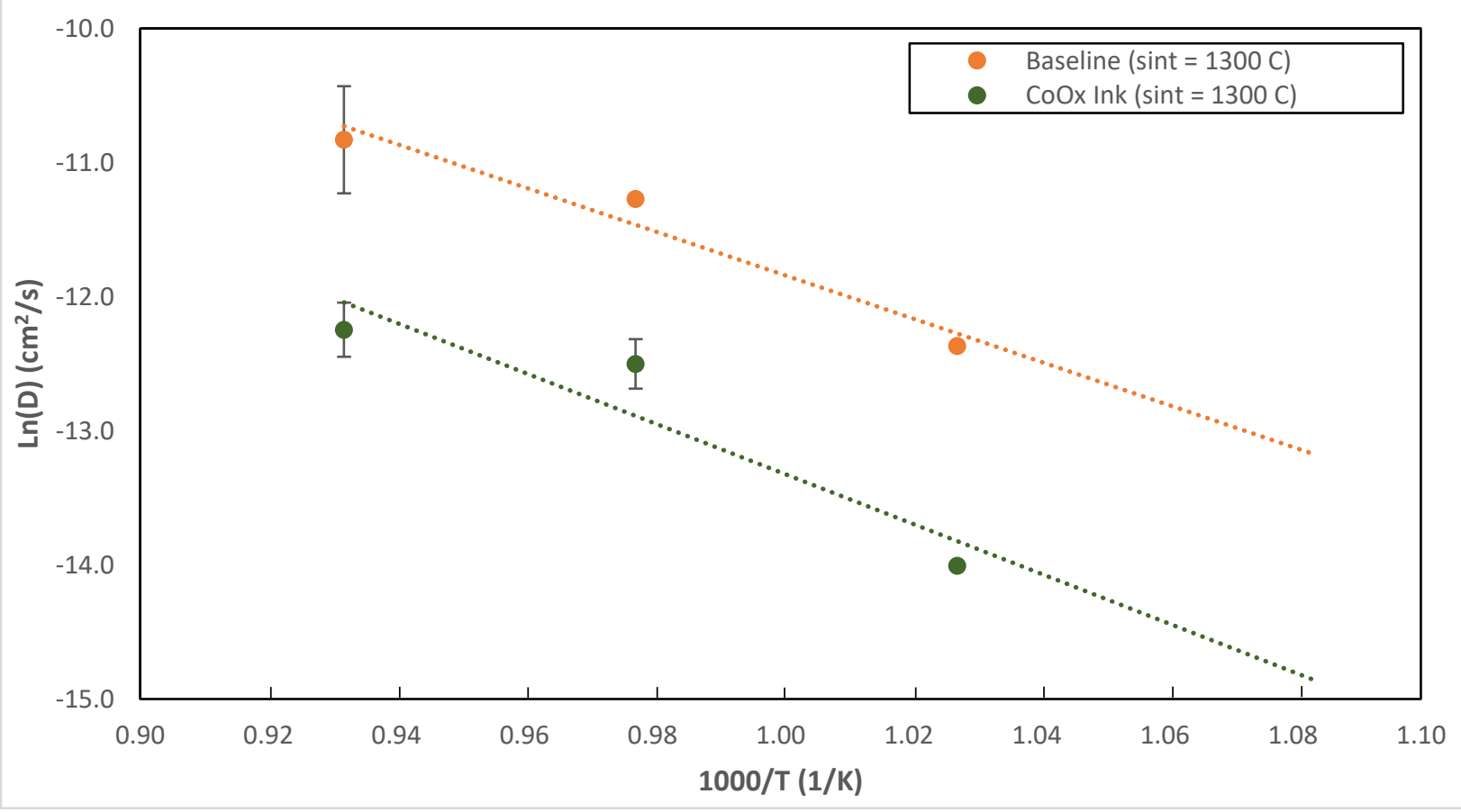

Figure 28 Bulk Diffusion Coefficient vs Temperature $-\mathrm{CoO}_{x}-\operatorname{lnk}\left(\operatorname{Sint}=1300{ }^{\circ} \mathrm{C}\right)$

In the previous figure, the $\ln (\mathrm{D})$ vs $1000 / T$ was plotted for $\mathrm{CoO}_{x}$-ink and baseline LSCF with sintering temperature of $1300^{\circ} \mathrm{C}$. The $\mathrm{CoO}_{x}$-ink and baseline LSCF samples follow the same trend where the diffusion coefficient increases as the temperature increases. However, the 
diffusion coefficient of the $\mathrm{CoO}_{\mathrm{x}}$-ink coated samples is reduced compared to the baseline LSCF. This agrees with the diffusion coefficient results seen for $\mathrm{CoO}_{x}-\mathrm{ALD}$ coated samples with a sintering temperature of $1300^{\circ} \mathrm{C}$ in section 4.3 .

In the following table, the natural log of the diffusion coefficient values that were plotted are shown for $\mathrm{CoO}_{x}$-ink and baseline LSCF with sintering temperature of $1300{ }^{\circ} \mathrm{C}$ :

Table 35 Bulk Diffusion Coefficient Values $-\mathrm{CoO}_{x}$-Ink (Sint $\left.=1300^{\circ} \mathrm{C}\right)$

\begin{tabular}{cccccc}
\hline $\begin{array}{c}\text { Composition of } \\
\text { LSCF }\end{array}$ & $\begin{array}{c}\text { Sintering Temp. } \\
\left({ }^{\circ} \mathrm{C}\right)\end{array}$ & \multicolumn{4}{c}{ Ln (D) (cm2/s) } \\
\cline { 3 - 6 } & 1300 & $\mathbf{6 5 0}\left({ }^{\circ} \mathrm{C}\right)$ & $\mathbf{7 0 0}\left({ }^{\circ} \mathrm{C}\right)$ & $\mathbf{7 5 0}\left({ }^{\circ} \mathrm{C}\right)$ & $\mathbf{8 0 0}\left({ }^{\circ} \mathrm{C}\right)$ \\
\hline Baseline & 1300 & 0.00 & -12.37 & -11.27 & -10.83 \\
\hline CoO $_{x}($ Ink $)$ & 0.00 & -14.01 & -12.50 & -12.25 \\
\hline
\end{tabular}

Table 36 Bulk Diffusion Coefficient \% Increase/Decrease $-\mathrm{CoO}_{x^{-}}$Ink (Sint $\left.=1300{ }^{\circ} \mathrm{C}\right)$

\begin{tabular}{cccccc}
\hline $\begin{array}{c}\text { Composition of } \\
\text { LSCF }\end{array}$ & $\begin{array}{c}\text { Sintering Temp. } \\
\left({ }^{\circ} \mathrm{C}\right)\end{array}$ & \multicolumn{3}{c}{$\%$ Increase/Decrease in Diffusion Coefficient } \\
& & $\mathbf{6 5 0}\left({ }^{\circ} \mathrm{C}\right)$ & $\mathbf{7 0 0}\left({ }^{\circ} \mathrm{C}\right)$ & $\mathbf{7 5 0}\left({ }^{\circ} \mathrm{C}\right)$ & $\mathbf{8 0 0}\left({ }^{\circ} \mathrm{C}\right)$ \\
\hline $\mathrm{CoO}_{\mathrm{x}}($ Ink $)$ & 1300 & - & $-13.27 \%$ & $-10.91 \%$ & $-13.08 \%$ \\
\hline
\end{tabular}

In the previous table, the percentage increase/decrease of the diffusion coefficient between the $\mathrm{CoO}_{\mathrm{x}}$-ink and baseline LSCF samples with a sintering temperature of $1300{ }^{\circ} \mathrm{C}$ is shown. The reduction seen for the $\mathrm{CoO}_{\mathrm{x}}$-ink coated samples compared to the baseline LSCF is significant; having a difference of $10 \%$ and higher. The reduction seen for the $\mathrm{CoO}_{\mathrm{x}}-\mathrm{ALD}$ coated samples with the same sintering temperature in section 4.3 is not as large; the difference there only reaches $10 \%$ at one temperature. Therefore, the ALD coating will not reduce the diffusion coefficient of LSCF as much as the ink coating.

\subsection{Effect of Ink $\mathrm{MnO}_{x}$ Coating on the Kinetic Properties of LSCF}

In section 5.4, the results obtained for the $\mathrm{MnO}_{\mathrm{x}}$-ink coated samples will be shown and discussed. The $\mathrm{MnO}_{\mathrm{x}}$-ink coating was added using the screen-printing machine as it was done before with the $\mathrm{CoO}_{x}$-ink samples in order to ensure a uniform layer throughout the whole LSCF sample. The $\mathrm{MnO}_{\mathrm{x}}$-ink coating samples were fabricated with sintering temperatures of 1200 and $1300{ }^{\circ} \mathrm{C}$. 
The list of samples that were analyzed using a $\mathrm{MnO}_{\mathrm{x}}$-ink coating and the abovementioned sintering temperatures is as follows:

Table $37 \mathrm{MnO}_{x^{-}}$Ink Coated LSCF Samples $\left(\right.$Sint $\left.=1200^{\circ} \mathrm{C}\right)$

\begin{tabular}{|c|c|c|c|c|c|c|c|}
\hline \multicolumn{8}{|c|}{ MnO2 Ink-Coated LSCF (sintering = 1200 C) } \\
\hline Sample & Temp. $\left({ }^{\circ} \mathrm{C}\right)$ & Temp. (K) & $1000 / \mathrm{T}(1 / \mathrm{K})$ & Surface Exchange $(\mathrm{k})(\mathrm{cm} / \mathrm{s})$ & Diffusion coefficient (D) $\left(\mathrm{cm}^{2} / \mathrm{s}\right)$ & $\ln (\mathbf{k})$ & $\ln (D)$ \\
\hline \multirow{2}{*}{95.2 ( $\mathrm{MnO} 2 \mathrm{Ink})$} & 750 & 1023.15 & 0.98 & $9.11 \mathrm{E}-04$ & $6.73 \mathrm{E}-06$ & -7.00 & -11.91 \\
\hline & 800 & 1073.15 & 0.93 & $1.13 \mathrm{E}-03$ & $7.94 \mathrm{E}-06$ & -6.78 & -11.74 \\
\hline \multirow{2}{*}{96.1 ( $\mathrm{MnO} 2 \mathrm{Ink})$} & 650 & 923.15 & 1.08 & $1.69 \mathrm{E}-04$ & 1.16E-06 & -8.68 & -13.66 \\
\hline & 700 & 973.15 & 1.03 & $1.00 \mathrm{E}-03$ & 1.75E-06 & -6.90 & -13.26 \\
\hline $96.2(\mathrm{MnO} 2 \mathrm{Ink})$ & 800 & 1073.15 & 0.93 & $3.88 \mathrm{E}-04$ & $2.59 \mathrm{E}-06$ & -7.85 & -12.87 \\
\hline \multirow{2}{*}{ 107.1 ( $\mathrm{MnO} 2$ Ink) } & 650 & 923.15 & 1.08 & $1.33 \mathrm{E}-04$ & $8.66 \mathrm{E}-07$ & -8.93 & -13.96 \\
\hline & 700 & 973.15 & 1.03 & $4.06 \mathrm{E}-04$ & $8.21 \mathrm{E}-07$ & -7.81 & -14.01 \\
\hline
\end{tabular}

Table $38 \mathrm{MnO}_{x}$-Ink Coated LSCF Samples $\left(\right.$ Sint $\left.=1300^{\circ} \mathrm{C}\right)$

\begin{tabular}{|c|c|c|c|c|c|c|c|}
\hline \multicolumn{8}{|c|}{ MnO2 Ink-Coated LSCF (sintering = $1300 \mathrm{C}$ ) } \\
\hline Sample & Temp. $\left({ }^{\circ} \mathrm{C}\right)$ & Temp. (K) & $1000 / \mathrm{T}(1 / \mathrm{K})$ & Surface Exchange $(\mathrm{k})(\mathrm{cm} / \mathrm{s})$ & Diffusion coefficient (D) $\left(\mathrm{cm}^{2} / \mathrm{s}\right)$ & $\ln (\mathbf{k})$ & $\ln (D)$ \\
\hline $77.1(\mathrm{MnO} 2 \mathrm{Ink})$ & 650 & 923.15 & 1.08 & $8.23 \mathrm{E}-04$ & $1.83 \mathrm{E}-06$ & -7.10 & -13.21 \\
\hline \multirow{2}{*}{78.2 ( $\mathrm{MnO} 2 \mathrm{Ink})$} & 750 & 1023.15 & 0.98 & $6.84 \mathrm{E}-04$ & $3.02 \mathrm{E}-06$ & -7.29 & -12.71 \\
\hline & 800 & 1073.15 & 0.93 & $5.51 \mathrm{E}-04$ & $5.77 \mathrm{E}-06$ & -7.50 & -12.06 \\
\hline 102.1 ( $\mathrm{MnO} 2$ Ink) & 800 & 1073.15 & 0.93 & $5.04 \mathrm{E}-04$ & $4.48 \mathrm{E}-06$ & -7.59 & -12.32 \\
\hline \multirow{4}{*}{102.2 (MnO2 Ink) } & 650 & 923.15 & 1.08 & $1.71 \mathrm{E}-04$ & $4.31 \mathrm{E}-07$ & -8.68 & -14.66 \\
\hline & 700 & 973.15 & 1.03 & $8.46 \mathrm{E}-05$ & $8.54 \mathrm{E}-07$ & -9.38 & -13.97 \\
\hline & 750 & 1023.15 & 0.98 & $1.93 \mathrm{E}-04$ & $1.86 \mathrm{E}-06$ & -8.55 & -13.20 \\
\hline & 800 & 1073.15 & 0.93 & $1.02 \mathrm{E}-04$ & $2.34 \mathrm{E}-06$ & -9.19 & -12.96 \\
\hline \multirow{4}{*}{103.1 (MnO2 Ink) } & 650 & 923.15 & 1.08 & $1.71 \mathrm{E}-04$ & $4.31 \mathrm{E}-07$ & -8.68 & -14.66 \\
\hline & 700 & 973.15 & 1.03 & $8.46 \mathrm{E}-05$ & $8.54 \mathrm{E}-07$ & -9.38 & -13.97 \\
\hline & 750 & 1023.15 & 0.98 & $1.93 \mathrm{E}-04$ & $1.86 \mathrm{E}-06$ & -8.55 & -13.20 \\
\hline & 800 & 1073.15 & 0.93 & 1.02E-04 & $2.34 \mathrm{E}-06$ & -9.19 & -12.96 \\
\hline \multirow{2}{*}{103.2 (MnO2 Ink) } & 650 & 923.15 & 1.08 & 1.69E-04 & $2.49 \mathrm{E}-07$ & -8.69 & -15.20 \\
\hline & 700 & 973.15 & 1.03 & $1.24 \mathrm{E}-04$ & $6.05 \mathrm{E}-07$ & -9.00 & -14.32 \\
\hline \multirow{3}{*}{104.1 (MnO2 Ink) } & 650 & 923.15 & 1.08 & $3.48 \mathrm{E}-04$ & $1.33 \mathrm{E}-06$ & -7.96 & -13.53 \\
\hline & 750 & 1023.15 & 0.98 & $3.91 \mathrm{E}-04$ & $2.52 \mathrm{E}-06$ & -7.85 & -12.89 \\
\hline & 800 & 1073.15 & 0.93 & $4.15 \mathrm{E}-04$ & $4.53 \mathrm{E}-06$ & -7.79 & -12.31 \\
\hline
\end{tabular}

The previous tables show the list of samples that were tested with a $\mathrm{MnO}_{\mathrm{x}}$-ink coating on their surface and sintering temperatures of $1200{ }^{\circ} \mathrm{C}$ and $1300{ }^{\circ} \mathrm{C}$. The tables show the temperatures that the samples were tested for as well as the kinetic properties that were obtained for each sample at each given temperature. The surface exchange coefficients obtained from the $\mathrm{MnO}_{x}$-ink coated samples were plotted in a $\ln (\mathrm{k})$ vs $1000 / \mathrm{T}$ graph along the LSCF baseline with the same sintering temperature as follows: 


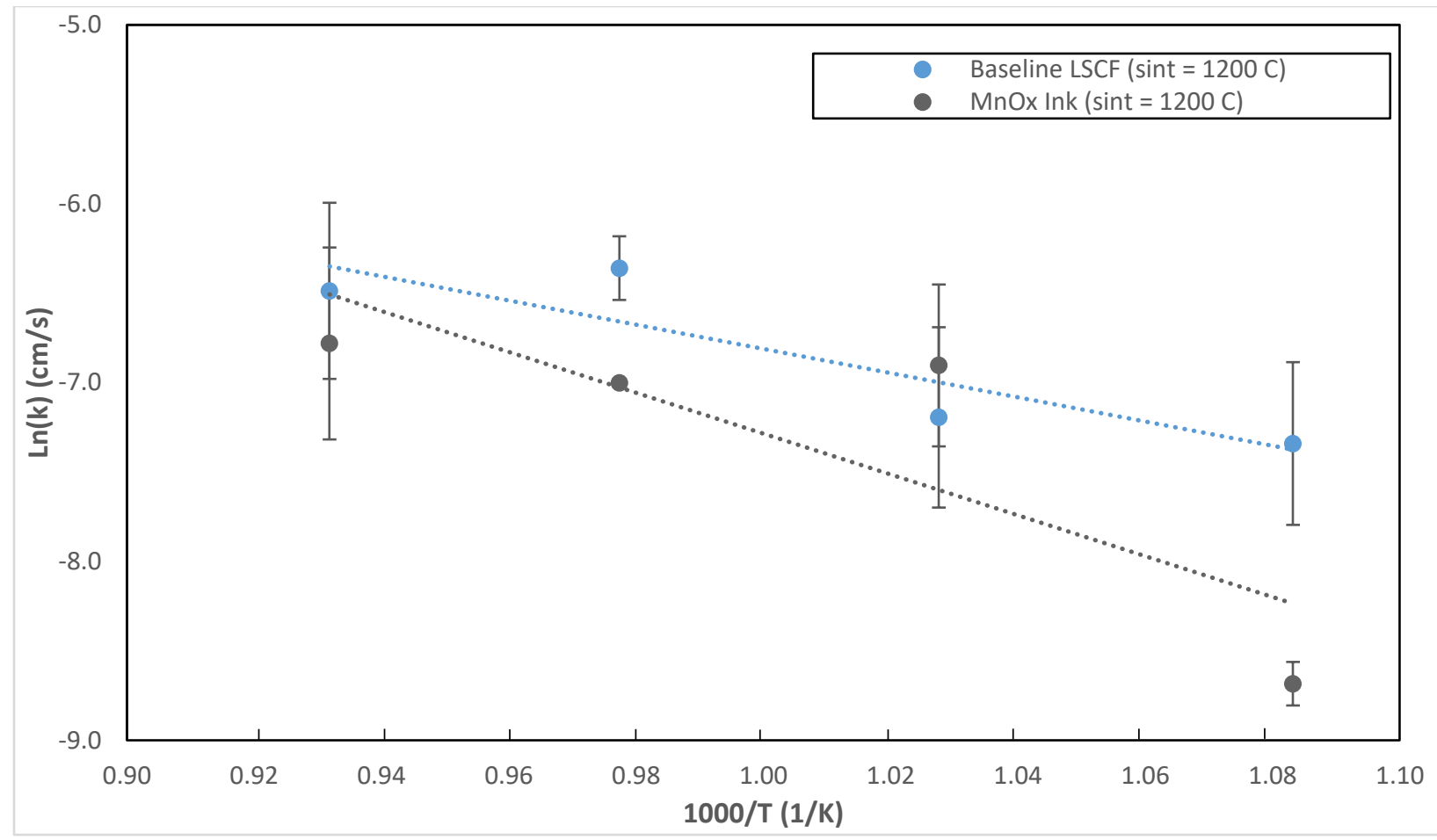

Figure 29 Surface Exchange vs Temperature $-\mathrm{MnO}_{x^{-}}$Ink (Sint $\left.=1200^{\circ} \mathrm{C}\right)$

In the previous figure, the $\ln (\mathrm{k})$ vs $1000 / \mathrm{T}$ graph was plotted for $\mathrm{MnO}_{\mathrm{x}}$-ink coated, and baseline LSCF sintered at $1200^{\circ} \mathrm{C}$. It is observed that the $\mathrm{MnO}_{\mathrm{x}}$-ink coated and baseline LSCF follow the same trend, the surface exchange increases as the temperature increases. However, the surface exchange seen for $\mathrm{MnO}_{\mathrm{x}}$-ink coated samples is reduced compared to the baseline. The natural log surface exchange values that were graphed for the surface exchange vs temperature graph for $\mathrm{MnO}_{\mathrm{x}}$-ink coated and baseline LSCF with sintering temperature of 1200 ${ }^{\circ} \mathrm{C}$ are shown in the following table for each temperature:

Table 39 Surface Exchange Values $-\mathrm{MnO}_{x}-\operatorname{lnk}\left(\operatorname{Sin} t=1200^{\circ} \mathrm{C}\right)$

\begin{tabular}{cccccc}
\hline $\begin{array}{c}\text { Composition of } \\
\text { LSCF }\end{array}$ & $\begin{array}{c}\text { Sintering Temp. } \\
\left.\mathbf{(}^{\circ} \mathbf{C}\right)\end{array}$ & \multicolumn{4}{c}{ Ln (k) $(\mathbf{c m} / \mathbf{s})$} \\
\cline { 2 - 6 } & 1200 & $\mathbf{6 5 0}\left({ }^{\circ} \mathrm{C}\right)$ & $\mathbf{7 0 0}\left({ }^{\circ} \mathbf{C}\right)$ & $\mathbf{7 5 0}\left({ }^{\circ} \mathbf{C}\right)$ & $\mathbf{8 0 0}\left({ }^{\circ} \mathbf{C}\right)$ \\
\hline Baseline & 1200 & -7.34 & -7.19 & -6.36 & -6.49 \\
\hline $\mathbf{M n O}_{\mathbf{x}}$ (Ink) & -8.68 & -6.90 & -7.00 & -6.78 \\
\hline
\end{tabular}


Table 40 Surface Exchange \% Increase/Decrease $-\mathrm{MnO}_{x}$-Ink $\left(\operatorname{Sint}=1200^{\circ} \mathrm{C}\right)$

\begin{tabular}{cccccc}
\hline $\begin{array}{c}\text { Composition of } \\
\text { LSCF }\end{array}$ & $\begin{array}{c}\text { Sintering Temp. } \\
\left({ }^{\circ} \mathrm{C}\right)\end{array}$ & \multicolumn{4}{c}{$\%$ Increase/Decrease in Surface Exchange } \\
& & $\mathbf{6 5 0}\left({ }^{\circ} \mathrm{C}\right)$ & $\mathbf{7 0 0}\left({ }^{\circ} \mathrm{C}\right)$ & $\mathbf{7 5 0}\left({ }^{\circ} \mathrm{C}\right)$ & $\mathbf{8 0 0}\left({ }^{\circ} \mathrm{C}\right)$ \\
\hline $\mathrm{MnO}_{\mathbf{x}}($ Ink) & 1200 & $-18.29 \%$ & $4.04 \%$ & $-10.08 \%$ & $-4.54 \%$ \\
\hline
\end{tabular}

In the previous table, the percentage increase/decrease of the surface exchange between the $\mathrm{MnO}_{\mathrm{x}}$-ink coated and baseline samples with a sintering temperature of $1200{ }^{\circ} \mathrm{C}$ is shown. The percentage decreased in surface exchange caused by this coating is significant compared to the baseline LSCF. The surface exchange is reduced greatly at low temperatures. However, the surface exchange difference between the coated and non-coated LSCF is less pronounced as the temperature increases. For temperature $700{ }^{\circ} \mathrm{C}$, the surface exchange measured for $\mathrm{MnO}_{x}$-ink coated samples is significantly higher compared to the rest of the values seen for the coated samples. The reduction seen in the surface exchange of $\mathrm{MnO}_{\mathrm{x}}$-ink coated samples can be attributed to a lower electrical conductivity of the $\mathrm{Mn}\left(6.2^{*} 10^{6} \mathrm{~S} / \mathrm{m}\right)$ in comparison to the electrical conductivity that is seen in Co $\left(1.7 * 10^{7} \mathrm{~S} / \mathrm{m}\right)$.

Furthermore, the $\mathrm{MnO}_{x}$-ink samples were also prepared, measured, and analyzed with a sintering temperature of $1300^{\circ} \mathrm{C}$. The natural log of the surface exchange versus the inverse of the temperature was plotted in the following graph and compared to baseline LSCF for samples with a sintering temperature of $1300^{\circ} \mathrm{C}$ : 


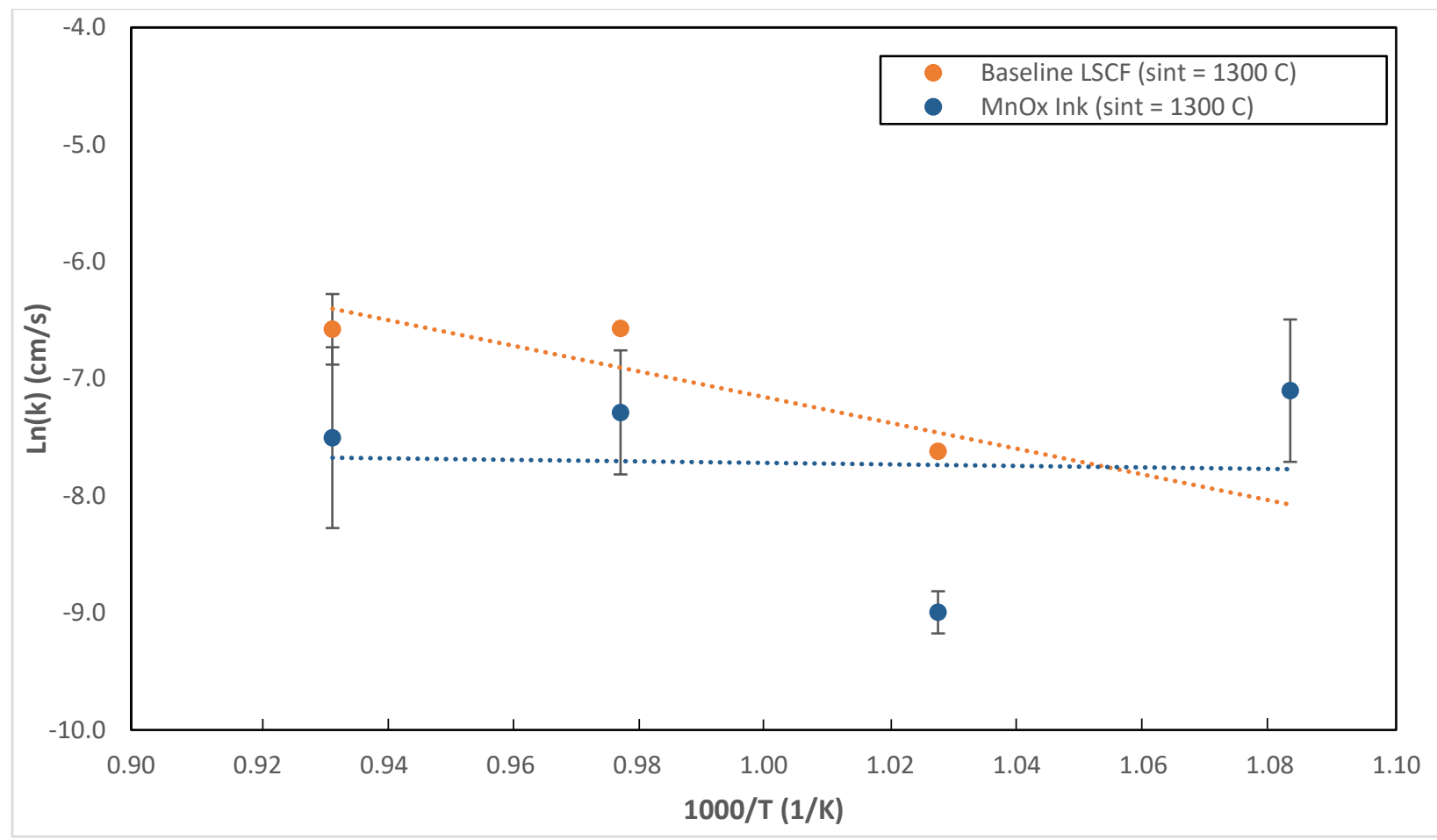

Figure 30 Surface Exchange vs Temperature $-\mathrm{MnO}_{x^{-}}$Ink (Sint $=1300^{\circ} \mathrm{C}$ )

The graph above shows the surface exchange of the $\mathrm{MnO}_{\mathrm{x}}$-ink coated samples compared to the LSCF baseline samples with a sintering temperature of $1300{ }^{\circ} \mathrm{C}$. As well as the samples with the sintering temperature of $1200^{\circ} \mathrm{C}$ this coating does not enhance the surface exchange of LSCF with sintering temperature of $1300^{\circ} \mathrm{C}$. However, the reduction seen in the surface exchange caused by the $\mathrm{MnO}_{\mathrm{x}}$-ink coating with a sintering temperature of $1300^{\circ} \mathrm{C}$ is not as pronounced as the one seen previously in this chapter.

The natural log surface exchange values that were graphed for the surface exchange vs temperature graph for $\mathrm{MnO}_{\mathrm{x}}$-ink coated and baseline LSCF with sintering temperature of 1300 ${ }^{\circ} \mathrm{C}$ are shown in the following table for each temperature:

Table 41 Surface Exchange Values $-\mathrm{MnO}_{x}-\operatorname{Ink}\left(\operatorname{Sint}=1300{ }^{\circ} \mathrm{C}\right)$

\begin{tabular}{cccccc}
\hline $\begin{array}{c}\text { Composition of } \\
\text { LSCF }\end{array}$ & $\begin{array}{c}\text { Sintering Temp. } \\
\left({ }^{\circ} \mathrm{C}\right)\end{array}$ & $\mathbf{6 5 0}\left({ }^{\circ} \mathrm{C}\right)$ & $\mathbf{7 0 0}\left({ }^{\circ} \mathrm{C}\right)$ & $\mathbf{7 5 0}\left({ }^{\circ} \mathrm{C}\right)$ & $\mathbf{8 0 0}\left({ }^{\circ} \mathrm{C}\right)$ \\
\hline Baseline & 1300 & 0.00 & -7.62 & -6.57 & -6.58 \\
\hline MnO $_{\mathbf{x}}$ (Ink) & 1300 & -7.10 & -9.00 & -7.29 & -7.50 \\
\hline
\end{tabular}


Table 42 Surface Exchange \% Increase/Decrease $-\mathrm{MnO}_{x}-\operatorname{Ink}\left(\operatorname{Sint}=1300{ }^{\circ} \mathrm{C}\right)$

\begin{tabular}{cccccc}
\hline $\begin{array}{c}\text { Composition of } \\
\text { LSCF }\end{array}$ & $\begin{array}{c}\text { Sintering Temp. } \\
\left({ }^{\circ} \mathrm{C}\right)\end{array}$ & \multicolumn{4}{c}{$\%$ Increase/Decrease in Surface Exchange } \\
& & \multicolumn{4}{c}{ Compared to Baseline } \\
\cline { 3 - 6 } & & $\mathbf{6 5 0}\left({ }^{\circ} \mathrm{C}\right)$ & $\mathbf{7 0 0}\left({ }^{\circ} \mathrm{C}\right)$ & $\mathbf{7 5 0}\left({ }^{\circ} \mathrm{C}\right)$ & $\mathbf{8 0 0}\left({ }^{\circ} \mathrm{C}\right)$ \\
\hline $\mathrm{MnO}_{\mathbf{x}}$ (Ink) & 1300 & - & $-18.05 \%$ & $-10.92 \%$ & $-14.06 \%$ \\
\hline
\end{tabular}

As mentioned before, the surface exchange of $\mathrm{MnO}_{\mathrm{x}}$-ink samples is reduced compared to baseline LSCF. The reduction seen in the $\mathrm{MnO}_{\mathrm{x}}$-ink coated samples with sintering temperature of $1300{ }^{\circ} \mathrm{C}$ is above $10 \%$ for all the temperatures. This is attributed to the smaller number of vacancies that are seen in higher sintering temperature samples. Moreover, the characterization of the bulk diffusion coefficient was also performed for $\mathrm{MnO}_{\mathrm{x}}$-ink coated samples and compared to baseline LSCF. The samples analyzed in this case are the same samples that were shown at the beginning of this section since the electrical conductivity relaxation method allows us to determine both oxygen transport kinetic properties simultaneously. The bulk diffusion coefficients obtained for $\mathrm{MnO}_{x}$-ink coated samples and baseline LSCF with sintering temperature of $1200{ }^{\circ} \mathrm{C}$ were plotted in a $\ln (\mathrm{D})$ vs $1000 / \mathrm{T}$ graph as follows: 


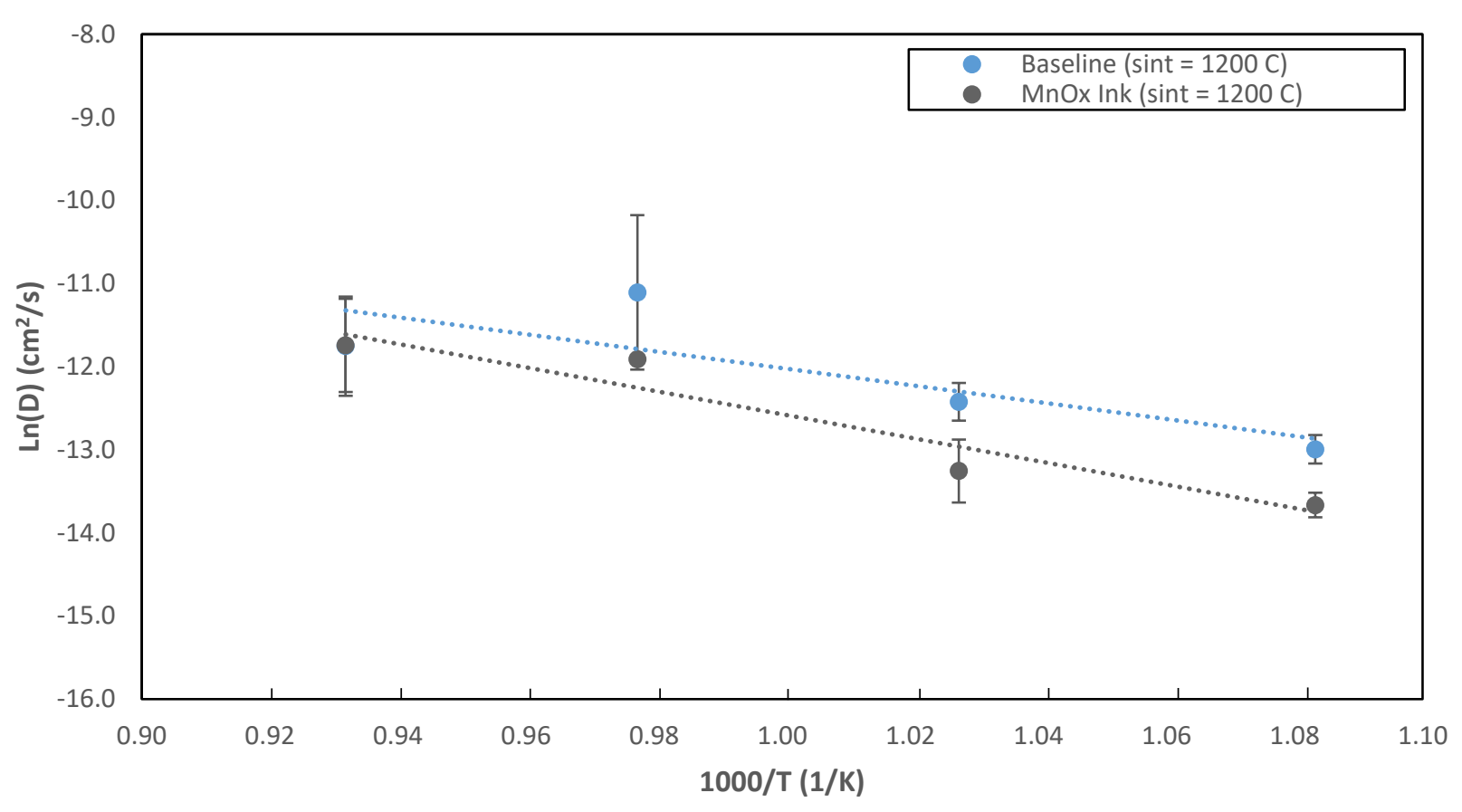

Figure 31 Bulk Diffusion Coefficient vs Temperature $-\mathrm{MnO}_{x^{-}}-\operatorname{Ink}\left(\operatorname{Sint}=1200^{\circ} \mathrm{C}\right)$

In the previous figure, the $\ln (\mathrm{D})$ vs $1000 / \mathrm{T}$ was plotted for $\mathrm{MnO}_{\mathrm{x}}$-ink samples and baseline LSCF with sintering temperature of $1200{ }^{\circ} \mathrm{C}$. The $\mathrm{MnO}_{\mathrm{x}}$-ink coated, and baseline LSCF samples follow the same trend, where the diffusion coefficient increases as the temperature increases. There is a reduction in the diffusion coefficient of LSCF when it is coated with $\mathrm{MnO}_{\mathrm{x}^{-}}$ ink. In the following table, the natural log of the diffusion coefficient values that were plotted are shown for $\mathrm{MnO}_{\mathrm{x}}$-ink and baseline LSCF with sintering temperature of $1200^{\circ} \mathrm{C}$ :

Table 43 Bulk Diffusion Coefficient Values $-\mathrm{MnO}_{x^{-}} \operatorname{lnk}\left(\operatorname{Sint}=1200{ }^{\circ} \mathrm{C}\right)$

\begin{tabular}{cccccc}
\hline $\begin{array}{c}\text { Composition of } \\
\text { LSCF }\end{array}$ & $\begin{array}{c}\text { Sintering Temp. } \\
\left({ }^{\circ} \mathrm{C}\right)\end{array}$ & $\mathbf{6 5 0}\left({ }^{\circ} \mathrm{C}\right)$ & $\mathbf{7 0 0}\left({ }^{\circ} \mathrm{C}\right)$ & $\mathbf{7 5 0}\left({ }^{\circ} \mathrm{C}\right)$ & $\mathbf{8 0 0}\left({ }^{\circ} \mathrm{C}\right)$ \\
\hline Baseline & 1200 & -12.99 & -12.42 & -11.11 & -11.75 \\
\hline $\mathbf{M n O}_{\mathbf{x}}$ (Ink) & 1200 & -13.66 & -13.26 & -11.91 & -11.74 \\
\hline
\end{tabular}

Table 44 Bulk Diffusion Coefficient \% Increase/Decrease $-\mathrm{MnO}_{x^{-}}$Ink (Sint $=1200^{\circ} \mathrm{C}$ )

\begin{tabular}{|c|c|c|c|c|c|}
\hline \multirow[t]{2}{*}{$\begin{array}{l}\text { Composition of } \\
\text { LSCF }\end{array}$} & \multirow[t]{2}{*}{$\begin{array}{l}\text { Sintering Temp. } \\
\left({ }^{\circ} \mathrm{C}\right)\end{array}$} & \multicolumn{4}{|c|}{$\begin{array}{c}\text { \% Increase/Decrease in Diffusion Coefficient } \\
\text { Compared to Baseline }\end{array}$} \\
\hline & & $650\left({ }^{\circ} \mathrm{C}\right)$ & $700\left({ }^{\circ} \mathrm{C}\right)$ & $750\left({ }^{\circ} \mathrm{C}\right)$ & $800\left({ }^{\circ} \mathrm{C}\right)$ \\
\hline
\end{tabular}




\begin{tabular}{|llllll|}
$\mathbf{M n O}_{\mathbf{x}}($ Ink) & 1200 & $-5.16 \%$ & $-6.71 \%$ & $-7.23 \%$ & $0.08 \%$ \\
\hline
\end{tabular}

There is a reduction of about $6 \%$ in the diffusion coefficient of the $\mathrm{MnO}_{\mathrm{x}}$-ink coated samples when compared to the baseline. Furthermore, the $\mathrm{MnO}_{\mathrm{x}}$-ink samples were also prepared, measured, and analyzed with a sintering temperature of $1300{ }^{\circ} \mathrm{C}$. The natural log of the diffusion coefficient versus the inverse of the temperature was plotted in the following graph and compared to baseline LSCF for samples with a sintering temperature of $130{ }^{\circ} \mathrm{C}$ :

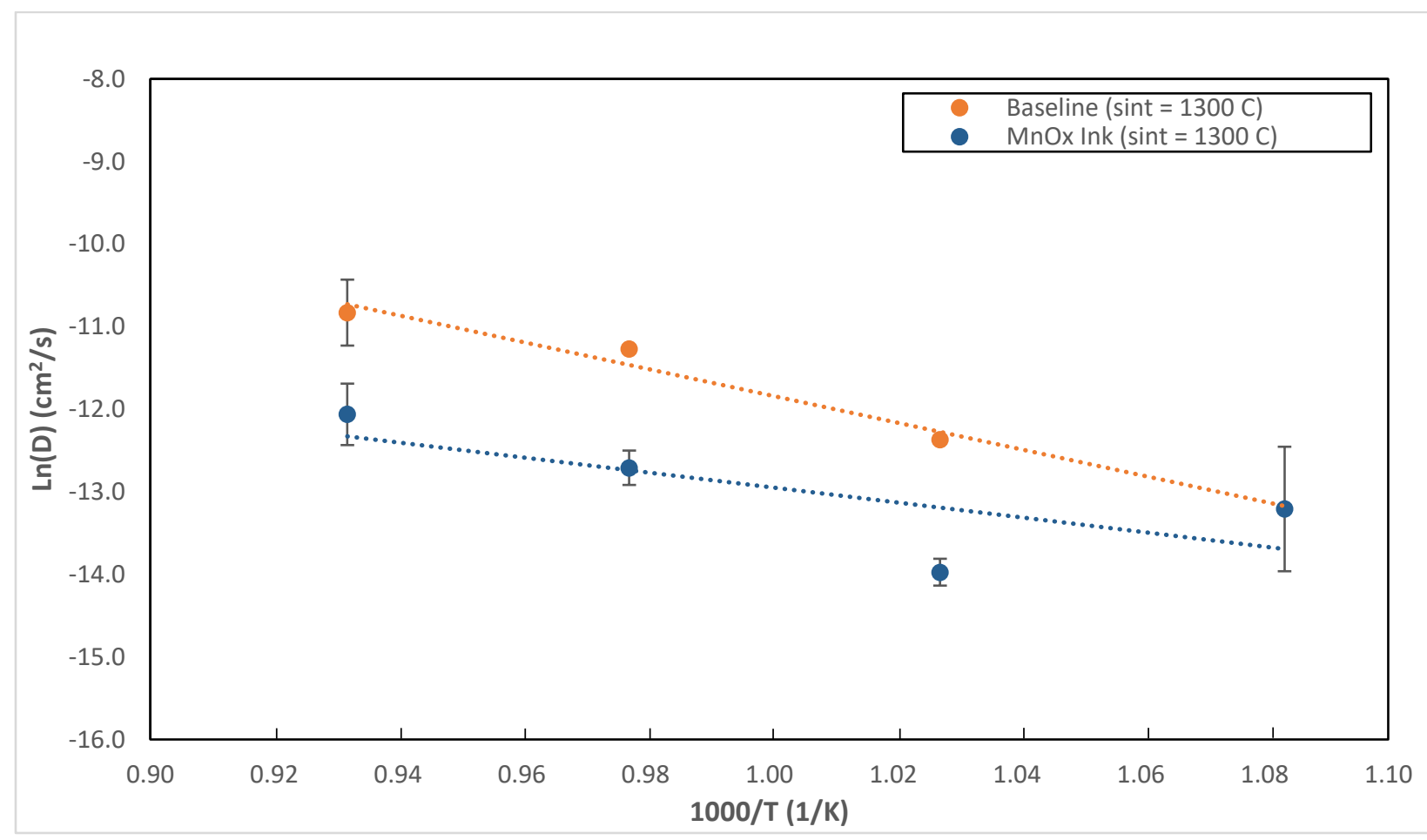

Figure 32 Bulk Diffusion Coefficient vs Temperature $-\mathrm{MnO}_{x}-\operatorname{Ink}\left(\operatorname{Sint}=1300^{\circ} \mathrm{C}\right)$

In the previous figure, the $\ln (\mathrm{D})$ vs $1000 / \mathrm{T}$ was plotted for $\mathrm{MnO}_{\mathrm{x}}$-ink and baseline LSCF with sintering temperature of $1300{ }^{\circ} \mathrm{C}$. As it was seen above with the lower sintering temperature samples, the diffusion coefficient is reduced for the $\mathrm{MnO}_{\mathrm{x}}$-ink coated samples when compared to the baseline. It can be observed in this graph that the reduction of the diffusion coefficient of the higher sintering temperature samples with the $\mathrm{MnO}_{\mathrm{x}}$-ink coating is more pronounced as it is expected for higher sintering temperature samples. In the following table, the natural log of the diffusion coefficient values that were plotted are shown for $\mathrm{MnO}_{\mathrm{x}}$ ink and baseline LSCF with sintering temperature of $1300^{\circ} \mathrm{C}$ : 
Table 45 Bulk Diffusion Coefficient Values $-\mathrm{MnO}_{x}-\operatorname{lnk}\left(\operatorname{Sint}=1300^{\circ} \mathrm{C}\right)$

\begin{tabular}{cccccc}
\hline $\begin{array}{c}\text { Composition of } \\
\text { LSCF }\end{array}$ & $\begin{array}{c}\text { Sintering Temp. } \\
\left({ }^{\circ} \mathrm{C}\right)\end{array}$ & $\mathbf{6 5 0}\left({ }^{\circ} \mathrm{C}\right)$ & $\mathbf{7 0 0}\left({ }^{\circ} \mathrm{C}\right)$ & $\mathbf{7 5 0}\left({ }^{\circ} \mathrm{C}\right)$ & $\mathbf{8 0 0}\left({ }^{\circ} \mathrm{C}\right)$ \\
\hline Baseline & 1300 & 0.00 & -12.37 & -11.27 & -10.83 \\
\hline MnO $_{\mathbf{x}}($ Ink $)$ & 1300 & -13.21 & -13.97 & -12.71 & -12.06 \\
\hline
\end{tabular}

Table 46 Bulk Diffusion Coefficient \% Increase/Decrease $-\mathrm{MnO}_{x}$ Ink (Sint $\left.=1300{ }^{\circ} \mathrm{C}\right)$

\begin{tabular}{cccccc}
\hline $\begin{array}{c}\text { Composition of } \\
\text { LSCF }\end{array}$ & $\begin{array}{c}\text { Sintering Temp. } \\
\left({ }^{\circ} \mathrm{C}\right)\end{array}$ & \multicolumn{3}{c}{$\%$ Increase/Decrease in Diffusion Coefficient } \\
& & $\mathbf{6 0 m p}\left({ }^{\circ} \mathrm{C}\right)$ & $\mathbf{7 0 0}\left({ }^{\circ} \mathrm{C}\right)$ & $\mathbf{7 5 0}\left({ }^{\circ} \mathrm{C}\right)$ & $\mathbf{8 0 0}\left({ }^{\circ} \mathrm{C}\right)$ \\
\cline { 3 - 6 } & 1300 & - & $-13.00 \%$ & $-12.76 \%$ & $-11.38 \%$ \\
\hline $\mathbf{M n O}_{\mathrm{x}}$ (Ink) & & &
\end{tabular}

In the previous table, the percentage increase/decrease of the diffusion coefficient between the $\mathrm{MnO}_{\mathrm{x}}$-ink and baseline LSCF samples with a sintering temperature of $1300{ }^{\circ} \mathrm{C}$ is shown. The reduction seen for $\mathrm{MnO}_{x}$-ink coated samples with sintering temperature of $1300^{\circ} \mathrm{C}$ is above $10 \%$ for all the temperatures, meanwhile for the samples with sintering temperature of $1200{ }^{\circ} \mathrm{C}$ is not larger than $7 \%$. Therefore, as it is expected for higher sintering temperature samples, the reduction produced on their diffusion coefficient value is larger due to the fewer number of vacancies found in them.

\subsection{Effect of Ink $\mathrm{Pr}_{2} \mathrm{O}_{x}$ Coating on the Kinetic Properties of LSCF}

The $\operatorname{Pr}_{2} \mathrm{O}_{x}$-ink coating was added using the screen-printing machine that was used for the two previous coatings to ensure a uniform layer throughout the whole LSCF sample. The $\mathrm{Pr}_{2} \mathrm{O}_{\mathrm{x}}$-ink coating samples were fabricated with sintering temperatures of 1200 and $130{ }^{\circ} \mathrm{C}$. The list of samples that were analyzed using a $\mathrm{Pr}_{2} \mathrm{O}_{x}$-ink coating and the above-mentioned sintering temperatures is as follows:

Table $47 \mathrm{Pr}_{2} \mathrm{O}_{x}$-Ink Coated LSCF Samples $\left(\right.$ Sint $\left.=1200^{\circ} \mathrm{C}\right)$

\begin{tabular}{|c|c|c|c|c|c|c|c|}
\hline \multicolumn{2}{|c|}{ Pr203 Ink-Coated LSCF (sintering = 1200 C) } \\
\hline Sample & Temp. $\left({ }^{\circ} \mathbf{C}\right)$ & Temp. (K) & $\mathbf{1 0 0 0 / T ~ ( 1 / K ) ~}$ & Surface Exchange (k) (cm/s) & Diffusion coefficient (D) $\left(\mathbf{c m}^{2} / \mathbf{s}\right)$ & $\operatorname{In}(\mathbf{k})$ & $\operatorname{In}(\mathbf{D})$ \\
\hline \multirow{2}{*}{97.1 (Pr2O3 Ink) } & 650 & 923.15 & 1.08 & $2.10 \mathrm{E}-04$ & $2.39 \mathrm{E}-06$ & -8.47 & -12.94 \\
\cline { 2 - 8 } & 700 & 973.15 & 1.03 & $8.77 \mathrm{E}-04$ & $2.40 \mathrm{E}-06$ & -7.04 & -12.94 \\
\hline 97.2 (Pr2O3 Ink) & 750 & 1023.15 & 0.98 & $4.37 \mathrm{E}-04$ & $9.27 \mathrm{E}-06$ & -7.74 & -11.59 \\
\hline 98.1 (Pr2O3 Ink) & 650 & 923.15 & 1.08 & $2.80 \mathrm{E}-04$ & $2.29 \mathrm{E}-06$ & -8.18 & -12.99 \\
\hline \multirow{2}{*}{98.2 (Pr2O3 Ink) } & 750 & 1023.15 & 0.98 & $7.01 \mathrm{E}-04$ & $3.85 \mathrm{E}-06$ & -7.26 & -12.47 \\
\cline { 2 - 8 } & 800 & 1073.15 & 0.93 & $5.80 \mathrm{E}-04$ & $7.24 \mathrm{E}-06$ & -7.45 & -11.84 \\
\hline
\end{tabular}


Table $48 \mathrm{Pr}_{2} \mathrm{O}_{x}$-Ink Coated LSCF Samples $\left(\right.$ Sint $\left.=1300^{\circ} \mathrm{C}\right)$

\begin{tabular}{|c|c|c|c|c|c|c|c|}
\hline \multicolumn{8}{|c|}{ Pr203 Ink-Coated LSCF (sintering = 1300 C) } \\
\hline Sample & Temp. $\left({ }^{\circ} \mathrm{C}\right)$ & Temp. (K) & $1000 / \mathrm{T}(1 / \mathrm{K})$ & Surface Exchange $(\mathrm{k})(\mathrm{cm} / \mathrm{s})$ & Diffusion coefficient (D) $\left(\mathrm{cm}^{2} / \mathrm{s}\right)$ & $\ln (\mathbf{k})$ & $\ln (D)$ \\
\hline 79.1 (Pr2O3 Ink) & 700 & 973.15 & 1.03 & $6.18 \mathrm{E}-04$ & $2.42 \mathrm{E}-06$ & -7.39 & -12.93 \\
\hline \multirow{2}{*}{79.2 (Pr2O3 Ink) } & 750 & 1023.15 & 0.98 & $6.00 \mathrm{E}-04$ & $5.14 \mathrm{E}-06$ & -7.42 & -12.18 \\
\hline & 800 & 1073.15 & 0.93 & $1.08 \mathrm{E}-03$ & 5.30E-06 & -6.83 & -12.15 \\
\hline \multirow{2}{*}{80.1 (Pr2O3 Ink) } & 650 & 923.15 & 1.08 & $4.78 \mathrm{E}-04$ & $2.17 E-06$ & -7.65 & -13.04 \\
\hline & 700 & 973.15 & 1.03 & $8.73 \mathrm{E}-04$ & $2.79 \mathrm{E}-06$ & -7.04 & -12.79 \\
\hline \multirow{2}{*}{80.2 (Pr2O3 Ink) } & 750 & 1023.15 & 0.98 & $1.14 \mathrm{E}-03$ & $4.23 \mathrm{E}-06$ & -6.78 & -12.37 \\
\hline & 800 & 1073.15 & 0.93 & $2.38 \mathrm{E}-03$ & $5.61 \mathrm{E}-06$ & -6.04 & -12.09 \\
\hline
\end{tabular}

The previous tables show the list of samples that were tested with a $\operatorname{Pr}_{2} \mathrm{O}_{\mathrm{x}}$-ink coating on their surface and sintering temperatures of $1200^{\circ} \mathrm{C}$ and $1300^{\circ} \mathrm{C}$. The tables show the temperatures that the samples were tested for as well as the kinetic properties that were obtained for each sample at each given temperature. The surface exchange coefficients obtained from the $\mathrm{Pr}_{2} \mathrm{O}_{\mathrm{x}}$-ink coated samples were plotted in a $\ln (\mathrm{k})$ vs 1000/T graph along the LSCF baseline with the same sintering temperature as follows:

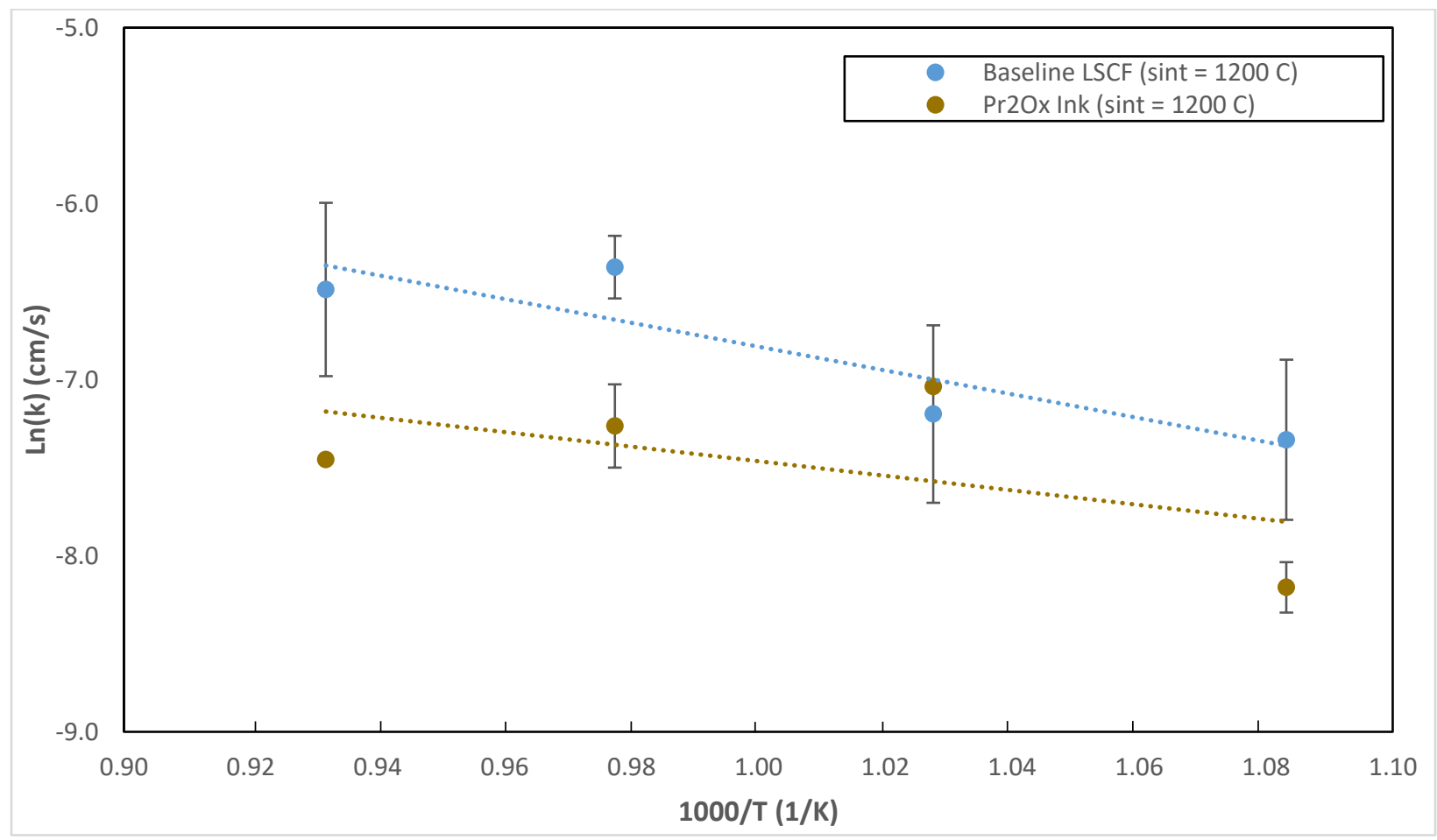

Figure 33 Surface Exchange vs Temperature $-\mathrm{Pr}_{2} \mathrm{O}_{x}-\operatorname{Ink}\left(\operatorname{Sint}=1200^{\circ} \mathrm{C}\right)$

In the previous figure, the $\ln (k)$ vs 1000/T graph was plotted for $\operatorname{Pr}_{2} \mathrm{O}_{\mathrm{x}}$-ink coated and baseline LSCF sintered at $1200^{\circ} \mathrm{C}$. The $\mathrm{Pr}_{2} \mathrm{O}_{\mathrm{x}}$-ink coating reduces the surface exchange of LSCF 
by almost an order of magnitude. The natural log surface exchange values that were graphed for the surface exchange vs temperature graph for $\mathrm{Pr}_{2} \mathrm{O}_{\mathrm{x}}$-ink coated and baseline LSCF with sintering temperature of $1200{ }^{\circ} \mathrm{C}$ are shown in the following table for each temperature:

\section{Table 49 Surface Exchange Values $-\operatorname{Pr}_{2} \mathrm{O}_{x}-\operatorname{Ink}\left(\operatorname{Sint}=1200{ }^{\circ} \mathrm{C}\right)$}

\begin{tabular}{cccccc}
\hline $\begin{array}{c}\text { Composition of } \\
\text { LSCF }\end{array}$ & $\begin{array}{c}\text { Sintering Temp. } \\
\left({ }^{\circ} \mathbf{C}\right)\end{array}$ & \multicolumn{4}{c}{ Ln (k) (cm/s) } \\
\cline { 3 - 6 } & 1200 & $\mathbf{6 5 0}\left({ }^{\circ} \mathbf{C}\right)$ & $\mathbf{7 0 0}\left({ }^{\circ} \mathbf{C}\right)$ & $\mathbf{7 5 0}\left({ }^{\circ} \mathbf{C}\right)$ & $\mathbf{8 0 0}\left({ }^{\circ} \mathbf{C}\right)$ \\
\hline Baseline & 1200 & -7.34 & -7.19 & -6.36 & -6.49 \\
\hline Pr2O $_{\mathbf{x}}$ (Ink) & 1200 & -7.04 & -7.26 & -7.45 \\
\hline
\end{tabular}

Table 50 Surface Exchange \% Increase/Decrease - $\operatorname{Pr}_{2} \mathrm{O}_{x}$-Ink $\left(\operatorname{Sint}=1200^{\circ} \mathrm{C}\right)$

\begin{tabular}{cccccc}
\hline $\begin{array}{c}\text { Composition of } \\
\text { LSCF }\end{array}$ & $\begin{array}{c}\text { Sintering Temp. } \\
\left({ }^{\circ} \mathrm{C}\right)\end{array}$ & \multicolumn{3}{c}{$\%$ Increase/Decrease in Surface Exchange } \\
& & \multicolumn{4}{c}{ Compared to Baseline } \\
\cline { 3 - 6 } & 1200 & $-11.42 \%$ & $2.16 \%$ & $-14.19 \%$ & $-14.88 \%$ \\
\hline Pr2O $_{\mathrm{x}}$ (Ink) & $1200\left({ }^{\circ} \mathrm{C}\right)$ & $\mathbf{7 0 0}$ & $\mathbf{7 5 0}\left({ }^{\circ} \mathrm{C}\right)$ & $\mathbf{8 0 0}\left({ }^{\circ} \mathrm{C}\right)$ \\
\hline
\end{tabular}

The percentage decrease in surface exchange of the $\mathrm{Pr}_{2} \mathrm{O}_{\mathrm{x}}$-ink coated samples is above $10 \%$ for all the temperatures except for $700{ }^{\circ} \mathrm{C}$. On temperature $700{ }^{\circ} \mathrm{C}$ the surface exchange seen for $\mathrm{Pr}_{2} \mathrm{O}_{\mathrm{x}}$-ink coating is larger when compared to the rest of measurements. This can be attributed to a larger number of vacancies found in that sample. Furthermore, the $\operatorname{Pr}_{2} \mathrm{O}_{\mathrm{x}}$-ink samples were also prepared, measured and analyzed with a sintering temperature of $1300{ }^{\circ} \mathrm{C}$. The natural log of the surface exchange versus the inverse of the temperature was plotted in the following graph and compared to baseline LSCF for samples with sintering temperature of $1300^{\circ} \mathrm{C}$ : 


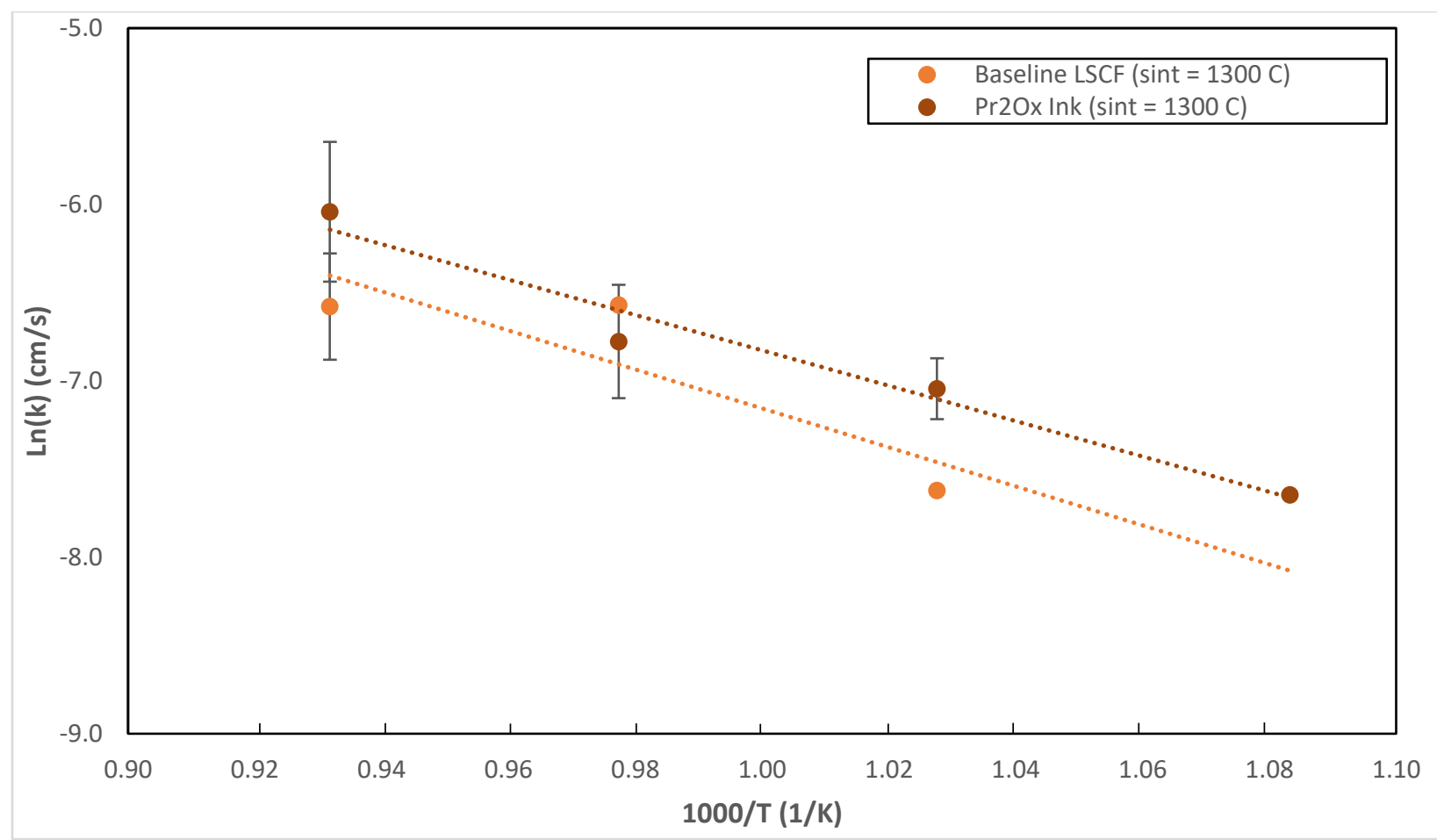

Figure 34 Surface Exchange vs Temperature $-\operatorname{Pr}_{2} \mathrm{O}_{x}-\operatorname{Ink}\left(\operatorname{Sint}=1300{ }^{\circ} \mathrm{C}\right)$

The graph above shows the surface exchange of the $\operatorname{Pr}_{2} \mathrm{O}_{x}$-ink coated samples compared to the LSCF baseline samples with a sintering temperature of $1300^{\circ} \mathrm{C}$. In contrast with all the results seen before, the $\mathrm{Pr}_{2} \mathrm{O}_{\mathrm{x}}$-ink coated samples with a sintering temperature of $1300{ }^{\circ} \mathrm{C}$ have a higher surface exchange rate than the baseline ones with the same sintering temperature. The natural log surface exchange values that were graphed for the surface exchange vs temperature graph for $\operatorname{Pr}_{2} \mathrm{O}_{x}$-ink coated and baseline LSCF with sintering temperature of 1300 ${ }^{\circ} \mathrm{C}$ are shown in the following table for each temperature:

\section{Table 51 Surface Exchange Values $-\mathrm{Pr}_{2} \mathrm{O}_{x}-\operatorname{Ink}\left(\operatorname{Sint}=1300{ }^{\circ} \mathrm{C}\right)$}

\begin{tabular}{cccccc}
\hline $\begin{array}{c}\text { Composition of } \\
\text { LSCF }\end{array}$ & $\begin{array}{c}\text { Sintering Temp. } \\
\left({ }^{\circ} \mathbf{C}\right)\end{array}$ & \multicolumn{4}{c}{ Ln (k) (cm/s) } \\
\cline { 3 - 6 } & 1300 & $\mathbf{6 5 0}\left({ }^{\circ} \mathbf{C}\right)$ & $\mathbf{7 0 0}\left({ }^{\circ} \mathbf{C}\right)$ & $\mathbf{7 5 0}\left({ }^{\circ} \mathbf{C}\right)$ & $\mathbf{8 0 0}\left({ }^{\circ} \mathbf{C}\right)$ \\
\hline Baseline & 13.00 & -7.62 & -6.57 & -6.58 \\
\hline Pr2O $_{\mathbf{x}}$ (Ink) & 1300 & -7.65 & -7.04 & -6.78 & -6.04 \\
\hline
\end{tabular}

Table 52 Surface Exchange \% Increase/Decrease $-\operatorname{Pr}_{2} \mathrm{O}_{x}-\operatorname{Ink}\left(\operatorname{Sint}=1200^{\circ} \mathrm{C}\right)$

$\begin{array}{ccc}\begin{array}{c}\text { Composition of } \\ \text { LSCF }\end{array} & \begin{array}{c}\text { Sintering Temp. } \\ \left({ }^{\circ} \mathrm{C}\right)\end{array} & \begin{array}{c}\text { \% Increase/Decrease in Surface Exchange } \\ \text { Compared to Baseline }\end{array}\end{array}$




\begin{tabular}{cccccc}
\hline & & $650\left({ }^{\circ} \mathrm{C}\right)$ & $\mathbf{7 0 0}\left({ }^{\circ} \mathrm{C}\right)$ & $\mathbf{7 5 0}\left({ }^{\circ} \mathrm{C}\right)$ & $800\left({ }^{\circ} \mathrm{C}\right)$ \\
\hline Pr2O $_{x}$ (Ink) & 1300 & - & $7.56 \%$ & $-3.14 \%$ & $8.17 \%$ \\
\hline
\end{tabular}

The $\operatorname{Pr}_{2} \mathrm{O}_{x}$-ink coated samples exhibit a higher surface exchange compared to the baseline. The difference between the surface exchange values is above $7 \%$ except for the results seen at $750{ }^{\circ} \mathrm{C}$ where the result seen for $\mathrm{Pr}_{2} \mathrm{O}_{\mathrm{x}}$-ink sample does not follow the trend the other results follow. Moreover, the characterization of the bulk diffusion coefficient was also performed for $\mathrm{Pr}_{2} \mathrm{O}_{x}$-ink coated samples and compared to baseline LSCF. The samples analyzed in this case are the same samples that were shown at the beginning of this section, since the electrical conductivity relaxation method allows to determine both oxygen transport kinetic properties simultaneously. The bulk diffusion coefficients obtained for $\operatorname{Pr}_{2} \mathrm{O}_{x}$-ink coated samples and baseline LSCF with sintering temperature of $1200^{\circ} \mathrm{C}$ were plotted in a $\ln (\mathrm{D}) \mathrm{vs} 1000 / \mathrm{T}$ graph as follows:

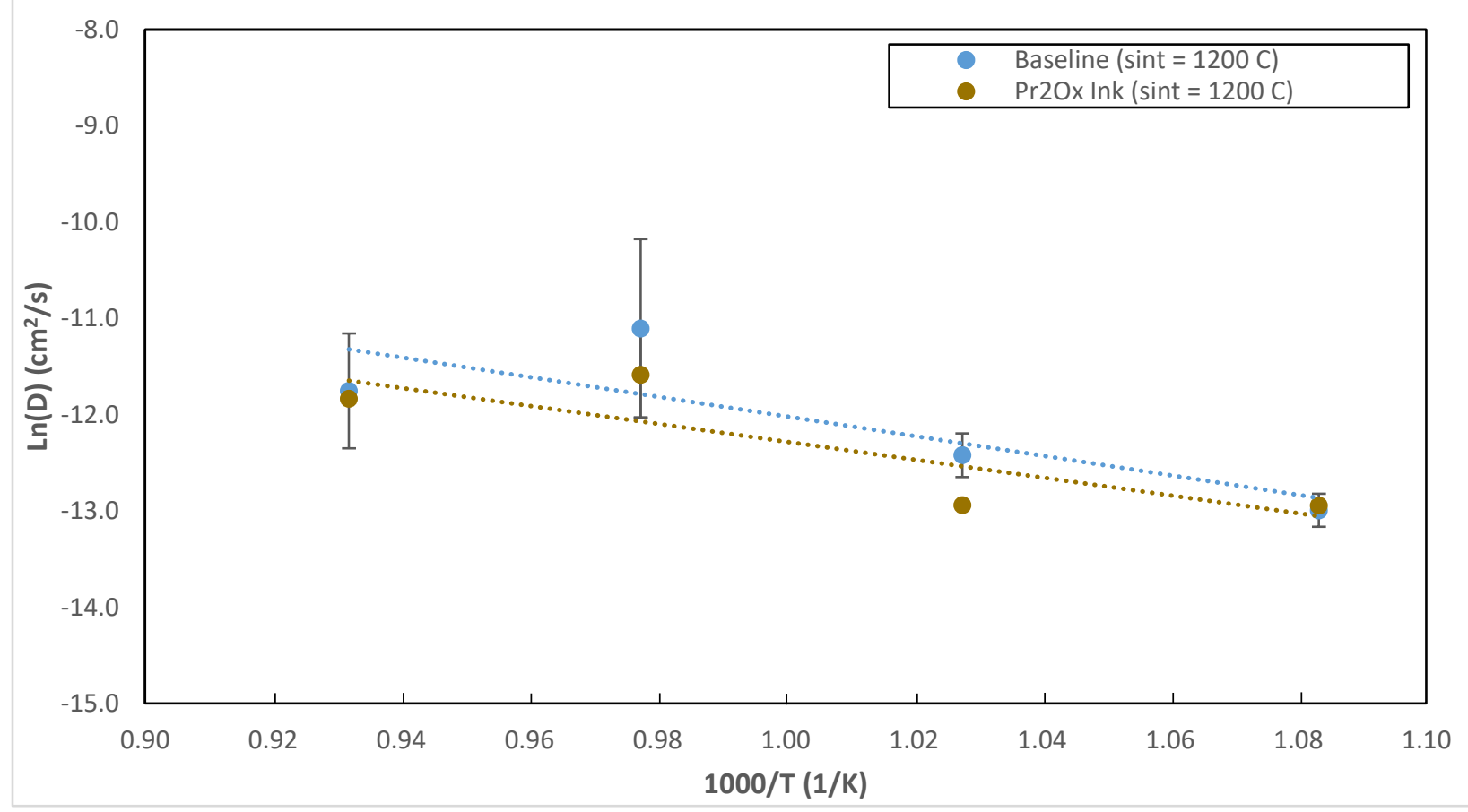

Figure 35 Bulk Diffusion Coefficient vs Temperature $-\mathrm{Pr}_{2} \mathrm{O}_{x}-\operatorname{lnk}\left(\operatorname{Sint}=1200{ }^{\circ} \mathrm{C}\right)$

In the previous figure, the $\ln (\mathrm{D})$ vs $1000 / T$ was plotted for $\mathrm{Pr}_{2} \mathrm{O}_{\mathrm{x}}$-ink samples and baseline LSCF with sintering temperature of $1200{ }^{\circ} \mathrm{C}$. The coated and non-coated samples 
follow the same trend. However, the diffusion coefficient of the coated samples is reduced when compared to the baseline one. In the following table, the natural log of the diffusion coefficient values that were plotted are shown for $\operatorname{Pr}_{2} \mathrm{O}_{x}$-ink and baseline LSCF with sintering temperature of $1200^{\circ} \mathrm{C}$ :

Table 53 Bulk Diffusion Coefficient Values $-\mathrm{Pr}_{2} \mathrm{O}_{x}-\operatorname{Ink}\left(\operatorname{Sint}=1200^{\circ} \mathrm{C}\right)$

\begin{tabular}{cccccc}
\hline $\begin{array}{c}\text { Composition of } \\
\text { LSCF }\end{array}$ & $\begin{array}{c}\text { Sintering Temp. } \\
\left({ }^{\circ} \mathrm{C}\right)\end{array}$ & $\mathbf{6 5 0}\left({ }^{\circ} \mathrm{C}\right)$ & $\mathbf{7 0 0}\left({ }^{\circ} \mathrm{C}\right)$ & $\mathbf{7 5 0}\left({ }^{\circ} \mathrm{C}\right)$ & $\mathbf{8 0 0}\left({ }^{\circ} \mathrm{C}\right)$ \\
\hline Baseline & 1200 & -12.99 & -12.42 & -11.11 & -11.75 \\
\hline Pr2O $_{\mathbf{x}}($ Ink $)$ & 1200 & -12.94 & -12.94 & -11.59 & -11.84 \\
\hline
\end{tabular}

Table 54 Bulk Diffusion Coefficient \% Increase/Decrease $-\operatorname{Pr}_{2} \mathrm{O}_{x}-$ Ink (Sint $\left.=1200{ }^{\circ} \mathrm{C}\right)$

\begin{tabular}{cccccc}
\hline $\begin{array}{c}\text { Composition of } \\
\text { LSCF }\end{array}$ & $\begin{array}{c}\text { Sintering Temp. } \\
\left({ }^{\circ} \mathrm{C}\right)\end{array}$ & \multicolumn{3}{c}{$\begin{array}{c}\% \text { Increase/Decrease in Diffusion Coefficient } \\
\text { Compared to Baseline }\end{array}$} \\
\cline { 3 - 6 } & & $\mathbf{6 5 0}\left({ }^{\circ} \mathrm{C}\right)$ & $\mathbf{7 0 0}\left({ }^{\circ} \mathrm{C}\right)$ & $\mathbf{7 5 0}\left({ }^{\circ} \mathrm{C}\right)$ & $\mathbf{8 0 0}\left({ }^{\circ} \mathbf{C}\right)$ \\
\hline Pr2O $_{\mathbf{x}}$ (Ink) & 1200 & $0.38 \%$ & $-4.18 \%$ & $-4.35 \%$ & $-0.70 \%$ \\
\hline
\end{tabular}

In the previous table, the percentage increase/decrease of the diffusion coefficient between the $\operatorname{Pr}_{2} \mathrm{O}_{x}$-ink and baseline LSCF samples with a sintering temperature of $1200{ }^{\circ} \mathrm{C}$ is shown. The reduction seen for the $\operatorname{Pr}_{2} \mathrm{O}_{\mathrm{x}}$-ink coated samples when compared to the baseline with a sintering temperature of $1200{ }^{\circ} \mathrm{C}$ is not larger than $4 \%$. The reduction can be attributed to the electrical conductivity of $\operatorname{Pr}\left(1.4^{*} 10^{6} \mathrm{~S} / \mathrm{m}\right)$. Furthermore, the $\operatorname{Pr}_{2} \mathrm{O}_{\mathrm{x}}$-ink samples were also prepared, measured, and analyzed with a sintering temperature of $1300{ }^{\circ} \mathrm{C}$. The natural log of the diffusion coefficient versus the inverse of the temperature was plotted in the following graph and compared to baseline LSCF for samples with a sintering temperature of $1300^{\circ} \mathrm{C}$ : 


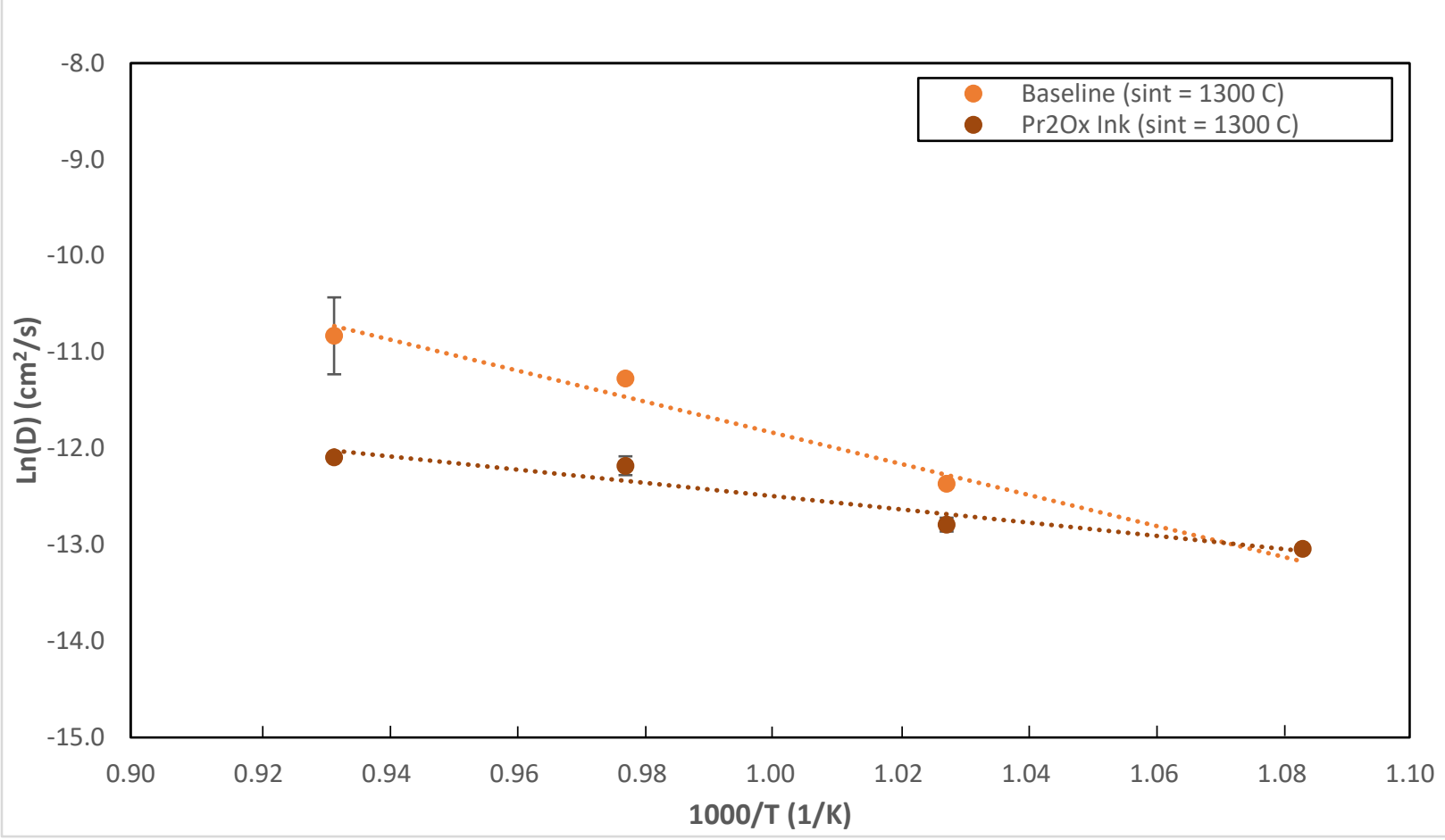

Figure 36 Bulk Diffusion Coefficient vs Temperature $-\mathrm{Pr}_{2} \mathrm{O}_{x}-\operatorname{Ink}\left(\operatorname{Sint}=1300{ }^{\circ} \mathrm{C}\right)$

In the previous figure, the $\ln (\mathrm{D})$ vs $1000 / \mathrm{T}$ was plotted for $\mathrm{Pr}_{2} \mathrm{O}_{\mathrm{x}}$-ink and baseline LSCF with sintering temperature of $1300^{\circ} \mathrm{C}$. The coated and non-coated samples follow the same trend where the diffusion coefficient increases as the temperature increases. There is a reduction in the diffusion coefficient of the $\mathrm{Pr}_{2} \mathrm{O}_{x}$-ink coated samples in comparison to the baseline samples. In the following table, the natural log of the diffusion coefficient values that were plotted are shown for $\mathrm{Pr}_{2} \mathrm{O}_{\mathrm{x}}$-ink and baseline LSCF with sintering temperature of $130{ }^{\circ} \mathrm{C}$ :

Table 55 Bulk Diffusion Coefficient Values $-\mathrm{Pr}_{2} \mathrm{O}_{x}-\operatorname{Ink}\left(\operatorname{Sint}=1300^{\circ} \mathrm{C}\right)$

\begin{tabular}{cccccc}
\hline $\begin{array}{c}\text { Composition of } \\
\text { LSCF }\end{array}$ & $\begin{array}{c}\text { Sintering Temp. } \\
\left({ }^{\circ} \mathrm{C}\right)\end{array}$ & \multicolumn{4}{c}{ Ln (D) (cm2/s) } \\
\cline { 3 - 6 } & 1300 & $\mathbf{6 5 0}\left({ }^{\circ} \mathrm{C}\right)$ & $\mathbf{7 0 0}\left({ }^{\circ} \mathrm{C}\right)$ & $\mathbf{7 5 0}\left({ }^{\circ} \mathrm{C}\right)$ & $\mathbf{8 0 0}\left({ }^{\circ} \mathrm{C}\right)$ \\
\hline Baseline & 1300 & -13.04 & -12.37 & -11.27 & -10.83 \\
\hline Pr2O $_{x}($ Ink & 130.79 & -12.18 & -12.09 \\
\hline
\end{tabular}

Table 56 Bulk Diffusion Coefficient \% Increase/Decrease $-\mathrm{Pr}_{2} \mathrm{O}_{x}-\operatorname{Ink}\left(\operatorname{Sint}=1300{ }^{\circ} \mathrm{C}\right)$

\begin{tabular}{cccccc}
\hline $\begin{array}{c}\text { Composition of } \\
\text { LSCF }\end{array}$ & $\begin{array}{c}\text { Sintering Temp. } \\
\left({ }^{\circ} \mathrm{C}\right)\end{array}$ & \multicolumn{3}{c}{$\%$ Increase/Decrease in Diffusion Coefficient } \\
& & \multicolumn{4}{c}{ Compared to Baseline } \\
\cline { 2 - 6 } & & $650\left({ }^{\circ} \mathrm{C}\right)$ & $700\left({ }^{\circ} \mathrm{C}\right)$ & $750\left({ }^{\circ} \mathrm{C}\right)$ & $800\left({ }^{\circ} \mathrm{C}\right)$ \\
\hline
\end{tabular}




$\begin{array}{llllll}\operatorname{Pr}_{\mathrm{x}}(\text { Ink) } & 1300 & - & -3.43 \% & -8.05 \% & -11.65 \%\end{array}$

As seen before for the lower sintering temperature samples, there is a reduction in the diffusion coefficient of the $\operatorname{Pr}_{2} \mathrm{O}_{x}$-ink samples when compared to the baseline samples. The reduction, in this case, is larger, and reaching $11 \%$ for a temperature of $800{ }^{\circ} \mathrm{C}$. This reduction is due to the fewer number of vacancies seen in higher sintering temperature samples.

\subsection{Summary of Ink Coated LSCF Results}

The characterization of $\mathrm{CoO}_{x}$-ink, $\mathrm{MnO}_{x}$-ink, and $\mathrm{Pr}_{2} \mathrm{O}_{\mathrm{x}}$-ink coated LSCF was performed for pellets with sintering temperatures of 1200 and $1300{ }^{\circ} \mathrm{C}$. It was observed that the addition of $\mathrm{CoO}_{x}$-ink coating enhances the surface exchange and diffusion coefficient of LSCF for samples with a sintering temperature of $1200^{\circ} \mathrm{C}$. This agrees with the $\mathrm{CoO}_{x}-\mathrm{ALD}$ coated samples that were characterized in chapter 4 . Samples with higher sintering temperature and a $\mathrm{CoO}_{\mathrm{x}}$-ink coating were observed to reduce the surface exchange and the diffusion coefficient of LSCF as it

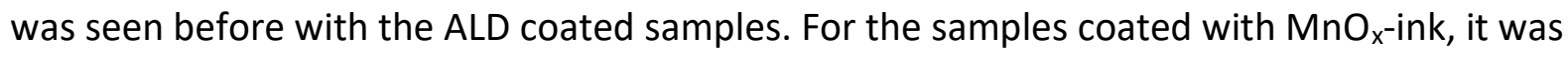
observed that the surface exchange and diffusion coefficient were reduced for samples with a sintering temperature of 1200 and $1300{ }^{\circ} \mathrm{C}$. However, for the higher sintering temperatures, the reduction was more pronounced. Lastly, the $\operatorname{Pr}_{2} \mathrm{O}_{\mathrm{x}}$-ink coated samples were observed to have a reduction in the surface exchange and diffusion coefficient for samples sintered at 1200 ${ }^{\circ} \mathrm{C}$. Unexpectedly, the samples with a sintering temperature of $1300{ }^{\circ} \mathrm{C}$ had a slightly enhanced surface exchange rate, but the diffusion coefficient was reduced as it was seen in all the previous coated samples with higher sintering temperature. 


\section{Chapter 6: Sources of Error, Conclusion and Future Work}

\subsection{Sources of Errors for ECR}

The ECR is an experiment that measures the conductance of MIEC materials after performing a step pressure change in the oxygen that is flowing around the sample. That conductance is then normalized and fit into a solution of Fick's second law, which allows determining the surface exchange coefficient and bulk diffusion coefficient of the MIEC simultaneously. The sources of error in this experiment encompass the sample fabrication process, and the experimental procedure using the ECR ${ }^{71}$. The sample fabrication process is the most complex part since it takes many steps and can easily lead to uncertainty. During the pressing process, the sample needs to be pressed axially; otherwise, the surface will not be smooth as it is assumed during the analysis. The sintering can potentially lead to contamination in the sample by adding a second phase material into the sample. The cutting can add cracks to the sample and, worse, the surface conditions that need to be smooth. The wiring is probably the biggest source of error during the fabrication process because the wires are assumed to be parallel to each other and fixed to the surface. However, when the wires are added to such a small sample is most likely that they will not be completely parallel. Additionally, the gold paste that was used to ensure the wires are well attached to the sample can contaminate the sample if the process is not done cautiously. Lastly, the vacancies found in each sample differ from one another. Since the vacancies are the transport mechanism in LSCF, having a different number of vacancies from sample to sample will create uncertainty.

The ECR experimental process can lead to errors due to the wiring. The wiring is the most important part because it is what is used to measure the values that will later be used to determine the kinetic properties of the sample. Improper wiring of the sample and attachment of the sample wires to the ECR wires can lead to noisy data that will lead to uncertainty. Also, it is important to ensure that the ECR circuit is well closed, and there are no gas leaks. Gas leaks will reduce the amount of gas that will circulate throughout the circuit, and the gas pressures will not comply with the desired pressures. After the experimental procedure is completed, the analysis can lead to errors due to the determination of both parameters $\mathrm{K}$ and $\mathrm{D}$ simultaneously ${ }^{72}$. Even though it is not completely reliable to determine both kinetic parameters 
simultaneously, it is possible to obtain a data trend from samples that are consistently fabricated using the same fabrication method.

\subsection{Conclusion}

This research project covered the oxygen transport kinetic properties characterization of baseline and surface modified LSCF. The Electrical Conductivity Relaxation method was used to determine both kinetic properties, surface exchange, and diffusion coefficient. Once the kinetic properties were characterized for baseline and surface modified LSCF, they were compared to each other to determine if the coating that was added would enhance any of the kinetic properties of the perovskite oxide.

The baseline characterization results showed that higher sintering temperatures will lead to the lower surface exchange rate for LSCF since the surface of higher sintering temperatures will have larger grain sizes. Since the grain size is larger for higher sintering temperature samples, the number of vacancies found in them will be reduced, and the oxygen ions will not be able to transport as fast across the surface of the perovskite oxide. However, the diffusion coefficient is not affected since both samples were pressed equally, and the bulk in them is similar. Therefore, the diffusion coefficient of baseline LSCF was not affected by the sintering temperature.

The atomic layer deposition characterization results showed that $\mathrm{CoO}_{x}$ would enhance the surface exchange of LSCF and slightly enhance the diffusion coefficient for lower sintering temperatures. For higher sintering temperatures, the $\mathrm{CoO}_{x}-\mathrm{ALD}$ coating will not enhance the surface exchange rate of LSCF and will worsen the diffusion coefficient of the perovskite oxide. However, the addition of $\mathrm{Pt}$ to the $\mathrm{CoO}_{x}$ coating will maintain the surface exchange coefficient of LSCF or improve it in the case of higher temperature samples compared to the $\mathrm{CoO}_{\mathrm{x}}$ coating alone. On the other hand, the diffusion coefficient will be reduced for lower temperature samples and will be enhanced for higher temperature samples due to the lower electrical conductivity of Pt.

The ink coating characterization results showed that $\mathrm{CoO}_{x}$ ink coating would agree with the results seen for $\mathrm{CoO}_{x}-A L D$ coating. The surface exchange will be enhanced for lower 
sintering temperature samples and will be unaffected for higher sintering temperatures. The diffusion coefficient will be slightly improved for lower sintering temperature samples and worsen for higher sintering temperature samples. The results seen for $\mathrm{MnO}_{\mathrm{x}}$-ink coating showed no enhancement neither for the surface exchange rate nor for the diffusion coefficient of the perovskite oxide. Lastly, the results seen for $\mathrm{Pr}_{2} \mathrm{O}_{\mathrm{x}}$ showed no improvement in the kinetic properties of lower temperature samples. However, for higher sintering temperature samples, there was an enhancement in the surface exchange due to lower electrical conductivity of $\mathrm{Pr}$ and a lower number of vacancies.

\subsection{Future Work}

This project encompassed the characterization of baseline LSCF and surface modified LSCF. The surface modifiers used were metal oxides with high electrical conductivity and ionic conductivity for oxygen. Such coated materials enhanced the absorption rate of oxygen ions from the air to the LSCF sample. However, the possible incorporation of ions from the coating layer into the LSCF impacts the ionic conductivity of both the coating layer and the the perovskite oxide matrix. The appropriate incorporation of those ions from the coating layer into the MIEC matrix is the most critical part because if the absorption rate of ions is enhanced, the number of vacancies will be alterted accordingly. Therefore, the surface modification and the resultant absorption rate and the transport mechanism of the MIEC need proper optimization to produce the highest enhancement possible in the oxygen transport kinetics of the LSCF. 


\section{References Cited}

\footnotetext{
${ }^{1}$ Adler, S. B. (2004). Factors governing oxygen reduction in solid oxide fuel cell cathodes. Chemical reviews, 104(10), 4791-4844.

${ }^{2}$ Yang, L., Wang, S., Blinn, K., Liu, M., Liu, Z., Cheng, Z., \& Liu, M. (2009). Enhanced sulfur and coking tolerance of a mixed ion conductor for SOFCs: BaZr0. 1Ce0. 7Y0. 2-xYbxO3-ס. Science, 326(5949), 126-129.

${ }^{3}$ Wachsman, E. D., \& Lee, K. T. (2011). Lowering the temperature of solid oxide fuel cells. Science, 334(6058), 935939.
}

${ }^{4}$ Singhal, S. C., \& Kendall, K. (Eds.). (2003). High-temperature solid oxide fuel cells: fundamentals, design and applications. Elsevier.

${ }^{5}$ Ding, D., Li, X., Lai, S. Y., Gerdes, K., \& Liu, M. (2014). Enhancing SOFC cathode performance by surface modification through infiltration. Energy \& Environmental Science, 7(2), 552-575.

${ }^{6}$ Gopal, C. B., \& Haile, S. M. (2014). An electrical conductivity relaxation study of oxygen transport in samarium doped ceria. Journal of Materials Chemistry A, 2(7), 2405-2417.

${ }^{7}$ Niedrig, C., Wagner, S. F., Menesklou, W., Baumann, S., \& Ivers-Tiffée, E. (2015). Oxygen equilibration kinetics of mixed-conducting perovskites BSCF, LSCF, and PSCF at $900 \mathrm{C}$ determined by electrical conductivity relaxation. Solid State lonics, 283, 30-37.

${ }^{8}$ Endler-Schuck, C., Joos, J., Niedrig, C., Weber, A., \& Ivers-Tiffée, E. (2015). The chemical oxygen surface exchange and bulk diffusion coefficient determined by impedance spectroscopy of porous La0. $58 \mathrm{SrO} .4 \mathrm{Co} 0.2 \mathrm{Fe} 0.803-\delta$ (LSCF) cathodes. Solid State lonics, 269, 67-79.

${ }^{9}$ Li, Y., Gerdes, K., Horita, T., \& Liu, X. (2013). Surface exchange and bulk diffusivity of LSCF as SOFC cathode: electrical conductivity relaxation and isotope exchange characterizations. Journal of the Electrochemical Society, 160(4), F343-F350.

${ }^{10}$ Boukamp, B. A. (2008). Electrochemical impedance spectroscopy. Nano-Electrocatalysis, U. Leiden, 24-28.

${ }^{11}$ Ballantine, Arne. Everything You Need to Know About Solid Oxide Fuel Cells. Bloom Energy. Mar. 2019. Available at: https://www.bloomenergy.com/blog/everything-you-need-know-about-solid-oxide-fuel-cells

${ }^{12}$ Dusastre, V., \& Kilner, J. A. (1999). Optimisation of composite cathodes for intermediate temperature SOFC applications. Solid state ionics, 126(1-2), 163-174.

${ }^{13}$ Wang, Y., Chen, K. S., Mishler, J., Cho, S. C., \& Adroher, X. C. (2011). A review of polymer electrolyte membrane fuel cells: Technology, applications, and needs on fundamental research. Applied energy, 88(4), 981-1007.

${ }^{14}$ Wasmus, S., \& Küver, A. (1999). Methanol oxidation and direct methanol fuel cells: a selective review. Journal of Electroanalytical Chemistry, 461(1-2), 14-31.

${ }^{15}$ Gülzow, E. (1996). Alkaline fuel cells: a critical view. Journal of Power Sources, 61(1-2), 99-104.

${ }^{16}$ Araya, S. S., Zhou, F., Liso, V., Sahlin, S. L., Vang, J. R., Thomas, S., ... \& Kær, S. K. (2016). A comprehensive review of PBI-based high temperature PEM fuel cells. International Journal of Hydrogen Energy, 41(46), 21310-21344. 
${ }^{17}$ Bischoff, M. (2006). Molten carbonate fuel cells: A high temperature fuel cell on the edge to commercialization. Journal of Power Sources, 160(2), 842-845.

${ }^{18}$ Types of Fuel Cells. Energy.gov. U.S. Department of Energy. 2019. Available at:

https://www.energy.gov/eere/fuelcells/types-fuel-cells

${ }^{19}$ Solid Oxide Fuel Cell (SOFC) Market is Determined to Exceed US\$ 1 billion by 2024. MarketWatch. Apr. 2019. Available at: marketwatch.com/press-release/solid-oxide-fuel-cell-sofc-market-is-determined-to-exceed-us-1billion-by-2024-2019-04-12

${ }^{20}$ Solid Oxide Fuel Cell. Netl.doe.gov. National Energy Technology Laboratory. U.S. Department of Energy. 2019. Available at: https://www.netl.doe.gov/coal/fuel-cells

${ }^{21}$ Riess, I. (2003). Mixed ionic-electronic conductors - material properties and applications. Solid State lonics, 157(1-4), 1-17.

${ }^{22}$ Riess, I. (2003). Mixed ionic-electronic conductors-material properties and applications. Solid State lonics, 157(1-4), 1-17.

${ }^{23}$ Zhu, S. (2017). OXYGEN TRANSPORT KINETICS OF SURFACE Pt \&Ag-MODIFIED PEROVSKITE OXIDE La0. 6SrO. 4Co0. 2Fe0. 803- $\delta$ (LSCF) (Master's thesis, University of Twente).

${ }^{24}$ Zhu, X., \& Yang, W. (2017). Mixed conducting ceramic membranes. Green Chemistry and Sustainable Technology.

${ }^{25}$ van der Haar, L. M. (2003). Mixed-conducting perovskite membranes for oxygen separation: Towards the development of a supported thin-film membrane.

${ }^{26}$ Solid Oxide Fuel Cells. FuelCellToday. 2019. Available at: http://www.fuelcelltoday.com/technologies/sofc

${ }^{27}$ Garrison, E. (2012). Solid Oxide Fuel Cells. Illinois Institute of Technology.

${ }^{28}$ Rüger, B., Weber, A., \& Ivers-Tiffee, E. (2007). 3D-modelling and performance evaluation of mixed conducting (MIEC) cathodes. ECS Transactions, 7(1), 2065.

${ }^{29}$ Boaro, M., \& Aricò, A. S. (Eds.). (2017). Advances in medium and high temperature solid oxide fuel cell technology (Vol. 574). Cham, Switzerland: Springer.

${ }^{30}$ Pervoskite. Wikipedia (2019). Available at: https://en.wikipedia.org/wiki/Perovskite

31 Jiang, S. P. (2019). Development of lanthanum strontium cobalt ferrite perovskite electrodes of solid oxide fuel cells-A review. International Journal of Hydrogen Energy, 44(14), 7448-7493.

${ }^{32}$ Singhal, S. C., \& Kendall, K. (Eds.). (2003). High-temperature solid oxide fuel cells: fundamentals, design and applications. Elsevier.

${ }^{33}$ Fuell Cell Technology. National Programme on Technology Enhanced Learning (NPTEL). 2012. Available at: nptel.ac.in/courses/103102015/\#

${ }^{34}$ Why SOFC Technology? Office of Fossil Energy. Energy.gov. 2019. Available at: https://www.energy.gov/fe/whysofc-technology 
${ }^{35}$ Yoo, H. I., \& Lee, C. E. (2009). Conductivity relaxation patterns of mixed conductor oxides under a chemical potential gradient. Solid State lonics, 180(4-5), 326-337.

${ }^{36}$ Asadi, A. A., Behrouzifar, A., Mohammadi, T., \& Pak, A. (2012). Effects of Nano Powder Synthesis Methods, Shaping and Sintering Conditions on Microstructure and Oxygen Permeation of La0. 6SrO. 4Co0. 2Fe0. 8O3- $\Delta$ (LSCF) Perovskite-type Membranes. High Temperature Materials and Processes, 31(1), 47-59.

${ }^{37}$ Zeng, P., Ran, R., Chen, Z., Gu, H., Shao, Z., da Costa, J. D., \& Liu, S. (2007). Significant effects of sintering temperature on the performance of $\mathrm{LaO} .6 \mathrm{SrO} .4 \mathrm{CoO} .2 \mathrm{Fe} 0.8 \mathrm{O} 3-\delta$ oxygen selective membranes. Journal of Membrane Science, 302(1-2), 171-179.

${ }^{38}$ DiGiuseppe, G., Boddapati, V., \& Mothikhana, H. (2017). Long-term Cell Testing of Interlayer-free Lanthanum Strontium Cobalt Ferrite Cathodes for Solid Oxide Fuel Cells. Journal of Advanced Catalysis Science and Technology, 4, 15-21.

${ }^{39}$ Ritzmann, A. M., Dieterich, J. M., \& Carter, E. A. (2016). Density functional theory investigation of the electronic structure and defect chemistry of Sr 1-x K x FeO 3. MRS Communications, 6(3), 145-150.

${ }^{40}$ Ha, M. N., Lu, G., Liu, Z., Wang, L., \& Zhao, Z. (2016). 3DOM-LaSrCoFeO 6- $\delta$ as a highly active catalyst for the thermal and photothermal reduction of $\mathrm{CO} 2$ with $\mathrm{H} 2 \mathrm{O}$ to $\mathrm{CH}$ 4. Journal of Materials Chemistry A, 4(34), 1315513165.

${ }^{41}$ AZoNano. Cobalt Oxide (Co3O4) Nanoparticles - Properties, Applications. AZOnano. Jul. 2013. Web

${ }^{42}$ Chen, Y., Hinerman, A., Liang, L., Gerdes, K., Navia, S. P., Prucz, J., \& Song, X. (2018). Conformal coating of cobalt oxide on solid oxide fuel cell cathode and resultant continuously increased oxygen reduction reaction kinetics upon operation. Journal of Power Sources, 405, 45-50.

${ }^{43}$ Huang, Y., Vohs, J. M., \& Gorte, R. J. (2006). An examination of LSM-LSCo mixtures for use in SOFC cathodes. Journal of The Electrochemical Society, 153(6), A951-A955.

${ }^{44}$ Ren, Y., Cheng, Y., Gorte, R. J., \& Huang, K. (2017). Toward stabilizing Co3O4 nanoparticles as an oxygen reduction reaction catalyst for intermediate-temperature SOFCs. Journal of The Electrochemical Society, 164(10), F3001-F3007.

${ }^{45}$ Yamahara, K., Jacobson, C. P., Visco, S. J., Zhang, X. F., \& De Jonghe, L. C. (2005). Thin film SOFCs with cobaltinfiltrated cathodes. Solid State Ionics, 176(3-4), 275-279.

${ }^{46}$ George, S. M. (2010). Atomic layer deposition: an overview. Chemical reviews, 110(1), 111-131.

${ }^{47}$ Miikkulainen, V., Leskelä, M., Ritala, M., \& Puurunen, R. L. (2013). Crystallinity of inorganic films grown by atomic layer deposition: Overview and general trends. Journal of Applied Physics, 113(2), 2.

${ }^{48}$ Chao, C. C., Motoyama, M., \& Prinz, F. B. (2012). Nanostructured Platinum Catalysts by Atomic-Layer Deposition for Solid-Oxide Fuel Cells. Advanced Energy Materials, 2(6), 651-654.

49 Jiang, X., Gür, T. M., Prinz, F. B., \& Bent, S. F. (2010). Atomic Layer Deposition (ALD) Co-Deposited Pt- Ru Binary and Pt Skin Catalysts for Concentrated Methanol Oxidation. Chemistry of Materials, 22(10), 3024-3032.

${ }^{50}$ O’Neill, B. J., Jackson, D. H., Lee, J., Canlas, C., Stair, P. C., Marshall, C. L., ... \& Huber, G. W. (2015). Catalyst design with atomic layer deposition. Acs Catalysis, 5(3), 1804-1825. 
${ }^{51}$ Choi, H. J., Bae, K., Grieshammer, S., Han, G. D., Park, S. W., Kim, J. W., ... \& Shim, J. H. (2018). Surface tuning of solid oxide fuel cell cathode by atomic layer deposition. Advanced Energy Materials, 8(33), 1802506.

52 O’Neill, B. J., Jackson, D. H., Lee, J., Canlas, C., Stair, P. C., Marshall, C. L., ... \& Huber, G. W. (2015). Catalyst design with atomic layer deposition. Acs Catalysis, 5(3), 1804-1825.

${ }^{53}$ Mutoro, E., Crumlin, E. J., Biegalski, M. D., Christen, H. M., \& Shao-Horn, Y. (2011). Enhanced oxygen reduction activity on surface-decorated perovskite thin films for solid oxide fuel cells. Energy \& Environmental Science, 4(9), 3689-3696.

${ }^{54}$ Choi, H. J., Bae, K., Jang, D. Y., Kim, J. W., \& Shim, J. H. (2015). Performance degradation of lanthanum strontium cobaltite after surface modification. Journal of The Electrochemical Society, 162(6), F622-F626.

${ }^{55}$ Ren, Y., Cheng, Y., Gorte, R. J., \& Huang, K. (2017). Toward stabilizing Co3O4 nanoparticles as an oxygen reduction reaction catalyst for intermediate-temperature SOFCs. Journal of The Electrochemical Society, 164(10), F3001-F3007.

${ }^{56}$ Cobalt (II) Oxide. Wikipedia.com (2019). Available at: https://en.wikipedia.org/wiki/Cobalt(II)_oxide

${ }^{57}$ Technical data for Cobalt. Periodictable.com (2019). Available at:

https://periodictable.com/Elements/027/data.html

${ }^{58}$ Chen, Y., Gerdes, K., \& Song, X. (2016). Nanoionics and nanocatalysts: conformal mesoporous surface scaffold for cathode of solid oxide fuel cells. Scientific reports, 6, 32997.

${ }^{59}$ Chen, Y., Gerdes, K., \& Song, X. (2019, September). Additive Dual Nano Catalysts to Accelerate Oxygen Reduction Reaction in Cathode of Solid Oxide Fuel Cells. In Meeting Abstracts (No. 40, pp. 1846-1846). The Electrochemical Society.

${ }^{60}$ Chen, Y., Gerdes, K., Paredes Navia, S. A., Liang, L., Hinerman, A., \& Song, X. (2019). Conformal Electrocatalytic Surface Nanoionics for Accelerating High-Temperature Electrochemical Reactions in Solid Oxide Fuel Cells. Nano letters, 19(12), 8767-8773.

${ }^{61}$ Chen, Y., Gerdes, K., \& Song, X. (2016). Nanoionics and nanocatalysts: conformal mesoporous surface scaffold for cathode of solid oxide fuel cells. Scientific reports, 6, 32997.

${ }^{62}$ Technical data for Platinum. Periodictable.com (2019). Available at:

https://periodictable.com/Elements/078/data.html

${ }^{63}$ AZoM. Platinum - Applications. AZOmaterials. Apr. 2002. Web

${ }^{64}$ Platinum. Wikipedia.com(2019). Available at: https://en.wikipedia.org/wiki/Platinum

${ }^{65}$ Manganese Oxide / Manganese Dioxide Powder (MnOx). Reade international corp. Web

${ }^{66}$ Technical data for Manganese. Periodictable.com (2019). Available at:

https://periodictable.com/Elements/025/data.html

${ }^{67}$ Manganese dioxide. Wikipedia.com (2019). Available at: https://en.wikipedia.org/wiki/Manganese_dioxide

${ }^{68}$ Technical data for Praseodymium. Periodictable.com (2019). Available at:

https://periodictable.com/Elements/059/data.html 
${ }^{69}$ Praseodymium oxide, Pr2Ox for Optical Coating. Materion. 2019. Web

70 Praseodymium(III) oxide. Wikipedia.com (2019). Available at:

https://en.wikipedia.org/wiki/Praseodymium(III)_oxide

${ }^{71}$ Niedrig, C. (2015). Electrochemical Performance and Stability of (Ba $0.5 \mathrm{Sr}$ 0.5)(Co 0.8 Fe 0.2) O 3- $\delta$ for Oxygen Transport Membranes (Doctoral dissertation, Dissertation, KIT Scientific Publishing).

${ }^{72}$ Cox-Galhotra, R. A., \& Mclntosh, S. (2010). Unreliability of simultaneously determining kchem and Dchem via conductivity relaxation for surface-modified La0. 6SrO. 4Co0. 2Fe0. 803- $\delta$. Solid State lonics, 181(31-32), 14291436. 